4 norden 



\section{Welfare and Health Services in the Nordic Countries}

Consumer Choices 
Welfare and health Services in the Nordic Countries

Consumer Choices

TemaNord 2005:575

(C) Nordic Council of Ministers, Copenhagen 2005

ISBN 92-893-1228-9

This publication can be ordered on www.norden.org/order. Other Nordic publications are available at www.norden.org/publications

Nordic Council of Ministers

Store Strandstræde 18

DK-1255 Copenhagen K

Phone (+45) 33960200

Fax (+45) 33960202

www.norden.org
Nordic Council

Store Strandstræde 18

DK-1255 Copenhagen K

Phone (+45) 33960400

Fax $(+45) 33111870$

\section{Consumer Co-operation in the Nordic Countries}

The aim of the co-operation in the Nordic Committee of Senior Officials on Consumer Affairs is to promote consumer safety, protect their financial and legal interests, inform consumers and promote their education, and promote consumer influence in society. Exchange of information, reports, and research will contribute to the Nordic consumer policy and provides a platform for joint Nordic presentation in international contexts.

\section{Nordic co-operation}

Nordic co-operation, one of the oldest and most wide-ranging regional partnerships in the world, involves Denmark, Finland, Iceland, Norway, Sweden, the Faroe Islands, Greenland and Åland. Cooperation reinforces the sense of Nordic community while respecting national differences and similarities, makes it possible to uphold Nordic interests in the world at large and promotes positive relations between neighbouring peoples.

Co-operation was formalised in 1952 when the Nordic Council was set up as a forum for parliamentarians and governments. The Helsinki Treaty of 1962 has formed the framework for Nordic partnership ever since. The Nordic Council of Ministers was set up in 1971 as the formal forum for co-operation between the governments of the Nordic countries and the political leadership of the autonomous areas, i.e. the Faroe Islands, Greenland and Åland. 


\section{Table of Contents}

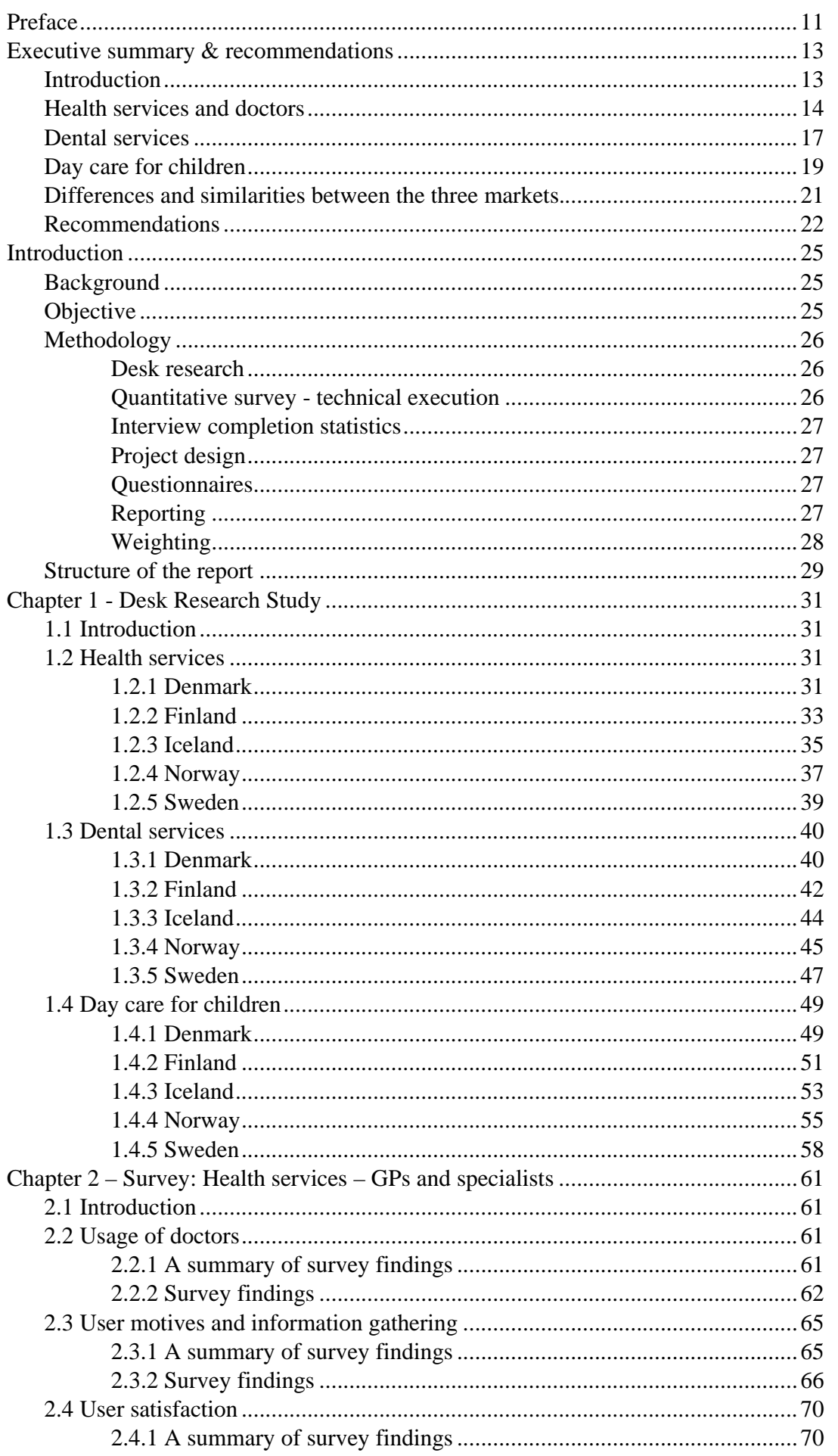




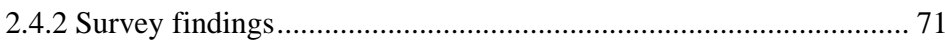

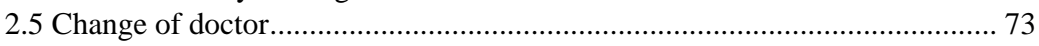

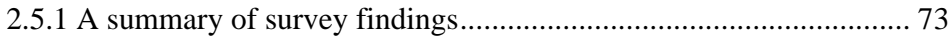

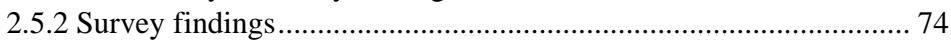

2.6 Possibilities of comparison and information ................................................... 78

2.6.1 A summary of survey findings........................................................ 78

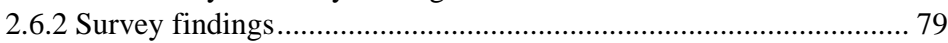

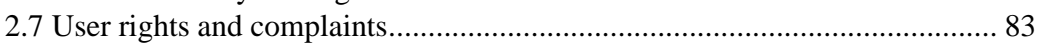

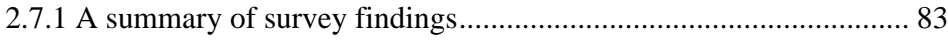

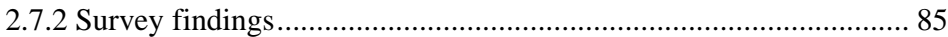

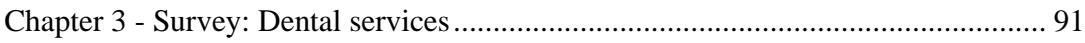

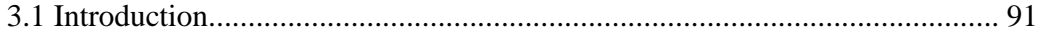

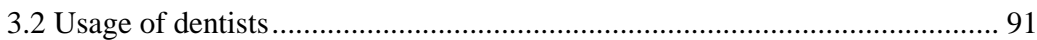

3.2.1 Summary of survey findings......................................................... 91

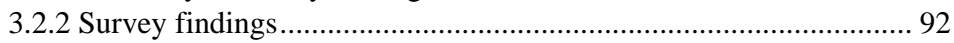

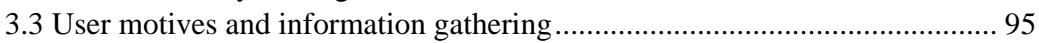

3.3.1 Summary of survey findings ......................................................... 95

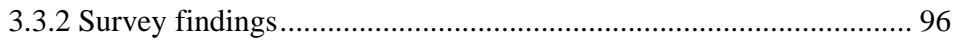

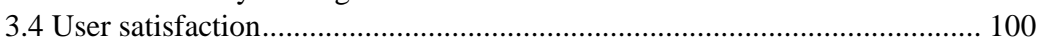

3.4.1 A summary of survey findings.................................................. 100

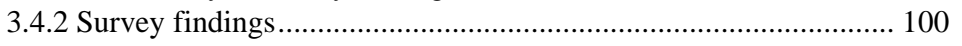

3.5 Change of dentist .................................................................................. 102

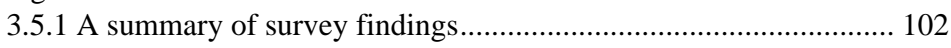

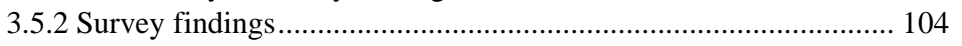

3.6 Possibilities of comparison and information ................................................. 107

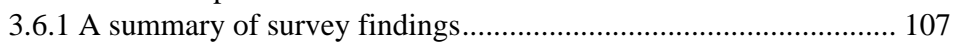

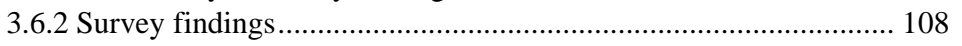

3.7 User rights and complaints.......................................................................... 112

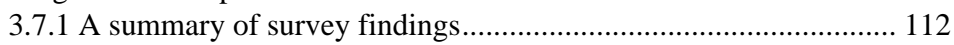

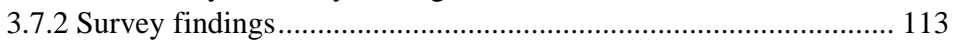

Chapter 4 - Survey: Day care for children........................................................ 119

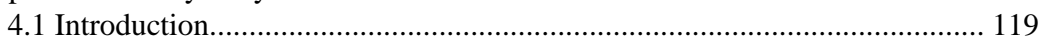

4.2 Usage of day care services ........................................................................... 119

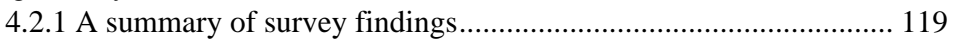

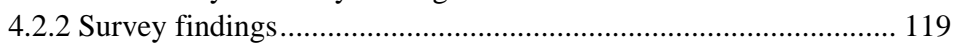

4.3 User motives and information gathering ................................................... 122

4.3.1 A summary of survey findings...................................................... 122

4.3.2 Survey findings ................................................................. 123

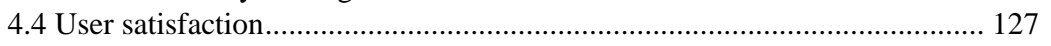

4.4.1 A summary of survey findings..................................................... 127

4.4.2 Survey findings ......................................................................... 127

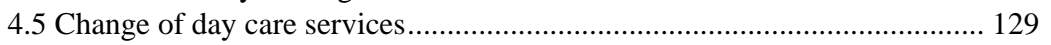

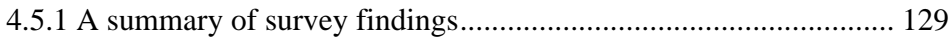

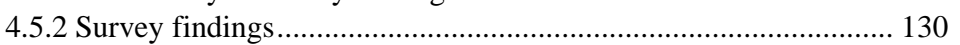

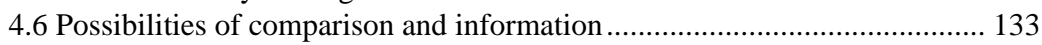

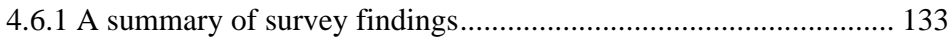

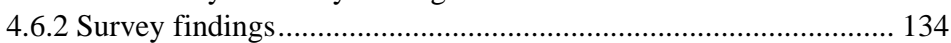

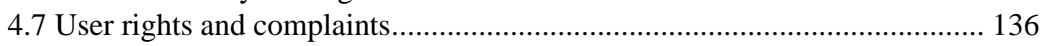

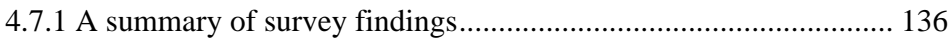

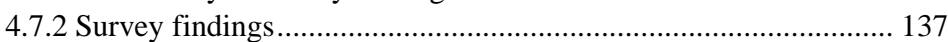




\section{List of Tables}

Table 1: Number of visits to a doctor within the last 12 month, $\%$ answering.....

Table 2: Type of doctor last consulted, \% answering ................................63

Table 3: Primary reasons for choosing doctor, \% answering ........................66

Table 4: Sources for information about doctor, \% answering more than one answer allowed.....

Table 5: Reasons for not gathering information on various doctors, $\%$ answering

Table 6: \% unable to assess their satisfaction with the possibilities for acquiring information about medical services..

Table 7: \% unable to assess their satisfaction with total service

Table 8: Three most important reasons for changing or considering changing doctor, \% answering - more than one answer allowed

Table 9: Three most important reasons for staying with current doctor, \% answering - more than one answer allowed

Table 10: \% unable to assess the possibilities for comparing price levels ....80

Table 11: \% unable to assess the possibilities for comparing waiting times at doctors

Table 12: \% unable to assess the possibilities for protection from wrong or defective advice/treatment .85

Table 13: \% unable to assess the possibilities for complaint .......................86

Table 14: Type of dentist last visited, \% answering.....................................93

Table 15: Primary reason for choice of dentist, \% answering........................96

Table 16: Sources of information about dentists, \% answering ....................98

Table 17: Reasons for not gathering information, \% answering ...................99

Table 18: \% unable to assess their satisfaction with the possibilities for acquiring general information about dental services . 101

Table 19: Most important reasons for change/ considering change of dentist, \% answering - more than one answer allowed

Table 20: The most important reasons for staying with current dentist, $\%$ answering - more than one answer allowed

Table 21: \% unable to assess the possibilities for comparing quality of dental treatment.....

Table 22: \% unable to assess the possibilities for comparing waiting time at dentists

Table 23: \% unable to assess the possibilities for comparing dentists' age

Table 24: \% unable to assess their satisfaction with the existence of protection from defective dental advice / treatment

Table 25: \% unable to assess the possibilities for complaint about their dental treatment 
Table 26: \% unable to assess the possibilities for acquiring information about how to complain

Table 27: Primary reasons for choosing current day care facility, $\%$ answering

Table 28: Sources of information about day care facilities, $\%$ answering - more than one answer allowed

Table 29: Reasons for not gathering prior information about day care facilities - more than answer allowed, \% answering.

Table 30: The most important reasons for change or consideration of change, \% answering - more than one answer allowed

Table 31: Three most important reasons for keeping child in current facility, \% answering - more than one answer allowed.

List of figures

Figure 1: \% consulting a doctor within the past 12 months......................... 62

Figure 2: Length of relationship with doctor ............................................ 64

Figure 3: \% gathering information prior to their first visit to their doctor.... 68

Figure 4: Satisfaction with possibilities for acquiring information about

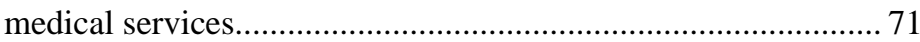

Figure 5: Satisfaction with the total service ............................................. 72

Figure 6: \% familiar with the legislation .................................................. 74

Figure 7: \% changing/considering changing doctor ................................... 75

Figure 8: Satisfaction with possibilities for comparing price levels............ 79

Figure 9: Satisfaction with possibilities of comparing the quality of the treatment of doctors ................................................................. 81

Figure 10: Satisfaction with possibilities for comparing waiting time at doctors

Figure 11: Satisfaction with the information available concerning doctors' age

Figure 12: The need to complain about a doctor in the last 12 months ........ 88

Figure 13: \% consulting a dentist within the past 12 months ..................... 92

Figure 14: Length of relationship with dentist ......................................... 94

Figure 15: Satisfaction with the possibilities for acquiring general information about dental services........................................... 100

Figure 16: Satisfaction with the total service after last dental visit ........... 102

Figure 17: \% changing/considering changing dentist................................ 104

Figure 18: Satisfaction with the possibility to compare prices of dentists

Figure 19: Satisfaction with possibilities for comparing the quality of dental treatment

Figure 20: Satisfaction with the possibility to compare waiting time at dentists

Figure 21: Satisfaction with the available information about a dentist's age..... 
Figure 22: Satisfaction with existence of protection from defective dental advice/treatment

Figure 23: Satisfaction with the possibility for complaint about their dental treatment)

Figure 24: Satisfaction with the possibility for acquiring information about how to complain

Figure 25: The need to complain within the past 3 years...........................117

Figure 26: Type of day care attended.......................................................120

Figure 27: Length of usage of current day care facility .............................121

Figure 28: \% gathering information prior to choosing the current day care facility

Figure 29: Satisfaction with possibilities for acquiring general information

Figure 30: Satisfaction in general with current day care facility. 128

Figure 31: \% who have changed or considered changing their child's day care

Figure 32: Satisfaction with the possibility for comparing prices of day care

Figure 33: Satisfaction with the possibilities for comparing quality of day care

Figure 34: Satisfaction with the possibilities for comparing factual information about day care

Figure 35: Satisfaction with the possibilities for complaint about day care

Figure 36: Satisfaction with the possibility for acquiring information about how to complain about day care

Figure 37: Need to complain about day care in the last 3 years 139 



\section{Preface}

Today we are witnessing the birth of more and more new markets because of the liberalisation of former public businesses or public monopolies. With this in mind, the background for this report was a need to understand the consumers' need for information about services that were formerly partly public businesses or public monopolies better.

Based on a survey among a representative sample of the populations of Denmark, Sweden, Norway, Finland and Iceland, this report looks at three different markets in which individual consumers now have a free choice of services. The three markets are: health services (general practitioners or specialists), dental services, and pre-school children's day care.

The report will uncover usage patterns and key reasons for consumer choices in these markets. In addition, the study will shed light on the level of consumer satisfaction with the services, the information accessible, and on consumer perceptions about their possibilities for complaint. Further more, the study will highlight significant differences on a Nordic level, on a country level and on a market level. Based on the survey results the report will comment on areas where there appears to be potential for improvement - either via more accessible information or an improved complaints process.

The project is financed by Nordic Council of Ministers, and conducted under the EK-Konsument, steering committee MoF (Market Analysis and Consumer Matters). The survey and report has been compiled and composed by consultants at Norstat, Denmark and Opinion AS, Norway. The consultants at Norstat, Denmark were Morten Rosentoft and Thomas Bonde; Pernille Nielsen and Helle Platz were project managers. From Opinion AS the project consultants were Ola Gaute Aas Askheim, Marius Jensen and Alexandra Monier-Williams who, together with Synne Fonkalsrud, Marianne Isaksen and Bjørn Ingeborgrud, were in charge of the desk research survey and the analysis of all data for this report.

The Nordic project group consisted of the following persons:

\begin{tabular}{lll}
\hline Denmark & Forbrugerstyrelsen & $\begin{array}{l}\text { Kenneth Skov Jensen (Head of Project) } \\
\text { Mette Pilgaard (Project Manager) }\end{array}$ \\
Finland & Konsumentverket & $\begin{array}{l}\text { Pirjo Tomperi } \\
\text { Iceland }\end{array}$ \\
Norway & Samkeppnisstofnun & Kristín Færseth \\
Sweden & SIFO & Gun Roos \\
& Konsumentverket & Barbro Turesson \\
\hline
\end{tabular}





\section{Executive summary \& recommendations}

\section{Introduction}

Having identified the need to better understand the consumer need for information about services that were formerly partly public businesses or public monopolies, the Danish Consumer Agency commissioned this survey about health services and doctors, dental services, and pre-school children's day care among a representative sample of the population in Denmark, Sweden, Norway, Finland and Iceland.

Through desk research and a survey comprising approximately 800 telephone interviews in each country, this report looks at these three concrete markets:

- Health services and doctors

- Dental Services

- Day care facilities for children of pre-school age

Desk research was conducted in all five Nordic countries. The desk research was of an explorative nature, and the research focused on laws, regulations and facts referred to in existing sources, mainly web sites and reports by governmental bodies and trade organisations. No primary sources (interviews or surveys) were used for this part of the study.

The desk research was carried out by native freelance researchers in each of the five countries in May and June 2005. While the report contains a thorough summary of the desk research, it should be noted that because the initial themes laid out by the project group were broad, comprising rather open questions, the findings from the five countries are not always comparable.

This chapter gives a summary of the findings detailed in Chapter 2 Desk Research Study, Chapter 3 - Survey: Health service and doctors, Chapter 4 - Survey: Dental services and Chapter 5 - Survey: Day care for children. The summary is based on an analysis of the Nordic region as a whole; where the individual countries show themselves to diverge from the Nordic "average" this is noted.

In this chapter we have chosen to summarise each area (doctors, dentists, day care for children) individually. We first look at the relationship to free choice of provider, then at the extent to which free choice is a reality and whether there are limitations to free choice. We go on to look at the structure within the market vis à vis type of provider and price and 
then we look at the relationship to changing provider, satisfaction with provider and finally at perceptions of the complaints process.

We also look at the survey findings in relationship to the actual situation (as documented in the desk research) i.e. instances where the actual situation can help explain differences found between the individual countries.

We have chosen to include results which show a high proportion of “don't know" answers. A high proportion of “don't know” answers is often an indication that knowledge is low, that information is hard to get or that consumers think the subject area irrelevant or unimportant.

Where relevant we have commented on the differences and similarities between the three areas (doctors, dentists, day care for children). We found this to be particularly relevant with respect to the opportunities for comparison of services, the length of the relationship between consumer and provider as well as for consumer experiences of the complaints process.

Finally we have commented on areas where there appears to be potential for improvement with respect to consumer satisfaction - either via more accessible information or an improved complaints process. However we would suggest that any recommendations arising out of these comments are backed up by both a further analysis of the base data and by additional research into these specific areas before implementation.

\section{Health services and doctors}

\section{Free choice of doctor}

Respondents in all countries were told in the survey that every citizen (in their country) has the legal right to choose their own doctor. This is not the exact truth for Iceland; choosing a specific doctor is not mentioned in the law on health services (law 97/90, §16:1). Most Icelanders therefore report that they are not aware of this legislation. In both Denmark and Norway around $80 \%$ of people are aware of this right. Awareness in Sweden and Finland lies at $65 \%$ and $50 \%$ respectively. Consumers are however generally satisfied with the availability of information about medical services, though satisfaction in Sweden and Norway is lowest. Very few people gathered information about doctors before their first visit, and Sweden and Finland stand out as the countries where fewest gather information.

\section{Limitations to free choice of doctor}

When we look at decisive factors in choice of doctor we see large differences between the countries. In Iceland more people say that their doctor 
was the only doctor available; in Finland more people say that their doctor is the company doctor; in Sweden more people say that their choice was by chance and in Denmark more people say their choice was based on either recommendation, location or the fact that their doctor is the family doctor.

The opportunity for comparing the quality of doctors' services is thought to be very poor in all countries though such possibilities are rated higher in Finland than in the rest of the Nordic region.

Real limitations, such as geographical distance (Iceland, Denmark and Norway), waiting time for treatment (Finland and Sweden) are, according to the survey, not perceived as problems when it comes to choice of doctor.

\section{Type of doctor}

GPs dominate in all countries. This is true to a greater degree in Denmark and Norway while specialists are more relevant for Icelanders and Swedes than for the other Nordic countries. Finland is the only country where company doctors play a prominent role, and the country in which the highest percentage of people report that their doctors are connected to a pubic health centre. This is true to a lesser degree in Sweden while in the other Nordic countries doctors with their own office or doctors based in an office with just a few other doctors dominate.

\section{Price and price difference - doctors}

In all countries consumers perceive the opportunity to compare prices as limited. Finland scores highest here while Iceland and Denmark (perhaps not surprisingly given that it does not cost anything to go to the doctor in Denmark) score lowest.

Researching actual prices in each country was complicated and difficult. However, as a rule of thumb, it seems that the price set by law for an individual consultation is $€ 11$ in Finland, $€ 13$ in Iceland (with a maximum price of $€ 277$ per year), $€ 15$ in Norway (GP with state subsidy) and $€ 28$ in Sweden.

It is possible to get both public and private insurance for health care in the Nordic countries. While the scope of this report did not include indepth secondary research into the relationship between insurance and the health services it should be borne in mind that people have the possibility for membership of a public insurance policy and/or have the possibility to take out private insurance for health care. 


\section{Change of doctor and satisfaction with doctor}

We also see large difference between the countries when it comes to changing doctor. While the Danes report having a very long relationship with their doctor, many of them having used the same doctor for over 15 years, Swedes and Finns tend to have shorter term relationships with their doctors. It is worth noting here that nearly 3 out of 10 Finns report not having a regular doctor at all. In Iceland and in Norway there are fairly even numbers of people who have a short, a medium and a long term relationship with their doctor. There are few findings in the desk research that point to there being differences between the countries as far as barriers to changing a doctor are concerned and the conclusion must be that the differences are down to culture, although in Denmark and Norway the user must apply to the local health authorities. In Denmark this costs $€ 20$.

Danes report being the most satisfied with their doctor, while Norwegians are least satisfied. Three out of four in the Nordic region have neither changed nor considered changing their doctor; in Finland this is the case for $80 \%$ of consumers (again it should be noted that in Finland nearly 30\% report having no regular doctor). There are more people in Norway and Denmark who have considered a change of doctor, or who have changed their doctor, than in the rest of the Nordic region.

For those who have changed their doctor, location, poor information from the doctor and a lack of trust in the doctor are the main reasons for the change.

\section{Complaints process for medical patients}

Satisfaction with the level of protection against wrong/defective treatment is not high in the Nordic region. One in five people answer "Don't know" when asked about this. Finns rate the level of protection highest, while Swedes rate them lowest. The opportunity for complaint is also rated fairly low and Icelanders rate this lowest of all. Again we find that one in five answer "Don't know" when asked to rate the opportunities for complaint. The opportunities for gathering information about the complaints process are rated somewhat higher. Finland scores highest while Sweden and Iceland score lowest. However the proportion answering "Don't know" remains at about one in five.

Although all countries have a formal system for the handling of complaints about doctors we found that knowledge about this is low amongst consumers. 


\section{Dental services}

\section{Free choice of dentist}

There is free choice of dentist in all the Nordic countries. With the exception of Finland this is not a legal right. In Finland all adult citizens have been given the right to public oral care or a refund of the cost of private oral care (reform dating from May 2001). In Sweden citizens also have the right to public oral care. In all countries, with small variations between them, children and seniors/pensioners have a legal right to free or subsidised dentistry.

Most consumers in the Nordic region (85\%) had not gathered any information about their dentist before their first visit. However in Norway and Iceland more consumers gather information before their first visit to their dentist.

Finland distinguishes itself as the country in which the fewest people visit the dentist just once a year while the Danes are the people who are most likely to visit their dentist more than once a year.

\section{Limitations to free choice of dentist}

"Recommendations from friends" is the most common reason given for choice of dentist in the Nordic countries. Finland is the only country in which another reason was cited most, namely that choice of dentist was by chance. These findings point towards there being few real barriers to free choice of dentist.

In Denmark and Iceland the connection to a family dentist was stronger than in the other Nordic countries and the location of the dentist also plays a more important role in choice of dentist in Denmark than in the rest of the Nordic region.

Even though there are geographical limitations to choice of dentist, for example in rural Norway and Iceland, this is not reflected in the results from the survey. Finland is the only country in which there are waiting lists for public dental care among the adult population, a situation linked to the reform of oral care mentioned above. This is first and foremost a situation found in the cities and larger towns.

The opportunities for comparing the quality of dentist are perceived as small. This could be interpreted as an indirect barrier to free choice. Paradoxically it is the Finns who rate the opportunity for comparison highest. 


\section{Type of dentist}

The groups within populations who have the right to free, or subsidised, dental care (seniors and children) mainly use the public dental service, while private practice is the dominant choice for all other groups.

Private practice dominates in the Nordic region. Seven out of ten visits to the dentist were to a private practitioner. However both Finland and Sweden have a higher proportion of people who go to public dentists than the other three countries, perhaps not surprisingly given that approximately half of all dentists in these two countries are connected to public dental service and that in Finland everyone has a right to public dental care.

\section{Price and price differences - dentists}

There are large differences in the cost of dental care in the Nordic region, and again this is an area with many exceptions and differences at different levels across the five countries. In Iceland, Norway and Sweden, where private practitioners dominate, the free market to a large extent decides the price. In Finland there is a set price within public dental care (currently €7 per visit) but free pricing in the private market. In Denmark prices for dental services are set by a collective agreement between dentists, and, as a rule of thumb, $40 \%$ of the bill is refunded by the state.

Consumers perceive the opportunities to compare price as small. Not surprisingly given set prices, Finns rate the opportunities for comparison highest but Norwegians also rate opportunities for comparison higher than the other three Nordic countries.

\section{Change of dentist and satisfaction with dentist}

Denmark is characterised by very long relationships between dentist and patient. Finland has the greatest proportion claiming that they have no permanent dentist and is also the country with the shortest relationship between dentist and patient, again a situation that can be explained by the oral care reform of May 2001.

There are quite good satisfaction levels when it comes to the accessibility of information about dental services. While Finland scores highest here, it should also be noted that one in four people in the Nordic countries give "Don't know" as an answer here.

Consumers are, generally speaking, satisfied with the service they get at their dentist. Icelanders are most satisfied and Norwegians are least satisfied.

Three out four in the Nordic region have not considered changing dentist. The share who have not considered changing dentist is higher in Norway which could be seen as paradoxical given they are the least satisfied. 
It is in Finland that we find the greatest proportion of people who have either changed dentist or have considered changing dentist. Price, location and quality are central drivers here, and, we believe, a result of the oral care reform.

\section{Complaints process for dental patients}

As with medical patients all Nordic countries have formal systems for complaint in place. Knowledge of these systems among consumers is low.

Satisfaction with the level of protection against wrong treatment is middle to low in the Nordic region; it is lowest in Iceland and Sweden and highest in Finland. 1 in 3 answers "Don't know" here. The opportunities for complaint and for gathering information about the complaints procedure are rated as low to middling and again one out of three answers, “Don't know” here.

However it should be noted that most people have not felt the need to complain.

\section{Day care for children}

\section{Free choice of day care for children}

In most Nordic countries there is a legal right to day care for children. The secondary data we collected did not clarify whether this legal right can be interpreted as a formal free choice of day care for children.

When it comes to consumer experience of, and interest in, the accessibility of information about various day care facilities we saw varying results. Norwegians and Swedes are more likely to gather information than the other Nordic countries. The Internet is a more usual source of information in Denmark and Norway, direct contact with the local authorities is more usual in Iceland and friends and family are a more usual source of information in Finland.

Generally consumers are fairly satisfied with the opportunities to access information. The Finns are the most satisfied here while the Swedes are least satisfied.

\section{Limitations to free choice of day care for children}

The availability of day care facilities varies in all countries. The most usual limitation to free choice is not surprisingly geography, and it is often the case that choice is limited to the day care facilities within the local authority. Capacity varies from local authority to local authority and this also contributes to limiting free choice. 
The variations are largest in Norway, where it is estimated that 20,000 children are on waiting lists for day care, but there are large variations from county to county. In addition there are large price differences between private and public day care facilities. This is well illustrated in that Norway has the most people reporting that their choice of day care was made because it was the only facility with places. More people in Denmark than in the other Nordic countries say that they chose their child's day care facility based on recommendations from friends, something that indicates a relatively freer choice than in the other Nordic countries.

However the opportunities for comparison of the quality of different day care facilities is perceived as poor. Finland scores best here while Denmark and Sweden score very poorly indeed.

\section{Type of day care}

In all five countries there is a combination of public and private day care for children in the home, and of public and private nursery facilities. In both Iceland and Finland day care is a part of the public education system at the pre school level.

There are, however, large variations between the countries as far as the type of day care facility are concerned even though public nursery facilities are the most usual in all countries. It should be noted that in Norway the proportion using private nurseries is almost the same as the proportion using public nurseries, while in the other Nordic countries very few use private nursery facilities.

In Denmark, Sweden and Finland use of public day care in the home is more common than in Norway and Iceland where it hardly exists at all.

\section{Price and price differences in day care for children}

Prices vary strongly between the five Nordic countries, but in each of them there is some form of public support and price regulation.

Prices are highest in Denmark and Norway. A typical price per child in these two countries is $€ 340$ per month, while in Iceland a typical price would be $€ 290$. Finland is the only country where there is means testing and where families with very low income are entitled to a free day care for their children. However the maximum price is $€ 200$ per month and is the lowest in the Nordic region.

Consumers perceive their possibilities to compare prices to be very limited, though Norway and Denmark score slightly better here than the other three countries. 
Change of day care for children and satisfaction with day care

A change of day care is theoretically possible in all five countries but is clearly limited by local availability. This, as we have already commented, varies a lot from both country to country and within each country.

Norway and Sweden are the countries where more people tend to stay with the day care they have, something which could indicate satisfaction but which could also be an indication of limited choice. In Denmark we see the shortest relationships with day care facilities, something illustrated through more frequent change of day care facility than in any other Nordic country. However the reason given for a change in day care facility is most often the age of the child and shows that a change of facility in Denmark is conditional to a very different extent than in the rest of the Nordic region. Finland is the country where fewest say they have not considered changing their child's day care during the last three years.

Additionally we see that Danes are the least satisfied with their child's day care while the Finns, Swedes and Icelanders are most satisfied.

\section{Complaints process for users of day care for children}

Although there is a formal system for complaint about day care facilities for children in all the Nordic countries, this is not as clearly defined as it is for medical and dental services. In most cases there is a vague reference to the responsibility of the local authority for child care, or to various committees.

The possibilities for formal complaint are perceived as average, neither particularly good nor particularly bad. Finns rate possibilities for complaint about their child's day care highest. The opportunities for gaining access to information about the complaints process is perceived in the same way.

About eight out of ten users of day care have not experienced anything in the last three years that has given them a reason to complain. Iceland and Finland have the most satisfied users of day care while the least satisfied are to be found in Denmark, Norway and Sweden but the difference is not very large.

\section{Differences and similarities between the three markets.}

With respect to the gathering of information, very few (between 10-15\%) have gathered information on different dentists and doctors before choosing. These two, then, are similar. Well over half have gathered information about different day care facilities for their children.

In all three markets there is a basic satisfaction with the service/offer. Norwegians are less satisfied with the service they get at their doctors and 
dentist than they are with their child's day care facility. For the Danes, the opposite is true. There is less need to complain about dental service than about both doctors and day care facility.

Accessibility of information is perceived as best for day care facilities and least good for dental services. Finns rate accessibility of information highest in all three markets. In the case of dental services this is undoubtedly a result of the information sent out in connection with the 2001 dental care reform, though clearly Finns feel better informed than their Nordic counterparts in all three markets.

The opportunities for comparison of prices are perceived as weak as far as dentists and doctors are concerned, average for day care and could not be said to be perceived as good in any of the three markets. (Finland again has the highest rating for both dentists and doctors here).

The opportunities for comparison of the quality of different providers are perceived as weak for dentists and doctors and a little better for day care facilities. (Finland again rated opportunities for comparison of quality as highest in all three markets).

The possibility for comparison of waiting times and the dentist/doctors age are rated poorly (same level) while the opportunities for comparison of day care facilities (opening times, number of children, number of employees) are rated much better.

We see similar patterns in the length of relationship between user and provider for both dentists and doctors. A large proportion of Danes report a relationship of 5 or more years while very few Finns report such long relationships with their providers. On the other hand Finns chose these services in a different way than their Nordic neighbours, something linked to the dental care reform of 2001. In all countries many more people have considered changing their day care facility than have considered changing doctor or dentist.

For doctors and dentists there is a basic perception that protection against wrong treatment is average; the same is true for perceptions of the possibilities for complaint. Again it is the Finns who rate these highest. The accessibility of information about the complaints process is rated as slightly higher for day care facilities than for dentists and doctors, but the difference is not great.

\section{Recommendations}

The following recommendations have been written with their basis in the current study. As stated in the opening of this chapter, there will be a need for further analysis before recommendations can be implemented. The following recommendations must therefore, first and foremost, be considered as recommendations for further analysis. 
In Finland and Sweden consumer knowledge about their legal right to free choice of doctor is considerably lower than in Norway and Denmark. While in Finland people using company doctors do not generally have a choice of doctor, something which could help explain the lower level of knowledge vis à vis free choice of doctor, there nonetheless seems to be a need to improve consumer knowledge in this area in both countries. This could be achieved through an advertising and information campaign. We suggest that cases that have proved successful in Denmark and/or Sweden could be used as benchmarks.

Users' possibilities for comparing the quality level, price levels, waiting times and age of different doctors are perceived as poor in all countries. This finding suggests a great need for improvement. In cases where information like this is unavailable, the users' freedom of choice is limited to some extent. A good solution may be to establish a service that enables a comparison of some sort. There are several excellent examples on the Internet e.g. in the travel and hospitality sector that could serve as inspiration.

The same pattern is also found when it comes to comparison of dental services, especially in Denmark, Sweden and Iceland. In the day care market the same pattern is found in Iceland, Finland and Sweden. Similar actions as for doctors should be considered.

Accessibility of information about the complaints process and the possibilities for complaint regarding doctor's services are perceived as very poor in all countries. There seems to be a wide information gap. This should be seen in the light of the possible very serious consequences of defective or wrong treatment by a doctor. We strongly suggest establishing a group or panel of users with a mandate to develop actions to improve the situation.

We see the same pattern when it comes to dental services though not to the same extent. The need to address this is perhaps less crucial than it is for health services. 



\section{Introduction}

\section{Background}

The Danish Consumer Agency commissioned Norstat Denmark and Opinion AS, Norway to carry out this survey about dental services, health services and doctors and pre-school children's day care among a representative sample of the population in Denmark, Sweden, Norway, Finland and Iceland.

\section{Objective}

The background for this project was a need to better understand the consumer need for information about services that were formerly partly public businesses. As mentioned, the survey covers three concrete markets:

1. Health services - general practitioners (GPs) or specialists

2. Dental services

3. Day care facilities for children of pre-school age (institutions, private day care etc.)

Today the individual consumer has free choice within these three markets and, with this in mind, this study will uncover:

- usage patterns within dental, health and day care services

- the key reasons for choices made within dental, health and day care services

- the level of consumer satisfaction with the information accessible to them while making decisions

- the level of satisfaction with specific aspects of dental, health and day care services and perceptions about their possibilities for complaint.

It is important to shed light on these areas as they form the basis for consumers making an appropriate and satisfactory choice.

We highlight significant differences in the consumers' knowledge of information, perception of services, knowledge about consumer protection etc. These differences will be discussed on a Nordic level (differences between countries), on a country level (differences based on demographic variables) and on a market level (differences between dental, health and day care services). 
Based on the survey results, we determine where, and with respect to which consumer groups, there is a need for a better system of information. Further we will determine whether there is a need to address issues within the area of consumer rights.

\section{Methodology}

\section{Desk research}

First a desk research analysis was performed to obtain information on the characteristics of the market. Results from the desk research reveal:

- existing types of provider

- price structures and price differences between regions or between types of providers

- the extent of formal free choice in the three markets and limitations on free choice

- change of provider

- rights to, and options for, complaint

\section{Quantitative survey - technical execution}

Within each of the three markets, interviews were completed with citizens who have used one or more of these services within the last 12 months in all five countries.

In each country a representative random sample, based on the variables sex, age and geography) was used. Data collection was carried out by the Norstat Group using CATI (Computer Assisted Telephone Interviewing) in the period from June 8th 2005 to June 25th 2005.

A total of 4,231 telephone interviews were completed. The interviews were executed on weekdays between 4:30 pm and 9:00 pm and during weekends between 12:00 am and 6:00 pm.

All respondents were screened to ensure that it was the adult (i.e. someone 18 years old or more) in the household whose birthday was coming up next who was interviewed. Up to 10 redials were made per telephone number. 
Interview completion statistics

\begin{tabular}{lrrrrrr}
\hline & Total & Denmark & Finland & Iceland & Norway & Sweden \\
\hline Gross sample & 45.695 & 6.000 & 13.370 & 10.000 & 11.075 & 5.250 \\
size & 23.526 & 2.551 & 7.768 & 7.698 & 4.437 & 1.072 \\
$\begin{array}{l}\text { Unused numbers } \\
\text { Wrong phone }\end{array}$ & 463 & 113 & 58 & 18 & 41 & 233 \\
number & 21.706 & 3.336 & 5.544 & 2.284 & 6597 & 3945 \\
Net sample size & 412 & 50 & 0 & 36 & 31 & 295 \\
$\begin{array}{l}\text { Appointments } \\
\text { No response/ not }\end{array}$ & 7.373 & 656 & 3274 & 562 & 1.960 & 921 \\
reached & 9.690 & 1.776 & 1435 & 838 & 3.765 & 1.876 \\
$\begin{array}{l}\text { Refusals } \\
\text { IScreened out }\end{array}$ & 4.231 & 854 & 835 & 848 & 841 & 853 \\
Responses & & & & & & \\
\hline
\end{tabular}

\section{Project design}

For this survey Norstat developed a project design in which about 800 interviews gross were performed per country as follows:

\begin{tabular}{|c|c|c|c|c|c|c|}
\hline & Total & Denmark & Finland & Iceland & Norway & Sweden \\
\hline $\begin{array}{l}\text { Gross number of } \\
\text { interview }\end{array}$ & 4.231 & 854 & 835 & 848 & 841 & 853 \\
\hline - consulted a doctor & 3.068 & 633 & 636 & 603 & 632 & 564 \\
\hline - consulted a dentist & 3.027 & 681 & 500 & 567 & 651 & 628 \\
\hline $\begin{array}{l}\text { - have children of } \\
\text { pre-school age }\end{array}$ & 769 & 151 & 152 & 166 & 150 & 150 \\
\hline $\begin{array}{l}\text { Average no of } \\
\text { markets interviewed }\end{array}$ & 1,62 & 1,72 & 1,54 & 1,58 & 1,70 & 1,57 \\
\hline
\end{tabular}

Please note that in order to obtain the minimum demand of 150 interviews in the group of pre-school age children, it was necessary to recruit via omnibuses in the individual countries. This means that there is a very small statistical basis for further analysis in this market.

\section{Questionnaires}

The questionnaire used in the survey was prepared by The Danish Consumer Agency and the project group in cooperation with Norstat and Opinion. Norstat was responsible for translation of the questionnaires into relevant languages via of an external translation agency. All questionnaires are included in the report in the appendix.

\section{Reporting}

The survey is reported in WebTab, tables in Excel, in total and per country, and in SPSS. 


\section{Weighting}

The data for the survey has been weighted according to the following criteria:

$$
\begin{array}{ll}
\hline \text { On the Nordic level: } & \text { population size } \\
\text { Per country: } & \text { sex and age }
\end{array}
$$

The individual respondent weights have been calculated in an iterative process, according to the method by Deming-Stephan.

The purpose of this study was to be able compare data at both a Nordic level and between countries i.e. it was not to look at each country as a completely separate entity. Data was collected on a quota basis with approximately 800 interviews per country. We weighted the data before running statistical significance tests to ensure representative data at a Nordic level i.e. the weighted data reflects the Nordic population and thus accounts for the different population sizes of each country. This then allows a statistical test of data against significance on a Nordic level which would otherwise have not been possible.

Data for all countries has been tested at significance level of a $95 \%$ ensuring that all conclusions, unless otherwise specified in the report, are based on significant findings. All observations on the Nordic and country level have been computed and tested using T-tests (at a 95\% significance level). This method has been chosen as it is a very good and reliable test method to get an overview of main significant differences when the scope is to see at differences with the specific focus the report is based upon. No other statistical tests have been performed on the dataset.

It is important to understand that we carried out approximately the same number of interviews in each of the Nordic countries to ensure meaningful data on a country level, but that we weighted the data on a Nordic level to ensure representative data at that level and ran significance tests on the weighted data. This has some implications when reading the data. The population of Iceland is approximately only $1 \%$ of the total Nordic population and this means that the population is simply too small to result in many significant differences with respect to the Nordic total. (This does not however mean that results for Iceland are unimportant, and we have therefore chosen to comment on Iceland where large discrepancies are found, even though in most cases they do not represent a significant difference. The significance, or otherwise, of findings are stated throughout the report). On the other hand, Sweden counts for approximately $37 \%$ of the total Nordic population and thus Swedish findings will result in more significant differences on the Nordic level.

Using this procedure of weighing and testing of statistical significance you can, in general, conclude that if the population size is relatively larger than the quota proportion of the survey, the more likely you will 
achieve to get significant findings and impact for that country when comparing to the total Nordic population.

\section{Structure of the report}

The report is divided into 4 chapters as follows:

- Desk research

- Health services - GPs and specialists

- Dental services

- Day care for children.

Each chapter begins with an introduction before going on to the survey findings. The survey findings for each market (health services and doctors, dental services and day care for children) are divided into the following areas:

- Usage of provider

- User motives and information gathering

- User satisfaction

- Change of provider

- Possibilities for comparison and information

- User rights and complaints

Findings on a Nordic level, a country level and a market level are summarised before the survey findings for each of these areas are detailed. 



\section{Chapter 1 - Desk Research Study}

\subsection{Introduction}

This chapter gives an overview of the current situation in the three different markets (doctors, dentists, day care) for each of the Nordic countries. The chapter has been structured so that each country is described separately. To make the information more easily accessible, the information for each country has been organized as follows:

- Existing types of supply

- Price structure

- Degree of formal free choice of services

- Limitations in free choice

- Change of provider

- Rights and opportunities of complaint

Although the researchers used a wide variety of different open sources such as information offices, the internet, brochures, etc, there are likely to be a number of specific issues and details that are not covered in the overview. The purpose of this chapter is therefore to give the reader a brief, but correct, overview, and not to provide deep and detailed insight into the given area.

\subsection{Health services}

\subsubsection{Denmark}

\section{Existing types of supply}

GPs are self-employed professionals who work for the public services on a contract basis. There are approximately 3400 GPs in Denmark. Each GP has a maximum of about 1600 patients.

The clinics are run as single doctor clinics or as partnerships with two or more doctors who share clients, staff, office and finances

All employees involved in the medical treatment are formally educated. The client is mostly connected to an individual doctor, rather than the clinic.

The running of clinics is private but the financing is mainly public. The counties and the municipalities finance the services partly through taxes, partly through block grants from the Government. 
Price structure

All residents in Denmark are covered by the Health Care Reimbursement Scheme. The citizens do not pay any special contributions to this scheme as it is financed through county taxes. People over the age of 16 have the right to choose between Group 1 and Group 2 insurance. Nearly all (9799\%) choose to be insured in Group 1.

People insured under Group 1 have the right to free medical help from their GP or his/her substitute. They may also, free of charge, visit another GP, while they are temporarily staying outside their own GP's area, in the case of sudden illness etc. Though the price of services may vary between different counties, the price structure does not affect the clients as they are covered by the Scheme.

People insured under Group 2 only receive part of the cost of medical help from a GP. The subsidy they receive corresponds to the cost of similar medical help from a GP for people in Group 1.

The public expenditure is controlled via payment agreements, and through the distribution of permits to operate under the Health Care Reimbursement Scheme

Degree of formal free choice of services

All users are free to choose their own general practitioner (GP). To be covered by The Health Care Reimbursement Scheme Group 1 the patient has to be registered with a GP. For those insured under Group 1 the GP will refer them to a specialist if necessary. Those insured under Group 2 are allowed to consult a specialist without a referral from a GP.

Limitations in free choice

For the patient to be covered by the Health Care Reimbursement Scheme under Group 1 insurance the doctor has to work in accordance with collective agreements between the counties (in Copenhagen and Frederiksberg it is the local authorities) and the respective unions. Most GPs are registered with the Scheme.

There are some limitations on choosing GP in terms of capacity and space. According to rules of capacity some GPs will not register additional patients unless the person is a child or a partner of a registered user.

The clinic must be no more than $15 \mathrm{~km}$ from the patient's home address. Otherwise the doctor has to write a letter of acceptance. In Copenhagen, Frederiksberg, Dragør and Tårnby the clinic has to be no more than $5 \mathrm{~km}$ from the patient's address.

Change of provider

The user is free to change GP by applying to the municipality. Change is effective 14 days after applying in writing and the user is charged 150 DKK, which covers a new Health Care Reimbursement Card with the 
name of the GP. A change of GP due to change of address is free of charge.

Rights and opportunities of complaint

A complaints system regarding professional treatment in the health system does exist. The Patient's Complaints Board is an impartial public authority which may express criticism of the medical staff or submit particularly serious cases to the public prosecutor with a view to taking the cases to court.

Complaints about treatment after January $1^{\text {st }} 2004$ can also be made to The Patients' Insurance (Patientforsikringen).

\subsubsection{Finland}

Existing types of supply

Public primary health care is the responsibility of health centres. Municipalities can have their own health centre or form joint municipal boards with health centres serving the participating municipalities. In 2003, there were 278 health centres in Finland, 70 of which were run by joint municipal boards and 208 by municipalities themselves. A health centre may comprise a number of units within the municipality or joint municipal board area. Most of the health centres also have a ward for inpatients.

Private healthcare acts as a complement to the public healthcare system. Private health services are mainly concentrated in large localities, offering medical and dental services, physiotherapy and occupational healthcare. Sickness insurance covers a part of private medical care. There is also a partial reimbursement of the costs of tests and treatment prescribed by a doctor.

There are over 10000 full time and nearly 4000 part-time professionals employed in the private healthcare sector.

By the end of 2000 there were 2883 valid licences to practice private healthcare issued in line with current legislation. The main areas of private healthcare were medical rehabilitation, appointments with doctors and dentists, occupational health and laboratory testing.

In 2002, the share of client fees in the funding of municipal health care services was approximately 8 per cent, while municipalities paid out 67 per cent and the government 25 per cent

There were 20119 doctors in Finland in the beginning of 2004. The number of doctors of working age (under 63 years) was 17641 .

Health centres vary greatly in size. The largest employ hundreds of doctors and provide highly specialized services. In health centres in remote areas, doctors have to be able to cope with emergencies as well as offering basic health care. 
Most Finnish municipalities have switched from a primary health-care system to a family doctor system. Each family doctor is responsible for about 2000 patients. The aim is for a patient to be able to contact her or his doctor and to have their needs for treatment assessed within three working days.

Outpatient care is also provided by occupational and private healthcare units. Employers are under an obligation to arrange occupational health care for employees. Occupational health care can be arranged through municipal health centres or private practitioners. About $4 \%$ of Finnish doctors work in occupational health care, offering both preventive services and primary health care

Private medical treatment supplements care provided by municipalities and the state. Particularly in cities, many doctors, dentists, and physiotherapists offer private care.

One third of doctors run a private practice in addition to working in a hospital or health centre. Most private practitioners now work in group practices.

Everyone in Finland is covered by obligatory health insurance, funded through taxes by the state, municipalities, employers and the insured population. The health insurance scheme among other things reimburses fees paid by patients to private doctors, costs of medicines prescribed, and transportation costs arising from treatment of illness. All licensed Finnish doctors are covered by the reimbursement system, which is administered by the Social Insurance Institution.

Price structure

Part of the fees charged by doctors in private practice is reimbursed by the National Health Insurance (NHI). 60\% of doctors' fees are reimbursed, according to a fixed scale of charges. The part of the fee that exceeds the fixed charge is not reimbursable. If a pharmacy charges a doctor's fee (e.g., when a doctor phones in a prescription), the refund is credited at the pharmacy.

Preventive health care at public health centres, such as the services of maternity and child health clinics is free of charge. Under-18s do not have to pay for health centre outpatient services, such as an appointment with a doctor or dentist, but may be required to pay a daily charge for up to 7 days for treatment on a ward of a health centre or hospital.

Visiting the maternity or child health clinic, appointments with a public nurse, and laboratory and X-ray examinations are free of charge at a public health centre.

Health centres may charge a single or annual payment for doctor's appointments. A single payment is $€ 11$, which can be charged for a maximum of three appointments, i.e. $€ 33$ per calendar year. An annual payment is a maximum of $€ 22$ per calendar year. A fee of $€ 15$ can be charged for a visit to the health centre emergency clinic on weekdays 
between 8 p.m. and 8 a.m., on Saturdays, on Sundays and on bank holidays.

Clients aged 15 and above may be required to pay a penalty charge of $€ 27$ for unattended appointments.

Degree of formal free choice of services

The law lays down the basic nature and operating framework for the health care services, but does not concern itself with detailed questions of the scope, content or organisation of services. There may therefore be differences in health service provision from one municipality to another.

Legislation does, nevertheless, prescribe the main primary health care and specialized medical services which all local authorities must provide.

Limitations in free choice

A major part of health care concerns emergency treatment where immediate attention is provided as soon as possible. New regulations effective from the beginning of March 2005 also set timeframes for access to nonemergency treatment.

Immediate access to health centres during working hours by phone or personal visit is guaranteed. If the treatment proposed requires the patient to pay a visit to the health centre an appointment will be arranged within three working days of contacting the centre.

Change of provider

The user can change his/hers doctor at the health care centre while booking an appointment. The system is very flexible.

Rights and opportunities of complaint

Clients are advised to direct any complaints they may have concerning the actions or behaviour of healthcare professionals to the head of the unit in which the professional works. Health centres and hospitals have a patient's ombudsman who can give advice on issues concerning patients' rights. If needed, the ombudsman will help draw up the complaint.

Complaints concerning healthcare staff are directed to state provincial offices, which may pass the complaint to the National Authority for Medico legal Affairs. The Ministry of Social Affairs and Health does not handle complaints.

\subsubsection{Iceland}

Existing types of supply

There are three types of health care centres:

- Category H2, employing at least two doctors (not counting other staff members) 
- Category H1, employing one doctor

- Category H0, employing a nurse or a midwife with facilities for regular consultation by a doctor.

In 2002 there were 38 health care centres in category H2 and 18 in category H1. The 28 health care centres in category H0 all operate in conjunction with a larger health care centre.

Specialist services in Iceland are almost exclusively located in Reykjavik and neighbouring communities and in Akureyri in the north. Most specialist outpatient care is provided by private practitioners working on their own or rented premises, sometimes in group practice.

The private practitioners work on a fee-for-service basis negotiated by the medical association and the health authorities.

All employees involved in the medical treatment are formally educated.

Price structure

There are no differences in prices of medical services in the health care centres between regions. The patient pays a minimum fee for the services of a general practitioner or of a specialist, outside of a hospital, while the rest is covered by insurance. This applies to most services. Old-age pensioners, invalidity pensioners and children with disabilities pay a lower fee

The charge for home visits within normal working hours by one's own doctor is normally:

- general population: €13 (ISK 1000);

- old age pensioners and disabled the charge is $€ 5$ (ISK 400).

Since 1993 people have been required to pay a fixed amount, plus $40 \%$ of the remaining total cost in cases of a consultation at a specialist (less for old age pensioners and children). The special groups pay about one third of the fixed amount paid by the general population. The ceiling for one calendar year for all these services is now $€ 277$ (ISK 18000) for the general population and $€ 76$ (ISK 6000) for the special groups. The same cost ceiling also applies to the total cost of these services for all the children in a single family. When the cost ceiling has been reached, the insured person receives a rebate card that guarantees much larger reimbursement for the rest of the year, according to certain regulations.

By law, preventive health care for mothers and children, as well as school health care, is free of charge.

The state pays the total operating and construction costs of the health care centres. 
Degree of formal free choice of services

The user has a free choice of a GP.

Patients have the right to seek help from the nearest health-care centre (in the Reykjavík metropolitan area and Akureyri, individuals are assigned to a certain doctor at a health-care centre). GPs at health-care centres refer patients to specialists if they think this is necessary. Patients also have the right to consult a specialist without going through a GP or a doctor at a health-care centre. Many people in Iceland make use of this right.

Limitations in free choice

A 1998 study by the University of Iceland showed that $95 \%$ of the population lived less than $20 \mathrm{~km}$ from the nearest health care centre, and $94 \%$ reported that they were able to reach it within 20 minutes. There are considerable differences among the health regions; in the capital area these figures are close to $100 \%$ but in the more sparsely populated regions, these figures were around $80 \%$. Nevertheless there is no significant difference in the mean total of doctor's visits for symptomatic illness among the health districts.

Change of provider

All inhabitants are entitled to seek medical assistance at the health care centre or clinic most easily accessible to them at any given time.

Individuals are assigned to a certain GP at a health-care centre, but are free to sign with another GP as long as the GP has the resources to take in a new patient.

Rights and opportunities of complaint

Complaints regarding waiting lists or general service in a health care centre should be given to the top authorities at the centre. Complaints about medical treatment should be given to the Directorate of Health in Iceland (Landlæknisembættid) which controls the works of doctors and hospitals.

\subsubsection{Norway}

Existing types of supply

There are 17529 public doctors under 67 years in Norway. The publicly funded doctors are price regulated by the government. The government funds GPs who are part of "fastlegeordningen" from taxes, and distribute the funds over five regional health organizations.

A private doctor does not receive any governmental funding. The number of non-funded doctors was in May 2005, 586. Company doctors are an example of non-funded doctors. Non-funded doctors are not price regulated. 
There is a tendency for more and more doctors to practice from a centre together with several doctors instead of operating alone.

As of 2005 there are 254 inhabitants per doctor under 67 years old in Norway, or 3.93 doctors per 1000 inhabitants. This represents the best doctor coverage in the Nordic countries.

All doctors must have an approved medical education to get authorisation to practice medicine.

Users are connected to an individual doctor.

Price structure

Through the public "fastlegeordningen", the price is be regulated if both the patient and the doctor are part of the "ordningen".

Currently the price for a normal consultation where both the patient and the doctor are part of "fastlegeordningen" is $€ 15$ (125 NOK).

During a calendar year a patient is exempted from covering more than $€ 196$ (1585 NOK) in medical expenses in accordance with government regulations. Expenses that exceed this amount will be refunded by the social security department (trygdeetaten).

There is no price regulation for doctors who do not receive funding from the government. Prices are therefore be defined by the free market

Degree of formal free choice of services

There is a free formal choice in selecting a GP. The user can choose from either within the "fastlegeordningen" or select a non-funded GP/doctor and pay a higher personal expense.

Limitations in free choice

Although everyone is free to choose a doctor in all municipalities, a possible barrier is that a GP that is part of "fastlegeordningen" is obliged to prioritize the local citizens over those from other municipalities or regions.

The free choice varies across the country due to lack of capacity. The west-coast of Norway has the most citizens per doctor.

Change of provider

If the user is part of the governmental health arrangement ('fastlegeordningen') the user is obliged to apply to the National Health Insurance Office (Trygdeetaten) for a change of doctor. This can be done twice a year.

Rights and opportunities of complaint

A patient can complain to the health service organization of the county (Helsetilsynet i fylket). 


\subsubsection{Sweden}

\section{Existing types of supply}

There are approx 5000 GPs under the age of 65 in Sweden, 85\% work in public sector and $15 \%$ in private sector. Public sector health care is the responsibility of the county council (Landstinget) and is financed by county council tax. When a user visits the health care centre or hospital he/she only needs to pay a patient fee. This fee varies from one county council to another, and is set by the individual county councils. In Stockholm the fee is approx $€ 15$.

The private sector includes private owners of health centres, hospitals or private clinics. However, all activities are almost exclusively financed by county council tax (as per an agreement between county council and care provider (vårdutförare). The user therefore pays the same amount of money whether they visit a private or public GP (local differences should be taken into consideration here).

There is a possibility for every user to be involved in the decisionmaking when it comes to choosing health centre, doctor or hospital. This is valid for both private and public care. The user has a right to influence, a right that has been strengthened over the last ten years by changes in the constitution. The county council is obliged to look after the user's right to choose a preferred doctor. This obligation is stated in "hälso- och sjukvårdslagen”, which is a law that aims to provide all Swedish citizens with quality care. The limits depend on the regulations and agreements made in the different county councils.

The user has a right to change doctor whenever he/she desires without having to apply to the authorities.

As of 2004 there were approximately 1800 inhabitants per GP in Sweden, a relatively low number of GPs per capita compared to similar countries. Initiatives have been launched to change the situation,

All doctors need an approved medical education in order to get authorisation to practice medicine.

\section{Price structure}

Price varies between different counties and between private and public services. The price is dependent on whether the county council has an agreement with the health centre or not. If such an agreement exists, the patient will only need to pay the "patient fee", which is €28 (260 SEK).

Degree of formal free choice of services

Users can involve themselves in the choice of health centre or doctor. This is valid for both private and public care. The user has a right to influence. This right has been strengthened by the fact that the county council is obliged to look after the patient's right to choose a doctor. 
When it comes to specialist care there are no formal legal rights for the patient to choose, even though the county council gives the patient certain rights.

Limitations in free choice

There are some limitations when it comes to freedom of choice such as space, time, price etc. It can take up until 8 days before getting an appointment with a doctor and up to 3 months after referral to get an appointment with a specialist.

In the case of a doctor being fully booked the patient can get an appointment with another doctor.

Change of provider

Every patient has a right to choose doctor whenever they desire and they can do this without having to apply to the authorities.

Rights and opportunities of complaint

The patient can turn to the head of the department, chief doctor or some other representative of the hospital/health care services

In cases of suspected ill-treatment users can press charges through "hälso och sjukvårds ansvarsnämnd" (The Health and Medical Liability Tribunal), HSAN.

\subsection{Dental services}

\subsubsection{Denmark}

Existing types of supply

Approximately $75 \%$ of the population over the age of 18 are connected to a private practitioner. All authorised dentists are free to set up their own clinic.

Most of the clinics are individual dentists with 1-2 clinical assistants or smaller clinics with 2-3 dentists, 1 dental hygienist and 3-5 clinical assistants.

The average number of registered clients per dentist is 800-1200.

All employees involved in dental treatment are formally educated.

The user is connected to an individual dentist.

Children under the age of 18, the partly disabled and people with physical or mental disabilities, who find it difficult to get out, are covered by different regulations for dental care.

Price structure

Dental treatment at private dentists is not free of charge for patients, with exceptions made for children and patients with special needs. 
For patients in general some treatments are partly subsidised, while other treatments are fully paid by the patient. Approximately $70-80 \%$ of adult dental expenses are paid by the patients themselves. The rest is paid by the public Health Care Reimbursement Scheme. In addition, 28\% of the population are covered by private health insurance which reimburses part of the cost of dentistry.

The municipalities offer children under 18 years old dentistry free of charge. Further more the municipalities/ counties offer the partly disabled and people with physical or mental disabilities who find it difficult to get out dentistry free of charge ("omsorgstandpleje" and "amtstandpleje"). If the user in such cases chooses another provider than the one offered, the public authorities are allowed to charge the user the difference in price according to governmental restrictions.

All residents in Denmark are covered by the Health Care Reimbursement Scheme. Citizens do not pay any special contributions to this scheme as it is financed through county taxes. People over the age of 16 have the right to choose between Group 1 and Group 2 insurance. Nearly all (97-99\%) choose to be insured in Group 1.

Both groups of patients (those insured with Group 1 and those insured with Group 2) have the right to receive reimbursements from the public Health Care Reimbursement Scheme. The reimbursement is subtracted from the bill and it covers either a certain amount of the fees or a percentage (typically $40 \%$ ) of the fees of certain dentistry treatments. The balance is paid by the user.

The practising dentists join collective agreements. The collective agreement, along with regulations stipulated by the government, specifies the level of public reimbursements and the prices (for patients with Group 1 insurance) for some the dental services. For patients with Group 1 insurance approximately $75 \%$ of dental services are subject to a stipulated price. For patients with Group 2 insurance all dental services can be freely priced by the dentist. For patients with Group 1 insurance the dentist is not allowed to demand extra payment in addition to that stipulated by the collective agreement. Dental services and prices not included in the collective agreements are priced freely by the dentist.

Degree of formal free choice of services

All users are free to choose their own practising dentist.

Limitations in free choice

There are no formal limitations to choice of practising dentist, but for the user to be covered by the public Health Care Reimbursement Scheme, the dentist has to be part of the collective agreements between the counties and the respective unions. Nearly all practising dentists are registered with the scheme. 
Capacity limitations are sometimes a reason for a dentist not taking on new clients.

\section{Change of supplier}

As the user is free to choose a practising dentist, changing dentist does not involve any authorities. Choice of dentist is a fully free and private matter.

Rights and opportunities of complaint

A complaints system exists for complaints about professional treatment in the health system. The Patients' Complaints Board is an impartial public authority which may express criticism of the medical staff or submit particularly serious cases to the public prosecutor with a view to taking the cases to court.

For complaints about public dentists, dental hygienists, dental technicians or dentists not part of the collective agreements the Patient's Complaints Board must also be contacted.

Complaints about practising dentists who are part of the Health Care Reimbursement Scheme are possible at two levels: the county (Amtstandlægenævnet) and the state (Landstandlægenævnet). The county to which the involved dentist belongs administrates the complaints. In Copenhagen and Frederiksberg it is the municipalities. Decisions made by the county can be appealed at state level.

It is also possible to complain to the Dental Societies Patient Injury Insurance (Dansk Tandlægeforenings Patientskadeforsikring).

\subsubsection{Finland}

\section{Existing types of supply}

Dental care in Finland is primarily funded from tax revenue. In 2003 there were 2200 dentists working in the public health centres. In the private sector there were 2100 dentists plus 700 working part time.

Local authorities receive a government grant for social welfare and health care, the level of which depends on the municipality's population, age distribution, unemployment rate and other related factors.

In 2002, the share of client fees in the funding of municipal health care services was approximately $8 \%$, while municipalities paid out $67 \%$ and the government $25 \%$.

Price structure

Dental care at public health centres is free of charge for the under 18's and other special groups. Dental care for adults at a health centre carries a basic fee of $€ 7$ per visit. Specialised dental care costs at most $€ 11$ per visit. In addition to the basic charge, dental treatment and examinations are charged according to a price list. 
Orthodontic care is reimbursed only if it is necessary for the treatment of illnesses other than dental problems. Denture and technical dentistry expenses are not reimbursed.

Health insurance covers the costs of medicines prescribed by a dentist the same way that costs are reimbursed for medicines prescribed by a doctor.

Municipal dental care is available to war veterans for preventive treatment and clinical work related to prosthetics free of charge. The Social Insurance Institution reimburses dental care for veterans at a higher rate than for the rest of the population.

If individuals use private dental services, their health insurance will cover check-up and dental work up to $60 \%$ of the rate confirmed by the Social Insurance Institution, and not of the actual expenses. Reimbursements for dental examinations are paid once a calendar year.

In the private sector the prices are set by the free market.

Degree of formal free choice of services

The entire adult population is entitled to municipal dental care or to be reimbursed for private dental fees. This right was extended to cover everyone from the beginning of December 2002.

Limitations in free choice

Legislation defining the time frame in which a person must be ensured access to necessary medical care came into force in 2005. The prescribed time frame may be exceeded by three months in oral health care provided under primary health care, if the treatment can be postponed on justifiable grounds without jeopardizing the patient's state of health.

If unable to arrange examinations and treatment within the time frame, the local authority or joint municipal board is responsible for arranging for the treatment of the patient awith a private dentist without a change to the client fee.

This right to municipal dental care or to be reimbursed for private dental fees was extended to cover the entire population from the beginning of December 2002. Due to this law there are approximately 7000 people queuing for municipal dental care and the most difficult situation is in the 10 biggest cities in Finland.

\section{Change of provider}

The big cities are divided into health care areas and the provider in the public health care is appointed by the municipality. Usually a person can use the nearest health care centre to his/her home.

In case of emergency (for example on holidays) a person can use health care centres administered by other municipals.

Users don't have to apply to the authorities when they want to change dentist. They can ask for a different dentist at the health care centre. 
At the moment there are more users wanting to change from the private sector into the public sector than there is capacity available.

Rights and opportunities of complaint

Clients are advised to direct any complaints they may have concerning the actions or behaviour of healthcare professionals to the head of the unit in which the professional works. Health centres have a patient's ombudsman who can give advice on issues concerning patients' rights. If needed, the ombudsman will help draw up the complaint.

Complaints concerning healthcare staff are directed to state provincial offices, which may pass the complaint to the National Authority for Medico legal Affairs. Statutory patient insurance covers physical injury caused to patients due to healthcare and hospital treatment.

Application forms for patient injury claims are available from nursing personnel, patient ombudspersons or the Patient Insurance Centre.

\subsubsection{Iceland}

Existing types of supply

Almost all dentists in Iceland are private practitioners. This makes the price competition free and therefore there can be large differences in prices between dentists. The services of a dentist are fully paid by the client with exceptions for children, old age pensioners and patients with special needs, who enjoy subsidised dental care.

Often two or more dentists form a clinic and share the running costs of the housing and reception, but they can still have different prices for their services.

The user is connected to one dentist of a choice at a time and is always free to change.

All dentists must get a license from the Ministry of Health and have a qualified education from the Faculty of Deontology from the University of Iceland or from abroad.

Dentists are obliged by law to update their knowledge and to give the best possible treatment according to the current general knowledge in their field.

Price structure

Prices are defined by the free market, and may vary between dentists. Competition is more intense in central areas and less in the more rural areas.

The health insurance scheme reimburses $75 \%$ of the cost of dental treatment for children under the age of 18 except for crowns, bridges and orthodontic treatment, in which case more specific rules apply.

People with chronic illness, old age pensioners and disabled pensioners can have their dental costs wholly or partially covered (up to 50\%). 
Dental treatment is fully paid by the rest of the population, except for treatment due to the serious consequences of congenital defects, accidents or illness that the SSSI (State Social Security Institute) helps cover.

Degree of formal free choice of services

Almost all dentists in Iceland are private practitioners, and the user can choose freely among them.

Dentists work under the general law of competition in a free market and are not allowed to cooperate on prices. This is meant to support the free market and lead to better prices for the client.

Limitations in free choice

More than 2/3 of all dentists work in the capital area in and around Reykjavík where also $2 / 3$ of the population live. There are dentist in all smaller towns in Iceland but not in all of the rural areas. People from the smallest and most rural areas have to go to the nearest town to get the services of a dentist. Therefore the population living in the bigger towns in Iceland and especially in the Reykjavík area has the easiest access and the greatest possibility of choice.

Change of provider

The choice of a dentist is absolutely free for the user in Iceland. There are no restrictions or limitations applying to choice of dental services.

Rights and opportunities of complaint

Complaints regarding dental services are taken up by a committee in the Consumers' association of Iceland working with the Public Health Authorities.

The committee includes 3 members, one from the Public Health Authorities, who is also the chairman of the committee, one from the Consumers' association of Iceland and one from the Dentists Association.

\subsubsection{Norway}

\section{Existing types of supply}

Approx 3/4 of all dentists are private practitioners. The private practitioners are not regulated by the authorities with regards to price. Their fees vary between each other and compared to public practitioners. Private practitioners do not receive funding from the government.

The remaining $1 / 4$ of the dentists are employed by county municipalities. The public practitioners are price regulated by the authorities, and funded by the county municipalities, who are also responsible for public dental health care. Prices in the public dental health care are determined by each county municipality, and vary across the country.

As of 2002 there were 1158 persons per dentist. 
There is a steady shift away from single practice clinics to dental health care centres with several dentists.

A dentist has to have a formal dentist education in order to obtain an authorisation to practice dentistry.

The user is normally connected to an individual dentist.

Price structure

Prices at private practitioners are defined by supply and demand, and may vary substantially. There are no defined prices from the authorities to guide private dentists, but the dentists have to provide a physical pricelist that the client can take with him/her.

Children and young people up to the age of 17, mentally disabled and seniors have a right to free necessary dental care by public dentists in the county in which they live or are temporarily are situated. County municipalities do also offer 19-20 year olds dental health care where a minimum of $75 \%$ of the expenses are covered by the county municipality.

Public practitioners can also treat adult paying patients. They are charged in accordance with fees corresponding to the tariffs set by the county municipality. The tariffs can vary between county municipalities.

Degree of formal free choice of services

The Norwegian law states that every Norwegian citizen described in the Dental Care Law § 1-3 has the right to dental care. The law does not state a formal free choice to select a dentist nor does it state the contrary. A free choice is implicit.

The Norwegian Dentist Society (NTF) has developed some guidelines for dentists. $\S 4$ in the Ethical Guidelines of NTF emphasize the free choice of a patient to select a dentist. A dentist can only decline to treat a patient when there is a reasonable cause. A dentist is obliged to serve a patient that needs immediate help.

Limitations in free choice

Everyone mentioned in the Dental Care Law § 1-3 has a right to free necessary dental care in the county in which they live or are temporarily situated. Therefore, there are few limitations on free choice with regards to price, but there may be limitations of geography.

Users that attend private dental care can experience a limitation in free choice, because the prices can vary between private practitioners.

Free choice can be limited by the lack of dentist in some regions in Norway, especially in rural and remote areas. The government stopped regulating the prices in private dental health care in 1994. This led to lack of dental health care in the outer districts of Norway and an overestablishment of private practices in central areas. 
Change of provider

No user of dental health care has to apply to the authorities to change dentist. The matter can be arranged between the patient and the dentist.

Rights and opportunities of complaint

If a conflict can not be settled between the patient and the dentist, one can address a local complaints board. All Dentist Associations local organizations have such a board. Its task is to answer inquiries and/or treat complaints from the general public concerning the technical performance of the treatment. The complaint boards do not have the competence to deal with demands for compensation. There is no charge made for the administration of a complaint. This is a service for patients whose dentist is a member of the Dentist Association. All patients can also consult the county medical officer (fylkestannlegen) or the Governmental Health Authorities.

\subsubsection{Sweden}

\section{Existing types of supply}

There are both public service- and private dental care in all municipalities, and the two markets are approx the same size. The private sector serves $60-65 \%$ of the adult market and approximately $10 \%$ of the population under 20. The remaining are served by public sector dentists.

\section{Price structure}

Pricing is free, but with the following restrictions: Dental care for people under 20 is free of charge. If such dental care is performed by a private dentist he or she is entitled to compensation from the county council according to the prices decided upon between the county council and the private dentists association.

Prosthetics for patients over the age of 65 years cannot cost more than $€ 822$ (7700 SEK) plus charges for materials and basic dental care. "Necessary dental care" in accordance with laws and regulations is normally fixed in price by the county council.

Private dental care is financed through patient fees, dental care reimbursement from the public insurance office and, for some dental care, by reimbursement from the county council.

Public dental care is financed through patient fees, dental care reimbursement from the public insurance office and through taxes.

Adult dental care is financed by the patients' fees and their insurances. 
Degree of formal free choice of services

No law specifically states that a patient may or may not freely choose his or her own dentist. Users can freely choose with whom they wish to enter into contract with regarding any service.

In certain cases it is expressly stated in the law that users have the right to choose dentist e.g. in cases of so called "necessary dental care". Such dental care shall be offered to certain patient groups (see Swedish law: Tandvårdslagen 8a§). In these cases the patient has a right to choose whether the dental care is to be performed by a public sector dentist or by a private sector dentist.

County councils have an obligation, through public sector dentists, to offer all people under 20 complete and regular dental care. Such dental care is free of charge for the patient.

Limitations in free choice

People under 20 living in the municipality of Kronoberg cannot choose freely.

Due to the restrictions on fees, certain dentists will not accept patients over the age of 65 . This may also be the case in cases for "necessary dental care".

There are also restrictions for users who choose to enter into an agreement with the public sector dentists in a so called "dental plan subscription”.

Change of provider

In the adult market patients can change without restrictions. In the market for people under 20 the different county councils have different rules. Generally patients under 20 can change dentist once a year on application.

Rights and opportunities of complaint

Within private dental care, complaints can be made to "Privattandläkarnas förtroendenämnder”. This board receive complaints made against dentists who are members of "Privattandläkarna". Their main task is to try to recon ciliate the parties or to make a recommendation about how to solve the issue. This tribunal deals with questions concerning treatment, not with questions concerning liability or questions concerning whether specific pricing was reasonable or not.

The The Health and Medical Liability Tribunal), HSAN will receive complaints from individuals or the social services. However this tribunal only treats questions of medical treatment, not financial questions. It will not directly help the patient but could give the dentist an official warning.

The Social Services Regional Surveillance Unit (Socialstyrelsens regionala tillsynsenhet) can receive complaints and decide if they should be investigated. Again this unit does not handle financial questions. 
A patient can also bring their case to court to claim his or her rights.

The public insurance office can deal with financial questions concerning dental insurance. A patient can also contact the "patientförsäkringen" to claim damages for treatment.

\subsection{Day care for children}

\subsubsection{Denmark}

\section{Existing types of supply}

The day care service is administered by the local authorities who are responsible according to the law and restrictions given by the state.

Public day care institutions (vuggestue, børnehave, integreret institution, selvejende institution) are established, run and financed by one or more municipalities or as an independent institution according to agreements with the local authority. Day care is staffed by a mix of formally educated people and unskilled assistants. In 2002 an average institution for the youngest children (vuggestue) had 3.4 children per fulltime employee, kindergarten had 7.1 children per fulltime employee, and an integrated institution (integreret institution) had 5.83 children per fulltime employee. The estimated number of day care places in 2005 was:

- Day nursery (vuggestue): 11,500

- Kindergarten (børnehave): 107,900

- Integrated institution: 106,700

Public day nurseries (dagpleje) are run in private homes according to agreements with the municipality, which also finances them. A single childminder has a maximum of five children (maximum of ten children if there are two minders). The estimated number of places in 2005 was 70,900

Pool institutions (puljeinstitution) are established and run by a private business, organization or a group of parents according to agreements with the local authority. The pool institution offers a similar day care offer to the day care centre and is partly financed by the authority through payments of a subsidy to each child. The estimated number of places in 2005 was 6,900.

Private day nursery (dagpleje) is one or two parents who are paid by the local authority to take care of two children - either one of their own and one from another family or two of their own in their own home. This is mostly a private arrangement between two families. The estimated number of places in 2004 was about 900.

A private childminder (børnepasning) may be hired by one or two families who is/are the formal employer of the childminder (minimum 
age of 18 and they must have a working and residence permit). The local authority pays a subsidy of maximum $70 \%$ of the expenses to the childminder. The estimated number of places in 2004 was approximately 3000 .

Private day care (stor børnepasningsordning) is established and run by e.g. a group of educated childminders and parents, but is a similar institution to the public day care centre with waiting lists etc.

Price structure

The subsidy paid by the municipality and the user fee are defined by the state but the specific amounts are regulated according to supply, local expenses, the family's individual situation etc.

By the law the subsidy paid by the municipality is a minimum of $67 \%$, and the user fee a maximum of $33 \%$ of the estimated expenses gross. In municipalities without a day care guarantee the subsidy is a minimum of $70 \%$ and the user payment a maximum of $30 \%$.

If a municipality with a day care guarantee is not able to offer a day care service according to the law, the municipality is legally bound to cover the expenses of a private day nursery or childminder. The subsidy is a maximum of the average expenses of a corresponding offer.

If the user chooses a day care service in another local authority than the one he/she is connected to, the subsidy corresponds to the expenses of a similar offer in the user's local authority. The subsidy is paid directly to the local authority of the chosen day care service. The user pays any difference between subsidy and running expenses.

The specific amount of subsidy and user payment varies across the country, but the general user payment for a fulltime place in Copenhagen 2004 illustrates the level:

Day nursery (vuggestue):

$€ 340$ (2513 DKK)

Day nursery (kommunal dagpleje): $\quad € 340$ (2513 DKK)

Private day nursery: $\quad € 340$ (2513 DKK)

Kindergarten: $\quad € 250$ (1844 DKK)

Degree of formal free choice of services

The user does not have a formal free choice in all aspects regarding day care for children, but in some aspects the user has formal rights. All children have a right to an offer of day care from a certain age.

Nearly all municipalities (98\%) have some sort of a day care guarantee regarding children on the local day care waiting list. Municipalities without a present day care guarantee are legally bound to introduce this from July 2005. The guarantee involves a right to a day care offer for all children at the age of 26 weeks.

All users have a right to notify specific wishes about specific day care supply and type of supply. 
All users have a right to transfer their subsidy for day care offer from one municipality to another.

All users have a right to use a subsidy for a private day care facility.

Limitations in free choice

Limitations vary greatly across the country as the day care offers depend on need and local capacity.

It is a government ambition that the day care guarantee is actually fulfilled, and that the user has some sort of a free choice in terms of specific day care supply. This is however not possible in larger communities like Copenhagen because of the size of the waiting lists for many institutions and kindergartens.

Though each family has a formal right to transfer their day care subsidy from their home municipality to another, local authorities are allowed to close their waiting lists to children from other municipalities. This is permitted when they do not have capacity and there is a waiting list for their own inhabitants. Approx 25\% of all municipalities estimated in 2004 that they would close their waiting lists for children from other municipalities.

\section{Change of provider}

The municipalities have different rules when changing provider. Typically, when changing or withdrawing from day care supply the user has to notify the local authority 1-2 months in advance.

Rights and opportunities of complaint

No channels regarding complaints about day care service exist. Only when it comes to the individual subsidy calculated by the municipality is it possible to complain about the amount of the subsidy to The Social Board (Det Social Nævn).

\subsubsection{Finland}

\section{Existing types of supply}

Over $90 \%$ of day care services are public (municipally provided).

About one half of all children under school age make use of municipal day care services, $75 \%$ of all children in day care are in full-time care.

The staffs in day care centres are required to have at least a secondarylevel degree in the field of social welfare and health care. One in three of the staff must have a post-secondary level degree. Pre-school teachers are required to have either a bachelor or master's degree in education, or a bachelor degree in social sciences with an additional pedagogical course.

The adult-child ratio in day care centres is one to seven for 3-6-yearolds and one to four for children under the age of three in full-time day 
care. For part-time day care the ratio for 3-6-year-olds is one to thirteen and for children under three the ratio is the same as in full-time service.

Family child minders must have appropriate training. In practice there is variation in the length and content of the training. In 2000 The National Board of Education presented a recommendation for a new vocational training for family child minders (Further Qualification for Child Minders, 2000). The adult-child ratio in family day care is one to four, including the child minder's own under school-aged children. Additionally, the child minder can provide part-time care for one pre-school or school-aged child.

\section{Price structure}

The day care fees are based on family size and income level. They range from between $€ 18-200$ per month. The costs decline with the second child in day care.

For families with one child, the charge is max $€ 200$ a month. For the second child the maximum charge is $€ 180$ for the next child $20 \%$ of the first child's charge. For low income families day care is free. Client fees cover about 15 percent of the total day care costs.

The costs of part-time day care are proportionally less. They are determined by the municipality.

Since August 1997, it has been possible for families to receive a private childcare allowance in order to provide their children with private care.

Degree of formal free choice of services

Finnish early childhood education and care (ECEC) covers both the child day care facilities offered to the families and the early childhood education for children. Day care in its different forms is the most important area of public ECEC activities. The Finnish ECEC-system consists of municipal and private services.

Municipal day care is provided at day care centres and in family day care. Several local authorities also organise various open activities, such as supervised play activities open to everyone in playgrounds and at open day care centres. As of 1996, parents of all children under school age have enjoyed the right to a place in day care for their child provided by their local authority.

After the parental leave period, families are provided with three different options up until the child begins compulsory school:

- Caring for the child at home and receiving child home care allowance (until the youngest child turns three years).

- Having the child cared for in private day care using the private child care allowance.

- Having the child cared for in municipal day care. 
These options are administered by the Ministry of Social Affairs and Health on the national level.

Limitations in free choice

Free choice of day care facility varies between different municipalities depending on local capacity.

\section{Change of provider}

The user can change his/her municipal day care by contacting the local administrative superior. The system is very flexible.

Rights and opportunities of complaint

If a need to complain arises, the user of municipal day care has several channels in use:

- The local administrative superior

- The director of municipal social services

- Municipal committee

- Provincial government

- National parliament and Ombudsman

\subsubsection{Iceland}

Existing types of supply

Public kindergartens (Leikskólar) are established, run and financed by the local authorities or are run as independent institutions according to agreements with the local authority. Private kindergartens are run on the same guidelines and depend on a licence from the local authorities to operate.

Kindergartens are to be available to all children from 18 months of age. This is however not always possible, due to lack of capacity. In municipalities where there may be insufficient room to accommodate all applicants, the children of families with a difficult social situation, single parents and students are often given priority. The user can apply for a space in kindergarten for a child from 6 months of age. If no space is available the child is placed on a waiting list.

There are a total of 261 kindergartens in Iceland (2004). The average number of children per child-care worker is approximately 4 .

In December 2004 there were 875 children from one year of age on waiting lists for kindergartens in Reykjavik.

Day parents (dagforeldrar) and day care mothers (dagmódir) are one or two parents taking care of children in their own homes. This service is administered by the social services of the local municipal authority. Those who take care of children in their own homes must fulfil certain 
requirements and the supervision of day care mothers is the responsibility of each local municipal authority.

Day care parents take children from 6 months and are therefore often used while children are on a waiting list for kindergarten.

Children in day care in private homes numbered 1964 in 2002. The number of private day carers (dagmodir, dagforeldrar) was 448 giving an average of 3.7 children per child carers in private homes.

Private kindergartens are given licenses by the local authorities, and work to the same standard of quality as the public kindergartens. Private kindergartens take in children as young as 6 months of age and are therefore often used while parents wait for an available space for a child in a public kindergarten. Of the 261 kindergartens, 28 are private.

Price structure

Prices vary between municipalities depending on the running costs of the kindergartens.

The local authorities cover around $67 \%$ of the expenses for every child (the cost being around $€ 870$ or IKR 70,000 in 2004) and the parents around $33 \%$. The subsidy for privately run kindergartens is $67 \%$ of the average cost for a child in the public kindergartens. The user pays the price difference.

The fee may be reduced as a result of the situation of the individual family (if the parents are students, single parents or suffer from a handicap). The fee is also affected by the child's age, where the expenses for older children are less than for the younger.

The price for day care in kindergarten reduces with each child; the actual sibling discount varies between municipalities. In Reykjavik the discount is $40 \%$ of the full price for the second child and $90 \%$ for the third child.

The cost of day care in private homes (day care parents/day care mother) is subsidised by the local authorities in each municipality according to the local regulations. These regulations vary between municipalities.

Degree of formal free choice of services

The user has a formal free choice between the Kindergartens and day care offered by the municipality. The different municipalities in the country run kindergartens in Iceland, and parents are free to choose from the existing offers within their municipality.

All children have a right to a day care offer from 6 months of age.

The user is free to choose day care in a private home by a child minder instead of a kindergarten.

All users have a right to use their subsidy for a private day care service. 


\section{Limitations in free choice}

The limitations regarding choice of day care facility vary depending on the size of the municipality and local capacity. In Reykjavik (the biggest municipality with the largest number of kindergartens) users are not always able to get a space in a kindergarten of their choice.

The municipality offers day care in kindergartens with available spaces. The user is free to take the offered space or choose to continue staying on a waiting list and apply for the child's transfer to the preferred kindergarten.

\section{Change of provider}

To change kindergarten the user applies to the local authorities to be signed up on a replacement list. This list is separated from normal waiting lists.

Most of the children (9 out of 10) in kindergartens are in full time day care (7-9 hours per day) which limits the flexibility within kindergartens.

Rights and opportunities of complaint

Complaints regarding waiting lists or the administration of a specific kindergarten are addressed to the board of that kindergarten or to the local authorities.

Complaints regarding the kindergarten and its educational qualities or other fundamental questions should be addressed to the proper authorities in the municipality.

\subsubsection{Norway}

Existing types of supply

The Ministry of Children and Family (Barne- og familiedepartementet) define funded day care centres/kindergartens as follows:

- Ordinary

- Family

- Open.

This division applies for both public and private day care centres.

By the end of 20032911 public and 3013 private kindergartens were registered. By the end of 2004, 213045 children had a place in an ordinary day care centre or a family day care centre. In addition 7000 children had an offer in open day care centres.

Other options that are not defined by the authorities as day care centres are children parks (barnepark) or nannies (dagmamma).

Both private and public kindergartens that are approved by the municipality as a day care centre are funded directly by the government. In addition, users pay a regulated monthly fee. 
The School and Day Care Centre Committee (Skole- og barnehageutvalget) in the municipality is responsible for supervision and the School and Day Care Centre Office in the municipality has the administrative responsibility according to the law and restrictions given by the state (Law of day care centres of May 5, 1995 and the regulations and directions from the Children- and family department (Barne- og familiedepartementet) in addition to municipal resolutions).

The supply varies greatly across the country.

There are no official statistics available about the size of day care facilities. However there are more children in public day care centres than in private day care centres.

In 2003, there were 3.5 children per employee in day care centres.

Of 58400 employed in the day care sector, 33\% had an authorized preschool education.

Price structure

There is a price roof for day care centres (public and private) that receive funding from the government. The price roof is currently $€ 340(2,750$ NOK).

Parents have a right to sibling discount in day care centres with governmental funding. This applies whether the siblings are in the same or different day care centres in the same municipality. It also applies if e.g. one child is enrolled in a public one and the other in a private. The discount should be a minimum of $30 \%$ for child number two and $50 \%$ for child number three and further children.

The day care centres are allowed to charge extra for serving food.

Users that have a child between the age of one and three in a day care centre that does not receive governmental funding, receive cash funding from the government.

This means that parents can receive cash support (kontantstøtte) for staying at home with their children. If the child is partly in a day care centre, the parents can receive reduced cash support.

There are no regional differences in price for publicly funded day care centres. Prices vary between options that are not publicly funded based on supply and demand.

Degree of formal free choice of services

Users do not have a formal free choice in all aspects regarding publicly funded day care offers.

The term "barnehage" (day care centre) in Norway is protected and can only be applied to centres that are approved by the municipality. Once they are approved they immediately receive funding from the government.

If the users want a place in a government funded day care centre the choice is narrowed because the users have to apply for a place in the day 
care centres in their municipality through a coordinated admission system (samordnet opptak) administrated by the School and Childcare Office (Skole- og barnehagekontoret). Parents can prioritize their wishes between public or private day care centres. They will then receive offers which they can choose from. Those who apply and do not receive a place will be registered on a waiting list.

Limitations in free choice

There are limitations in free choice in terms of geography, time, price and the age of the child.

A day care centre can only be provided for in the municipality where the users are living. The total coverage ratio in Norway by 2004 was 72 percent. Over half of the Norwegian municipalities have $100 \%$ coverage, so in these municipalities the users will experience a greater feeling of free choice. The government has a goal to offer a child care place to everyone who wants it within 2005, but this is to be evaluated on the basis of demand.

As of September 2004, there were almost 21000 children on a waiting list for a place in day care. These children were concentrated in relatively few municipalities. Over half of the municipalities do not have any waiting lists, while almost half of the children that are on waiting lists can be found in five municipalities. The municipalities with full coverage are relatively small and situated in more rural areas.

There is no guaranteed place for children on waiting lists.

The owner or management of the day care centre determines the admission criteria. The Day Care Law (barnehageloven) does not lay down any rules concerning vacations or opening hours, and owners/ management are free to decide on these matters.

Parents that enrol their child in a funded public or private day care centre experience free choice concerning price. The maximum price that can be charged is the same for either option.

Parents that choose other options for their child such as child parks (barneparker) or nannies can experience a limitation of free choice as the difference in price between the players vary and are not regulated by the government.

\section{Change of provider}

In order to change day care facility, the user can apply to the day care facility of interest. In some municipalities users have to apply to the school and day care centre office in the municipality.

Rights and opportunities of complaint

A user can only complain if the refusal is from a public day care centre in accordance with the central and local government administration law 
(Forvaltningsloven $\S 28$ and §29). The complaint is directed toward the school and day care centre office in the municipality.

\subsubsection{Sweden}

\section{Existing types of supply}

The legislation does not distinguish between public or private day care services.

There are no formal regulations about the space and in each kindergarten. The building size will determine if there is room to accept more children. The authorities often use the rule that there should be no more than 5 children to each staff member.

In the autumn $200476 \%$ of children in day care in the age of 1-5 attended "förskola" and 7\% attended "familjedaghem". In Stockholm approximately $10 \%$ of "familjedagehem" were municipal and $90 \%$ were private in 2004. These numbers vary around the country.

Every child should be offered day care (föreskola) free of charge for at least 525 hours per year from the autumn they turn four (allmän förskola).

Price structure

The day care facility management are allowed to charge a reasonable fee, but the fee may not exceed the running costs. The authorities imposed a system called Maxtaxa, in 2002, to keep the costs down.

Family income affects the fee, and sibling discount is granted for all families. Maximum fees are $€ 135$ (1,260 SEK) for the first child, €90 (840 SEK) for the second and $€ 45$ (420 SEK) for the third. All municipalities have been using Maxtaxa since January 2005.

Degree of formal free choice of services

Kindergarten, "förskoleverksamhet", in Sweden consists of "förskola", "familjedaghem (dagmamma)", and "öppen förskola”. The rights and obligations of these three types of activities are regulated by law (Skollagen).

Municipalities are responsible for providing day care for children who live in Sweden on a permanent basis (Skollagen §1). Parents can choose the preferred form of day care. "Förskola" is an educationalist group activity for children in the age of 1-5. In the "familjedaghem", child minders care for children whose parents work or study. The activity is usually in the child minders home. In the "öppna förskolan" the non-working parents have an opportunity to develop an educational group activity together with the social services.

Places should be offered without unreasonable delay, which is normally within 3 to 4 months after the parents have applied for day care. Parents can contact a handling officer to apply for different day care al- 
ternatives. In cases where no place is available, the handling officer will look for alternatives in other municipalities.

Limitations in free choice

The options for choice of day care facility vary greatly throughout the country. Space and capacity are the most important factors, and each municipality must decide whether they can accept more children or not. There is a waiting list for parents wanting to apply for a specific day care alternative. Waiting time varies around the country.

Change of provider

Users must apply to the municipal authorities, and the matter will be decided based on availability at the preferred kindergarten.

Rights and opportunities of complaint

In cases of dissatisfaction with the kindergarten, complaints should be directed to the facility itself. If the response is non satisfactory, complaints are taken to the municipal authorities. Finally, 'Skolverket' can also handle cases of complaints. 



\section{Chapter 2 - Survey: Health services - GPs and specialists}

\subsection{Introduction}

This chapter will look at all survey findings within the area of health services and doctors. Findings on a Nordic level, a country level and a market level are summarised before the findings for each area of investigation are detailed.

\subsection{Usage of doctors}

\subsubsection{A summary of survey findings}

Most people in the Nordic countries (73\%) have visited a doctor in the past 12 months. Around one quarter of them have been once and one quarter of them five times or more. Most have consulted a GP (68\%).

In Sweden and Denmark more women than men go to the doctor. Furthermore people over 50 years of age and people on low incomes are more likely to go to the doctor in Sweden, Denmark and Norway.

Almost 4 out of ten people are likely to visit a specialist in Sweden and Finland, and in Finland almost 2 out of 10 used their company doctor on their last visit to the doctor.

The age group between 18-29 years old distinguish themselves as more likely to go to a GP than other age groups in Norway and Sweden while in Finland and Sweden they are more likely not to have a regular doctor at all.

If we compare usage of doctors and usage of dentists across the Nordic region we see that the visiting pattern is similar with nearly three quarters visiting a doctor and a dentist at least once in the last 12 months. More people visit their doctor more than once a year than visit their dentist more than once a year.

When it comes to type of doctor $68 \%$ have visited a GP while the same percentage has visited a private dentist.

We see some differences when it comes to length of relationship with their current doctor and dentist. Nearly $40 \%$ say that they have either had the doctor for less than a year or that they have no regular doctor while the majority reports a relationship of over 5 years with their current dentist. Danes have the longest relationship with both their doctors and dentist. 


\subsubsection{Survey findings}

Figure 1: \% consulting a doctor within the past 12 months

Q1: Have you, and how often, within the past 12 months, consulted a doctor, a specialist in a non-emergency situation?

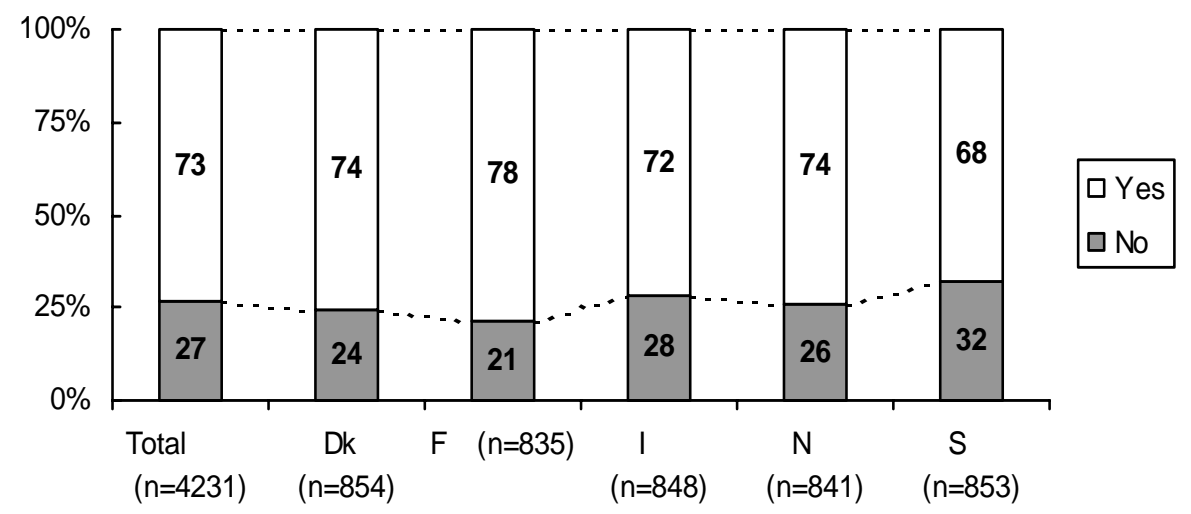

Table 1: Number of visits to a doctor within the last 12 month, $\%$ answering

\begin{tabular}{rrrrrrr} 
& $\begin{array}{r}\text { Total } \\
\mathbf{N = 3 0 6 8}\end{array}$ & $\begin{array}{r}\text { Denmark } \\
\mathbf{N = 6 3 3}\end{array}$ & $\begin{array}{r}\text { Finland } \\
\mathbf{N}=\mathbf{6 3 6}\end{array}$ & $\begin{array}{r}\text { Iceland } \\
\mathbf{N}=\mathbf{6 0 3}\end{array}$ & $\begin{array}{r}\text { Norway } \\
\mathbf{N}=\mathbf{6 3 2}\end{array}$ & $\begin{array}{r}\text { Sweden } \\
\mathbf{N}=\mathbf{5 6 4}\end{array}$ \\
\hline 0 times & 2 & 2 & 0 & 1 & 0 & 3 \\
Once & 24 & 18 & 27 & 10 & 19 & 28 \\
Twice & 22 & 22 & 22 & 24 & 20 & 22 \\
3 times & 16 & 16 & 16 & 16 & 17 & 16 \\
4 times & 10 & 10 & 11 & 9 & 11 & 7 \\
5 times & 26 & 32 & 23 & 30 & 31 & 23 \\
Don't know & 1 & 2 & 0 & 2 & 2 & 1 \\
\hline
\end{tabular}

- Looking at the Nordic countries as a whole we see that the majority (73\%) have consulted their doctor in the last 12 months. Nearly one in four (24\%) have consulted their doctor once, while just over one in four (26\%) have consulted their doctor 5 times or more.

- Significantly fewer Danes (18\%) and Norwegians (19\%) than the Nordic average (24\%) have visited their doctor just once while significantly more have visited their doctors 5 times or more (32\% and $31 \%$ respectively).

- In Sweden the reverse is true - significantly more Swedes (28\%) have visited their doctor just once in the last 12 months than is average for the Nordic countries while significantly fewer have been to the doctor 5 times or more.

- It is also worth noting that $30 \%$ of Icelanders have visited their doctor 5 times or more and 19\% have visited their doctor just once in the last 12 months. These percentages are not significant in terms of the Nordic average. 
- Looking at the individual countries we see that in Sweden and Denmark significantly more women have consulted a doctor than men.

- In all countries significantly more older people have consulted a doctor.

- In Norway, Sweden and Denmark significantly more people with an income under $€ 30.000$ have consulted a doctor while significantly fewer people in households with 3 adults have done the same.

- In Sweden and Finland significantly more people who live alone have consulted a doctor while significantly fewer 30-39 year olds have done the same.

- It is also worth noting that in Iceland women, people over 60 years old and those with a household income of $€ 30.000$ or less are more likely to have visited the doctor.

- In Sweden we see that those living in larger towns and those in the age group 40-49 years are significantly more likely to have visited the doctor 5 times or more. Significantly fewer single people visit the doctor just once and the same is true of people earning under $€ 30.000$.

- In Denmark those with an income of under $€ 30.000$ are significantly more likely to have visited a doctor 5 or more times

- In Finland people living in metropolitan areas and those with one child are significantly less likely to have visited the doctor just once whereas people living alone are significantly less likely to have visited the doctor 5 times or more.

- For Iceland it is worth noting that men, people in households with three adults, those living in households with three children and those living in larger metropolitan towns are more likely to visit the doctor just once. Those over 70 years old, those with incomes under $€ 30.000$ and widowers are more likely to visit the doctor 5 times a year or more.

Table 2: Type of doctor last consulted, \% answering

Q2: Which kind of doctor did you consult at your last medical visit?

\begin{tabular}{lrrrrrr}
\hline & $\begin{array}{r}\text { Total } \\
\mathbf{N}=\mathbf{3 0 6 8}\end{array}$ & $\begin{array}{r}\text { Denmark } \\
\mathbf{N = 6 3 3}\end{array}$ & $\begin{array}{r}\text { Finland } \\
\mathbf{N}=\mathbf{6 3 6}\end{array}$ & $\begin{array}{r}\text { Iceland } \\
\mathbf{N = 6 0 3}\end{array}$ & $\begin{array}{r}\text { Norway } \\
\mathbf{N}=\mathbf{6 3 2}\end{array}$ & $\begin{array}{r}\text { Sweden } \\
\mathbf{N}=\mathbf{5 6 4}\end{array}$ \\
\hline General practitioner & 63 & 79 & 46 & 52 & 75 & 57 \\
Specialist & 31 & 19 & 37 & 46 & 20 & 39 \\
Company doctor & 5 & 0 & 17 & 0 & 2 & 3 \\
Other & 1 & 2 & 0 & 2 & 2 & 1 \\
\hline
\end{tabular}

- Looking at the Nordic countries as a whole we see that a majority (63\%) consulted a GP at their last medical visit.

- Significantly more Danes (79\%) and Norwegians (75\%) visited their GP than is average for the Nordic region.

- Significantly more Swedes (39\%) and Finns (37\%) visited a specialist the last time they were at the doctor than the Nordic average (31\%). 
- It is worth noting that $46 \%$ of Icelanders visited a specialist at their last medical visit, although this percentage is not significantly different in terms of the Nordic average. The high percentage here probably due to the fact that Icelanders are allowed to establish direct contact with a specialist.

- Significantly more Finns (17\%) visited the company's doctor compared to the Nordic average of 5\%. Company doctors are found more often in Finland than any other Nordic country. Significantly fewer Swedes and Norwegians did the same (3\% and $2 \%$ respectively).

- Looking at the individual countries we see that significantly more 1829 year olds and those with a household income of under $€ 30.000$ in Norway have visited a GP

- In Sweden significantly more 18-29 year olds and those living in a metropolitan area have visited a specialist while significantly more who have a household income of $€ 65.000$ or more have visited their company doctor.

- In Finland significantly fewer between 40-49 years old have visited a GP while significantly more of them have visited a company doctor. Those over 60 years are significantly more likely to have visited a GP while those living in a metropolitan area are significantly more likely to have visited a specialist.

- In Iceland it is worth noting that those living in smaller towns, those living in larger provincial towns and those with one child in the household are more likely to have visited a GP on their last visit.

Figure 2: Length of relationship with doctor

Q3:For how long have you had this doctor?

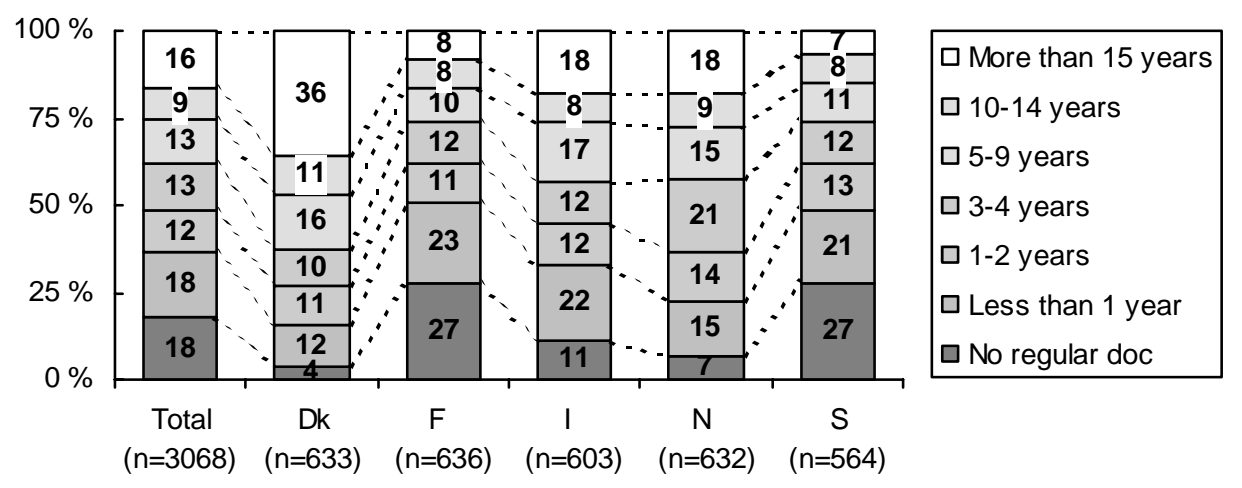

- Looking at the Nordic countries as whole we see that $18 \%$ state that they have had their doctor for less than a year. A further $18 \%$ state that they do not have a regular doctor/medical clinic (18\%) while $16 \%$ state that they have had their doctor for more than 15 years.

- Danes are significantly more likely to have kept their doctor for more than 15 years (36\%) while Swedes (7\%) and Finns (8\%) are 
significantly less likely to have done the same when compared to the Nordic average. For Denmark, there may be a price barrier to change, as Danes must both apply and pay for this.

- Norwegians are significantly more likely to have had their doctor for 3-4 years than their Nordic counterparts (average of 13\%).

"Fastlegeordningen" which was introduced 4 years ago may explain this.

- Both Finns and Swedes are significantly more likely to have had their doctor for less than a year or not to have a regular doctor.

- Looking at the individual countries we see that in Sweden and Finland significantly more 18-29 year olds have no regular doctor.

- In Sweden, Norway and Finland significantly fewer 30-39 year olds have had their doctor for more than 15 years

- In Norway and Denmark those living in metropolitan areas are significantly less likely to have had a doctor for more than 15 years.

- For Iceland it is worth noting that those living in larger provincial towns are more likely to have had their doctor for more than 15 years.

\subsection{User motives and information gathering}

\subsubsection{A summary of survey findings}

"By chance" was the most mentioned reason for choosing a current doctor in the Nordic countries and was most likely to be mentioned by Swedes (23\%). The second and third most mentioned reasons were that "the doctor had been recommended by health personnel" and "location of the clinic". Location was most likely to be mentioned by Danes and Norwegians.

Over 2 out of 10 Icelanders mentioned that "the doctor was the only one with an available place" while almost 2 out 10 Finns said "it was the company doctor".

$83 \%$ of people in the Nordic countries did not gather information before the first visit to their doctor. Of those who did over half of them used family friends as a source of information.

One quarter of those who did not gather information prior to their first visit to their doctor excused this by saying that the doctor had been recommended by health personnel. However it is worth noting that over 1 out of 10 said that they simply didn't want to spend time gathering information.

If we compare motives for choice of provider and user information gathering patterns across the markets in the Nordic region we see that location and recommendations from either friends or from professionals were also important reasons for choice of provider for all three markets. 
However it should be noted that the most popular reason for choice of doctor (given by $17 \%$ of people) was "by chance".

Most people did not gather information about different doctors and dentists; however $61 \%$ did gather information about different day care facilities. For people who did gather information most cited friends and family as their main source of information in all three markets. Not suprisingly, the fact that they had a recommendation was the main reason cited for not gathering information about different doctors and dentists before choice. However when it came to day care provider "other" reasons were most cited when people were asked why they did not gather information.

\subsubsection{Survey findings}

Table 3: Primary reasons for choosing doctor, $\%$ answering

Q4: Now I ask you to think of the first time you visited this doctor. Do you remember the primary reason why you chose this doctor?

\begin{tabular}{|c|c|c|c|c|c|c|}
\hline & $\begin{array}{r}\text { Total } \\
\mathrm{N}=3068\end{array}$ & $\begin{array}{r}\text { Denmark } \\
\qquad N=633\end{array}$ & $\begin{array}{r}\text { Finland } \\
\mathrm{N}=636\end{array}$ & $\begin{array}{l}\text { Iceland } \\
\qquad \mathrm{N}=603\end{array}$ & $\begin{array}{r}\text { Norway } \\
\mathrm{N}=632\end{array}$ & $\begin{array}{r}\text { Sweden } \\
\mathrm{N}=564\end{array}$ \\
\hline By chance & 17 & 7 & 17 & 10 & 18 & 23 \\
\hline Recommended by doctor/health & & & & & & \\
\hline personnel & 15 & 10 & 18 & 18 & 15 & 15 \\
\hline Location & 10 & 17 & 4 & 6 & 14 & 7 \\
\hline It is the family doctor/medical clinic & 9 & 14 & 8 & 8 & 8 & 6 \\
\hline Recommended by friends & 8 & 14 & 3 & 13 & 9 & 7 \\
\hline $\begin{array}{l}\text { It is the company's doctor/the industrial } \\
\text { medical officer }\end{array}$ & 7 & 1 & 18 & 0 & 4 & 4 \\
\hline Transferred/old doctor stopped & 7 & 7 & 1 & 0 & 2 & 14 \\
\hline Only doctor with available places for & & & & & & \\
\hline new patients & 6 & 5 & 4 & 22 & 6 & 6 \\
\hline Don't remember/don't know & 6 & 8 & 2 & 8 & 8 & 7 \\
\hline The doctors personal data (age, sex) & 4 & 8 & 2 & 8 & 5 & 1 \\
\hline Previous experiences/good reputation & 4 & 3 & 2 & 0 & 5 & 6 \\
\hline Good opening hours & 1 & 0 & 2 & 1 & 0 & 0 \\
\hline Price & 1 & 0 & 3 & 0 & 0 & 0 \\
\hline Suggested by health insurance & 1 & 3 & 0 & 0 & 1 & 0 \\
\hline Size of clinic & 0 & 0 & 1 & 0 & 1 & 0 \\
\hline Other & 5 & 2 & 16 & 8 & 1 & 2 \\
\hline Don't remember/don't know & 6 & 8 & 2 & 8 & 8 & 7 \\
\hline
\end{tabular}

- Across the Nordic region "by chance" (17\%) and "recommended by doctor/health personnel" (15\%) were the most common reasons cited for choosing their current doctor. 10\% mentioned "location". It should be noted that almost 1 in 3 gave "other" reasons for their choice of doctor.

- Danes were significantly less likely to give "by chance" (7\%) as a reason for choosing their doctor while Swedes were significantly more likely to (23\%).

- Significantly fewer Danes gave recommendations from health personnel (10\%) while significantly more Danes (17\% versus a 
Nordic average of $10 \%$ ) gave "location" as the reason for choosing their doctor.

- "Location" was also significantly more important as a reason for choosing a doctor for Norwegians (14\%)

- Icelanders were significantly more likely to say that there current doctor was "Only doctor with available places for new patients" (22\% versus a Nordic average of $6 \%$ )

- Other findings worth noting here are that significantly more Finns (18\%) gave "It is the company's doctor/the industrial medical officer" as a reason for choosing their doctor than the Nordic average of 7\%; however we should note here that company doctor's are much more usual in Finland than in the other Nordic countries.

- Significantly more Danes gave "family doctor" and "recommendations from friends" as a primary reason for choosing a doctor (both $14 \%$ versus an average of $9 \%$ and $8 \%$ respectively). In Denmark, capacity limitations described in the desk research study may explain this, as when faced with limited capacity doctors will only accept children and/or partner of clients.

- Swedes were significantly more likely to cite "transferral” (14\% versus an average of 7\%).

- Looking at the individual countries we see that in Sweden significantly more men than women have had their doctor recommended by another doctor. Significantly more 18-29 year olds have had their doctor recommended by friends and those living with their partners or with one child in the household are significantly more likely to have chosen their doctor by chance.

- In Norway 18-29 year olds are significantly more likely to state that they chose their doctor because he/she is the family doctor and significantly less likely to say they chose their doctor by chance; those living in metropolitan areas are significantly more likely to have chosen on the basis of location while the opposite is true for single people

- In Finland 40-59 year olds are significantly more likely to have chosen their doctor because he/she is the company doctor and 18-29 year olds are significantly more likely to have chosen on the basis of price.

- For Iceland it is worth noting that men were more likely to choose their doctor by chance while women were more likely than men to choose their doctor on the basis of the doctor's personal data. Furthermore those living with three children in the household were less likely to choose their doctor on the basis of a recommendation from health personnel and widowers were less likely to say that their doctor was the only one with available places. 
Figure 3: \% gathering information prior to their first visit to their docto

Q5: Did you gather information on various doctors prior to your first visit to this doctor?

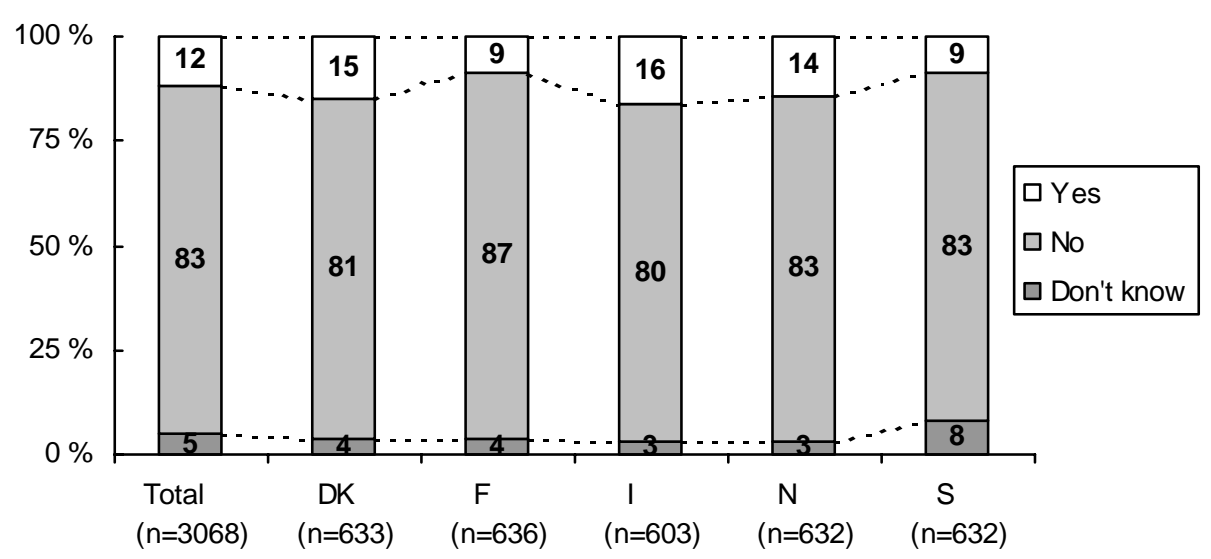

- Looking at the Nordic countries as a whole we see that $83 \%$ did not gather information prior to their first visit to their doctor.

- Significantly more Finns (87\%) did not gather information.

- Significantly more Danes (15\%) gathered information prior to their first visit, while significantly fewer did so in Sweden and Finland (both $9 \%$ against a Nordic average of $12 \%$ ).

- It is also worth noting that $16 \%$ of Icelanders gathered information prior to their first visit to their doctor, though this percentage is not significantly different in terms of the Nordic average.

- Looking at the individual countries we see that in both Norway and Finland men are less likely to gather information prior to a first visit to a doctor than women. In Iceland it is worth noting that 18-29 year olds are less likely to gather information.

Table 4: Sources for information about doctor, \% answering more than one answer allowed

Q6: If Yes to Q5. Which sources did you use to gather information about different doctors?

\begin{tabular}{|c|c|c|c|c|c|c|}
\hline & $\begin{array}{r}\text { Total } \\
\mathrm{N}=420\end{array}$ & $\begin{array}{r}\text { Denmark } \\
\mathrm{N}=103\end{array}$ & $\begin{array}{r}\text { Finland } \\
\mathrm{N}=68\end{array}$ & $\begin{array}{l}\text { Iceland } \\
\mathrm{N}=101\end{array}$ & $\begin{array}{r}\text { Norway } \\
N=94\end{array}$ & $\begin{array}{r}\text { Sweden } \\
\mathrm{N}=54\end{array}$ \\
\hline Spoke to family/friends & 57 & 60 & 52 & 58 & 61 & 54 \\
\hline Contacted one medical clinic & 18 & 6 & 13 & 38 & 16 & 34 \\
\hline Contacted public authorities & 9 & 14 & 1 & 4 & 16 & 2 \\
\hline Contacted several medical clinics & 6 & 3 & 6 & 11 & 5 & 10 \\
\hline Surfed the internet & 6 & 9 & 9 & 0 & 4 & 5 \\
\hline $\begin{array}{l}\text { Saw advertising material in } \\
\text { phone books/ papers/ magazines } \\
\text { Read article in }\end{array}$ & 5 & 2 & 14 & 1 & 1 & 5 \\
\hline newspaper/magazine & 4 & 1 & 11 & 1 & 4 & 5 \\
\hline $\begin{array}{l}\text { Received information without } \\
\text { asking for it }\end{array}$ & 2 & 8 & 0 & 0 & 0 & 0 \\
\hline Other & 10 & 10 & 15 & 6 & 12 & 6 \\
\hline Don't remember/don't know & 2 & 1 & 2 & 3 & 2 & 3 \\
\hline
\end{tabular}


- Looking at the Nordic countries as a whole we see that $57 \%$ state that they collected their information from family/friends. The second most cited source of information was "contact with one medical clinic" (18\%).

- Significantly more Swedes (34\%) contacted one medical clinic and gathered information while significantly fewer Danes did so (6\%). Although the percentages are not significantly different in terms of the Nordic average, it is also worth noting that $38 \%$ of Icelanders also contacted just one medical clinic while $11 \%$ contacted more than one medical clinic.

- Danes were the only people who gave "information received without asking for it” as a source (8\%).

- Significantly more Finns (14\%) had seen advertising material in phone books/newspapers/magazines compared to a Nordic average of $5 \%$ and just $1 \%$ of Norwegians and Icelanders (not a significant difference)

- Looking at the individual countries we see that in Sweden 18-29 year olds, those living in 1 person households and single people are significantly more likely to say they contacted one clinic to gather information. And those living in metropolitan areas are significantly more likely to say that they surfed the internet for information.

- In Finland those living with a partner were significantly more likely to gain information from newspaper and magazine articles and $100 \%$ of 18-29 year olds mentioned family and friends as a source of information.

Table 5: Reasons for not gathering information on various doctors, $\%$ answering

Q7:If No to Q.5: What is the reason for not gathering information on various doctors prior to your first visit to this doctor?

\begin{tabular}{|c|c|c|c|c|c|c|}
\hline & $\begin{array}{r}\text { Total } \\
\mathrm{N}=2522\end{array}$ & $\begin{array}{r}\text { Denmark } \\
\mathrm{N}=509\end{array}$ & $\begin{array}{l}\text { Finland } \\
\mathrm{N}=546\end{array}$ & $\begin{array}{l}\text { Iceland } \\
\mathrm{N}=481\end{array}$ & $\begin{array}{r}\text { Norway } \\
\mathrm{N}=517\end{array}$ & $\begin{array}{r}\text { Sweden } \\
\mathrm{N}=469\end{array}$ \\
\hline $\begin{array}{l}\text { Doctor/health personnel had recom- } \\
\text { mended the doctor }\end{array}$ & 25 & 16 & 35 & 16 & 19 & 28 \\
\hline $\begin{array}{l}\text { Did not want to spend time gathering } \\
\text { the information }\end{array}$ & 13 & 9 & 15 & 12 & 15 & 14 \\
\hline $\begin{array}{l}\text { Other friends/relatives had } \\
\text { recommended the doctor }\end{array}$ & 11 & 25 & 6 & 18 & 10 & 7 \\
\hline $\begin{array}{l}\text { The doctor is the only one close to my } \\
\text { home/work }\end{array}$ & 10 & 12 & 8 & 11 & 15 & 6 \\
\hline I have good experiences with the doctor & 9 & 16 & 4 & 8 & 11 & 7 \\
\hline No choice/forced & 7 & 5 & 4 & 14 & 3 & 11 \\
\hline Difficult to find information & 2 & 5 & 1 & 3 & 2 & 2 \\
\hline Transferred/old doctor stopped & 2 & 4 & 0 & 0 & 1 & 2 \\
\hline Other & 10 & 5 & 12 & 15 & 6 & 14 \\
\hline Don't know/don't remember & 16 & 13 & 17 & 6 & 19 & 16 \\
\hline
\end{tabular}

- Looking at the Nordic countries as a whole we see that $25 \%$ gave "a doctor/health personnel recommended the doctor" as a reason for not gathering information; 16\% stated that they “didn't remember/didn't 
know” while $13 \%$ said they didn't want to spend their time gathering information.

- The Finns were significantly more likely to give "doctor/health personnel had recommended the doctor" as a reason for not gathering information (35\%).

- Significantly fewer Danes gave recommendation from health personnel as a reason (16\%) and the fact that they did not want to spend their time gathering information (9\%). On the other hand significantly more Danes cited having had good experiences with the doctor as a reason for not gathering information (16\% versus a Nordic average of 9\%).

- Norwegians were significantly less likely to give "the doctor/health personnel had recommended the doctor" as a reason for not gathering information (19\%) while they were significantly more likely to give "The doctor is the only one close to my home/work" as a reason (15\% versus a Nordic average of $10 \%$ ).

- Although the percentages are not significantly different in terms of the Nordic average, it is worth noting that $18 \%$ of Icelanders gave "friends or relatives had recommended the doctor" as a reason for not gathering information while $14 \%$ said they had no choice in which doctor they chose.

\subsection{User satisfaction}

\subsubsection{A summary of survey findings}

With mean Nordic scores of well over 5 for the following 2 questions the overall impression here is that people in the Nordic region are well satisfied with both the possibilities for acquiring general information and with the total service they received on their last medical visit. Finns and Danes are the most satisfied.

If we compare satisfaction with the accessibility of information across the three markets in the Nordic region we see that satisfaction is greatest with day care facilities with mean scores of over 7 in all countries except Sweden. Doctors scored over average while satisfaction with dentists was just a little better than average.

Satisfaction with total service scored high in all three markets. 


\subsubsection{Survey findings}

Figure 4: Satisfaction with possibilities for acquiring information about medical services ( 0 is 'not at all satisfied' and 10 is' very satisfied')

Q8: Based on your experience, how satisfied are you with the possibilities for acquiring general information about medical services? (on a scale from 0-10; 0 is "not at all satisfied" and 10 is "very satisfied")

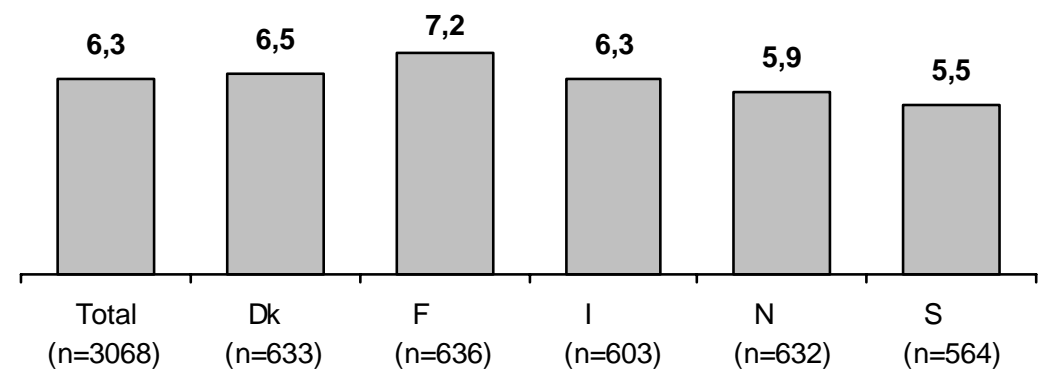

$\square$ M ean value

Table 6: \% unable to assess their satisfaction with the possibilities for acquiring information about medical services

\begin{tabular}{lrrrrrr}
\hline & $\begin{array}{r}\text { Total } \\
\mathrm{N}=\mathbf{3 0 6 8}\end{array}$ & $\begin{array}{r}\text { Denmark } \\
\mathrm{N}=\mathbf{6 3 3}\end{array}$ & $\begin{array}{r}\text { Finland } \\
\mathrm{N}=\mathbf{6 3 6}\end{array}$ & $\begin{array}{r}\text { Iceland } \\
\mathrm{N}=\mathbf{6 0 3}\end{array}$ & $\begin{array}{r}\text { Norway } \\
\mathrm{N}=\mathbf{6 3 2}\end{array}$ & $\begin{array}{r}\text { Sweden } \\
\mathrm{N}=\mathbf{5 6 4}\end{array}$ \\
\hline Do not know/cannot asses & 16 & 20 & 4 & 14 & 21 & 20 \\
\hline
\end{tabular}

- Overall it seems that people in the Nordic Countries are a little over averagely satisfied with the possibilities for acquiring general information about medical services. The mean score for all countries was 6.3. However it should be noted that on average of $16 \%$ were unable to assess their satisfaction with acquiring general information though this was only true for $4 \%$ of Finns.

- The Finns were most satisfied with a mean score of 7.2 but the Danes were also significantly more satisfied than the Nordic average with a mean score of 6.5

- The Swedes and Norwegians were significantly less satisfied with a mean score of 5.5 and 5.9 respectively, while Icelanders satisfaction rating was average for the Nordic countries as a whole (6.3).

- Looking at the individual countries we see that in Norway, Sweden and Denmark widowers are significantly more satisfied with the possibilities for acquiring general information about medical services.

- In Finland and Denmark 18-29 year olds and people living with their partners are significantly less satisfied. In Denmark we also see that people with a household income of under $€ 30.000$ are significantly more satisfied.

- In Sweden and Norway 30-39 year olds are less satisfied and in Sweden we also see that people with a household income of over 
$€ 65.000$ and those living in villages are significantly more satisfied with the possibilities for acquiring general information on medical services.

Figure 5: Satisfaction with the total service ( 0 is 'not at all satisfied' and 10 is 'very satisfied')

Q9: On a scale from 0-10, where 0 is "not at all satisfied" and 10 is "very satisfied", how satisfied were you with the total service after your last medical visit to the doctor?

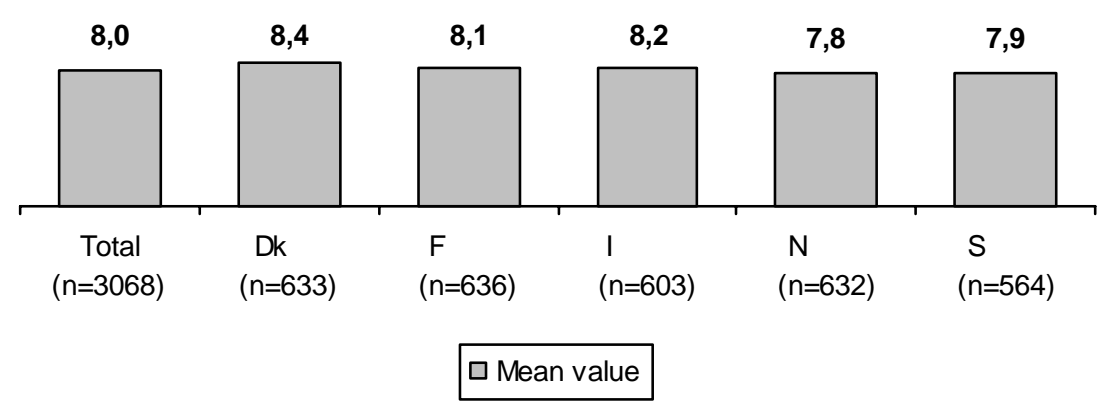

Table 7: \% unable to assess their satisfaction with total service

\begin{tabular}{lrrrrrr}
\hline & $\begin{array}{r}\text { Total } \\
\mathrm{N}=\mathbf{3 0 6 8}\end{array}$ & $\begin{array}{r}\text { Denmark } \\
\mathrm{N}=\mathbf{6 3 3}\end{array}$ & $\begin{array}{r}\text { Finland } \\
\mathrm{N}=636\end{array}$ & $\begin{array}{r}\text { Iceland } \\
\mathbf{N}=603\end{array}$ & $\begin{array}{r}\text { Norway } \\
\mathrm{N}=632\end{array}$ & $\begin{array}{r}\text { Sweden } \\
\mathrm{N}=564\end{array}$ \\
\hline Do not know/cannot asses & 1 & 1 & 1 & 1 & 1 & 2 \\
\hline
\end{tabular}

- Over all it seems that people in the Nordic Countries are satisfied with the total service after their last medical visit. The mean score for all countries was 8.

- The Danes were significantly more satisfied with a mean score of 8.4 while the Swedes and Norwegians were significantly less satisfied registering a mean score of 7.9 and 7.8 respectively.

- Iceland's mean score of 8.2 is not significantly different in terms of the Nordic average.

- The Finns were significantly more likely to choose either alternative 8 or 9 (39\% and 31\% versus a Nordic average of $23 \%$ and $17 \%$ respectively ) while the Swedes and the Danes were significantly more likely to chose alternative 10 "very satisfied" (40\% and 37\% versus a Nordic average of 32\%) respectively.

- Swedes were also significantly more likely to choose the middle ratings of 4-6.

- Looking at the individual countries we see that in Sweden, Norway, Finland and Denmark 18-29 year olds are significantly less satisfied with the total service after their last medical visit.

- In Sweden and Norway widowers are significantly more likely to be satisfied while people living in metropolitan areas in Sweden are significantly less likely to be satisfied. 
- In Denmark people living in households of 3 adults are significantly less likely to be satisfied while the Swedes living in households of 3 adults are significantly more likely to be satisfied.

- It is worth noting that those living in larger provincial towns in Iceland were less satisfied with the total service after their last visit to the doctor.

\subsection{Change of doctor}

\subsubsection{A summary of survey findings}

Over three quarters of people in the Nordic countries have not changed, or considered changing, their doctor within the past three years. This is despite nearly 7 out of 10 being aware of legislation that says they have the right to choose a doctor.

Icelanders were the least aware of the above mentioned legislation with fewer than 2 out of 10 saying they were familiar with the legislation. However as we saw in the desk research Icelandic legislation only gives the right to health care and not necessarily to a preferred doctor.

Of those who say they have changed or have considered changing their doctor relocation was the most mentioned reason and was most likely to be mentioned by Danes (36\%). Next most mentioned was dissatisfaction with their previous doctor which was most likely to be mentioned by Swedes. A lack of trust in their former doctor is again an important reason for change amongst Danes.

If we look at the reasons people in the Nordic region give for staying with their doctor satisfaction with their current doctor is a clear winner with $64 \%$ of people citing this. Danes and Norwegians are particularly likely to cite satisfaction as a reason.

18-29 year olds in Sweden and Denmark are less likely to give satisfaction with their current doctor as a reason for staying with that doctor.

If we compare how often people change their provider across the three markets in the Nordic region we see that over $70 \%$ of people have neither considered changing or have changed provider in all three markets. More people have considered changing their child's day care facility than have considered changing either their doctor or dentist.

For those who have either changed or considered changing provider relocation was an important reason in all three markets, together with concerns about quality of (and dissatisfaction with) the service; satisfaction was the main reason for staying with their current provider in all three markets. 


\subsubsection{Survey findings}

\section{Figure 6: \% familiar with the legislation}

Q10: Today in your country, legislation ensures that you as a citizen have the right to choose which doctor you wish to consult. Are you familiar with this legislation?

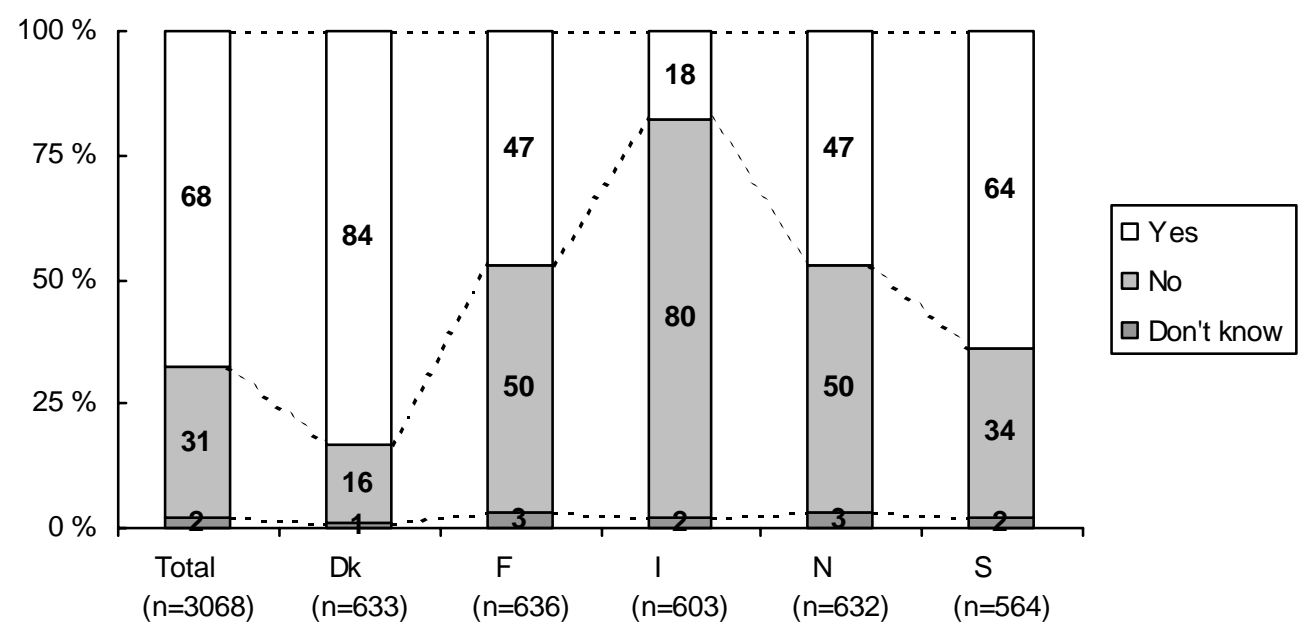

- Looking at the Nordic countries as a whole, $68 \%$ are familiar with the legislation concerning selecting a doctor.

- Significantly more Danes and Norwegians are aware of this legislation (84\% and 82\% respectively) while significantly fewer Swedes (64\%), Finns (47\%) and Icelanders (18\%) are aware of this legislation.

However as we saw in the desk research Icelandic legislation only gives the right to health care and not necessarily to a preferred doctor.

- Looking at the individual countries we see that significantly fewer 1829 year olds in Sweden, Finland and Denmark are aware of the legislation.

- In Norway, Sweden and Denmark significantly fewer single people are aware of the legislation.

- In Sweden and Denmark significantly more married people are aware of the legislation

- In Norway significantly more widowers and those between 60-69 are aware of the legislation. 
Figure 7: \% changing/considering changing doctor

Q11: Have you changed or considered changing your doctor/regular doctor within the past three years?

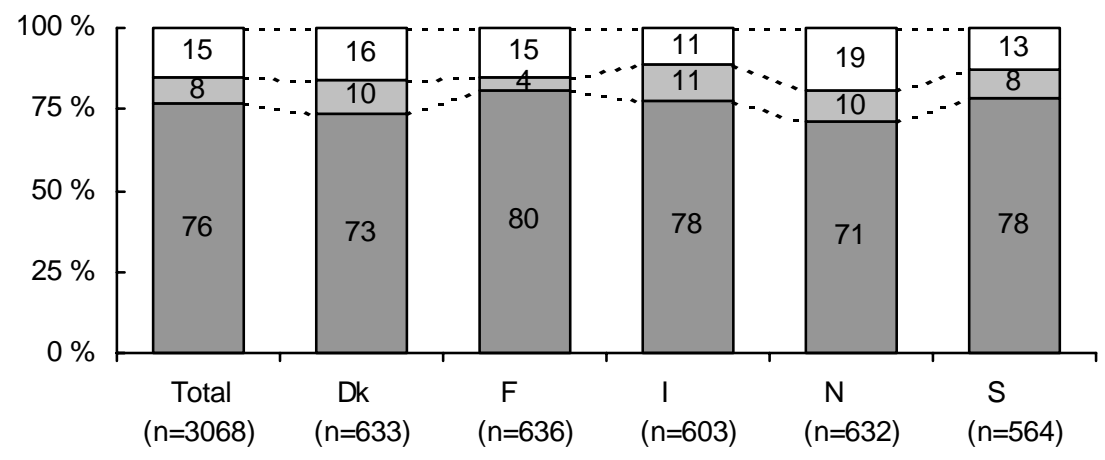

$\square$ No, have not changed $\square$ Yes, have considered changing $\square$ Yes, have changed

- Looking at the Nordic countries as a whole, $76 \%$ have not changed or considered changing their doctor within the past three years.

- Significantly more Finns have not changed or considered changing their doctor (80\%) while this is true for significantly fewer Norwegians (71\%). There are no indications from the desk research that barriers to change of doctor are stronger in Finland.

- From the last two questions we see that significantly more Danes (84\%) and Norwegians (82\%) are familiar with the legislation concerning selecting a doctor and these are the two countries with the highest share of people who have changed or considered changing their doctor (16\% in Denmark and 19\% in Norway).

- Regulations in Norway and Denmark that stipulate that a formal application has to be made (and in Denmark a fee paid) in order to change doctor, do not seem to be a barrier for change of doctor.

- Looking at the individual countries we see that in Sweden significantly more women have changed doctor. Significantly more widowers have changed doctor whilst significantly less married people have done the same. Significantly more people in 1 person households have changed their doctor.

- In Norway significantly fewer people living in a household of 3 adults have changed their doctor.

- In Denmark significantly more 18-29 year olds have changed their doctor.

- For Iceland it is worth noting that those living in middle sized provincial towns are less likely to have changed doctor but more likely to have considered changing doctor. 
Table 8: Three most important reasons for changing or considering changing doctor, \% answering - more than one answer allowed

Q12: (This question is asked if the respondent answers (1) or (2) to q. 11:) What are the three most important reasons for your change of, or for your having considered changing, doctor?

\begin{tabular}{|c|c|c|c|c|c|c|}
\hline & $\begin{array}{r}\text { Total } \\
\mathrm{N}=720\end{array}$ & $\begin{array}{r}\text { Demark } \\
\mathrm{N}=155\end{array}$ & $\begin{array}{r}\text { Finland } \\
\mathrm{N}=122\end{array}$ & $\begin{array}{l}\begin{array}{l}\text { Iceland } \\
\mathrm{N}=135\end{array}\end{array}$ & $\begin{array}{r}\text { Norway } \\
\mathrm{N}=184\end{array}$ & $\begin{array}{r}\text { Sweden } \\
\mathrm{N}=124\end{array}$ \\
\hline $\begin{array}{l}\text { Want doctor with different loca- } \\
\text { tion (e.g. due to own removal) }\end{array}$ & 26 & 36 & 14 & 27 & 31 & 20 \\
\hline $\begin{array}{l}\text { Dissatisfied with former doctor's } \\
\text { information/service }\end{array}$ & 23 & 25 & 10 & 27 & 22 & 32 \\
\hline Lack of trust in former doctors & 21 & 27 & 7 & 11 & 24 & 21 \\
\hline Concern regarding quality & 19 & 19 & 18 & 17 & 17 & 19 \\
\hline My former doctor moved/closed & 17 & 10 & 23 & 18 & 22 & 16 \\
\hline $\begin{array}{l}\text { A wish to avoid waiting hours at } \\
\text { former doctor }\end{array}$ & 7 & 7 & 5 & 3 & 6 & 9 \\
\hline A wish for a specialist & 5 & 2 & 7 & 1 & 3 & 8 \\
\hline The doctor'spersonal data & 5 & 5 & 9 & 7 & 5 & 3 \\
\hline Recommendation from others & 4 & 3 & 2 & 1 & 0 & 9 \\
\hline Price & 1 & 0 & 5 & 0 & 0 & 1 \\
\hline $\begin{array}{l}\text { A wish for different opening } \\
\text { hours }\end{array}$ & 1 & 0 & 2 & 2 & 1 & 2 \\
\hline I turned 18 & 1 & 0 & 1 & 0 & 0 & 2 \\
\hline Other & 11 & 6 & 36 & 17 & 3 & 7 \\
\hline Don't know/don't remember & 1 & 0 & 0 & 0 & 3 & 0 \\
\hline
\end{tabular}

- Across the five countries the most mentioned reasons for changing or considering changing doctor are: relocation (26\%), dissatisfaction with former doctor's information/ service (23\%), lack of trust in former doctor (21\%) and concerns regarding quality (19\%).

- Significantly more Danes (36\%) gave relocation as a reason for changing doctor whilst the same was true for significantly fewer Finns (14\%) and Swedes (20\%). We saw earlier (q4) that Danes are also significantly more likely to chose their doctor on the basis of location while Swedes and Finns are significantly less likely to do the same.

- Significantly more Swedes (32\%) gave dissatisfaction with their former doctor's information/ service whilst significantly fewer Finns (10\%) did the same.

- Danes were significantly more likely to give lack of trust in their former doctor as a reason for a change of doctor (27\%) and again it was Finns who were significantly less likely to give this reason (7\%). Although not significantly different in terms of the Nordic average, only $11 \%$ of Icelanders gave this reason as a reason for a change or for considering a change of doctor.

- Other findings worth noting are that $36 \%$ of Finns gave "other" reasons, together with $17 \%$ of Icelanders (not significantly different), as against a Nordic average of $11 \%$.

- Looking at the individual countries we see that in Sweden significantly more men changed doctor because of recommendations from friends. Significantly more 18-29 year olds were dissatisfied with their former doctor while significantly more 30 -39 year olds changed doctor because of a lack of trust in their former doctor. 
Widowers were significantly more likely to cite the need for a specialist.

- In Norway and Denmark significantly more 18-29 year olds cited relocation as a reason for changing their doctor while people in households of 3 adults were significantly more likely to cite a lack of trust in their former doctor.

- Widowers in Norway and Sweden were significantly more likely to cite the fact that their doctor relocated as a reason for change.

- In Finland people living in a household with one child were significantly more likely to cite dissatisfaction with their former doctor as a reason for change.

Table 9: Three most important reasons for staying with current doctor, $\%$ answering - more than one answer allowed

Q13: What are the three most important reasons for you staying with your current doctor?

\begin{tabular}{|c|c|c|c|c|c|c|}
\hline & $\begin{array}{r}\text { Total } \\
\mathrm{N}=2622\end{array}$ & $\begin{array}{r}\text { Denmark } \\
N=540\end{array}$ & $\begin{array}{l}\text { Finland } \\
\qquad \mathrm{N}=542\end{array}$ & $\begin{array}{l}\begin{array}{l}\text { Iceland } \\
\mathrm{N}=537\end{array}\end{array}$ & $\begin{array}{r}\text { Norway } \\
\mathrm{N}=518\end{array}$ & $\begin{array}{r}\text { Sweden } \\
\mathrm{N}=485\end{array}$ \\
\hline Satisfied with my current doctor & 64 & 83 & 59 & 63 & 75 & 50 \\
\hline $\begin{array}{l}\text { Have to built up personal relation- } \\
\text { ship between doctor and patient } \\
\text { again if change }\end{array}$ & 20 & 23 & 12 & 20 & 28 & 19 \\
\hline $\begin{array}{l}\text { Superfluous trouble to change } \\
\text { because I seldom go the doctor }\end{array}$ & 11 & 9 & 13 & 8 & 9 & 12 \\
\hline $\begin{array}{l}\text { The clinic has the most convenient } \\
\text { location (of many clinics in the area) }\end{array}$ & 10 & 13 & 6 & 4 & 10 & 10 \\
\hline Have not had the time & 4 & 3 & 4 & 2 & 3 & 5 \\
\hline The clinic is the only one nearby & 4 & 3 & 6 & 7 & 4 & 3 \\
\hline Difficult/bureaucratic to change & 3 & 2 & 5 & 3 & 3 & 4 \\
\hline $\begin{array}{l}\text { Difficult to find information on other } \\
\text { doctors }\end{array}$ & 3 & 1 & 4 & 2 & 1 & 5 \\
\hline The waiting time at the doctor I want & 2 & 2 & 1 & 3 & 1 & 2 \\
\hline $\begin{array}{l}\text { Under treatment (want treatment } \\
\text { prior to change) }\end{array}$ & 2 & 1 & 2 & 1 & 2 & 3 \\
\hline Money - can't afford to change & 2 & 0 & 4 & 0 & 1 & 2 \\
\hline The doctor'spersonal data (age, sex) & 2 & 4 & 3 & 1 & 1 & 0 \\
\hline Waiting time is good & 2 & 2 & 1 & 0 & 3 & 3 \\
\hline $\begin{array}{l}\text { Am afraid to lose my journal if I } \\
\text { change }\end{array}$ & 1 & 0 & 0 & 0 & 1 & 2 \\
\hline Other & 14 & 4 & 28 & 22 & 2 & 16 \\
\hline Don't remember/don't know & 1 & 0 & 0 & 0 & 5 & 0 \\
\hline
\end{tabular}

- The reason most people in the Nordic region give for remaining with their current doctor is satisfaction with the service they get (64\%).

- Danes and Norwegians were significantly more likely to cite satisfaction as a reason to stay with their current doctor (83\% and $75 \%$ respectively) while Swedes and Finns were significantly less likely to do the same (50\% and 59\% respectively).

- The next most mentioned reason across the Nordic region was that changing doctor would mean they would "Have to built up personal relationship with the doctor” (20\%). Significantly more Norwegians gave this reason and significantly fewer Finns (12\%) did the same.

- Other findings worth noting are that again significantly more Finns (28\%) gave "other" reasons, together with $22 \%$ of Icelanders (not 
significantly different), for staying with their doctor than was average for the Nordic countries (14\%)

- Looking at the individual countries we see that in Sweden 18-29 year olds are significantly more likely to cite a lack of time and significantly less likely to cite satisfaction with their current doctor as a reason for remaining with that doctor. 40-49 year olds, those over 60 and those living in larger provincial towns are significantly more likely to cite satisfaction with their current doctor. Those living with their partner and those living in households with one child are significantly more likely to say there is no point them changing doctor because they rarely to go to the doctor.

- In Norway those living in metropolitan areas and those living in households with 2 children are significantly more likely to cite the location of the clinic as a reason for remaining with their doctor while widowers are significantly more likely to cite satisfaction with their current doctor.

- In Finland both widowers and people living alone are significantly more likely to say there is no point them changing doctor because they rarely go to the doctor.

- In Denmark significantly more 30-39 year olds cite satisfaction with their current doctor while significantly fewer 18-29 year olds cite the same reason for staying with their current doctor. Significantly more 18-29 year olds are likely to say they think it is difficult to find information about other doctors. People living in larger provincial towns are significantly more likely to cite satisfaction with their current doctor while those living in metropolitan areas in Denmark are less likely to give this as a reason for staying with their current doctor.

- For Iceland it is worth noting that widowers are more likely to say that they are satisfied with their current doctor while those living in smaller towns are less likely to cite the same reason for remaining with their current doctor and more likely to cite the fact that their doctor has the most convenient location.

\subsection{Possibilities of comparison and information}

\subsubsection{A summary of survey findings}

With mean Nordic scores below 5 for each of the following 4 questions the overall impression here is that people in the Nordic region are rather dissatisfied with the possibilities for comparison of the doctors' service (rated on price, quality, waiting time \& age of dentist/doctor). We see that the Finns are most likely to rate the possibilities for comparison highest of the Nordic people with all mean scores registering just over the middle score of 5 while the Swedes and the Danes were most likely to 
give the possibilities a lower rating. We also see that there is a sizeable minority in the Nordic region who simply do not feel able to answer questions concerning the possibilities of comparison.

Widowers in Norway, Sweden and Denmark rate the possibilities for price comparison higher while those living with 2 children in the household rated them lower.

In Norway, Sweden and Denmark those between 30-49 years rate possibilities for comparison of the quality of treatment lower while in Norway and Denmark widowers rate the possibilities higher.

If we compare the three markets with regard to the ratings given to the possibilities for comparison of the service provided across the Nordic countries we see that there is a basic level of dissatisfaction when it comes to doctors and dentists but that people are more satisfied with the possibilities of comparison of day care facilities' service (opening hours, number of children, number of employees). Finns are most satisfied as far as doctors and dentists are concerned and Danes are most satisfied as far as their child's day care facilities are concerned.

Furthermore we see that across all markets there is a sizeable minority that feel incapable of answering questions about the possibilities for comparison of these aspects of service. This is particularly true for Swedes.

\subsubsection{Survey findings}

Figure 8: Satisfaction with possibilities for comparing price levels ( 0 is 'very poor' and 10 is 'very good')

Q14: If you usually pay for your medical service, how would you assess the possibilities for comparing the price level of different doctors e.g. via the internet, pamphlets, newspapers or magazines? (Scale of 0-10, where 0 is "Very poor" and 10 is "Very good").

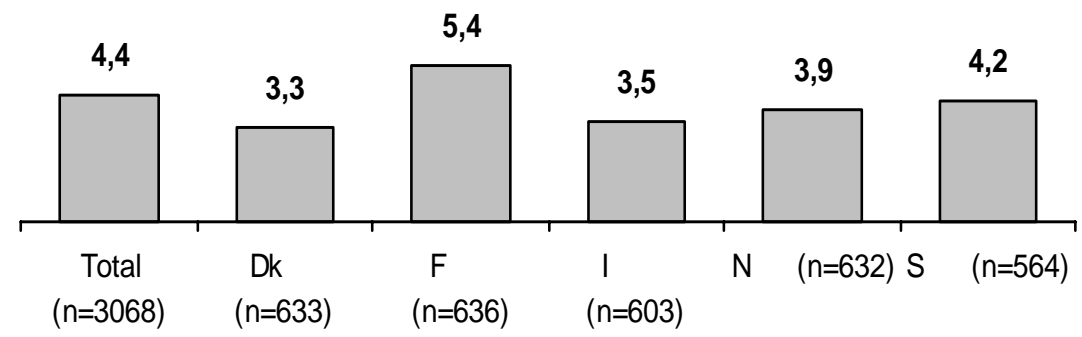

$\square$ Mean value 
Table 10: \% unable to assess the possibilities for comparing price levels

\begin{tabular}{ccccccc}
\hline & $\begin{array}{c}\text { Total } \\
\mathrm{N}=\mathbf{3 0 6 8}\end{array}$ & $\begin{array}{c}\text { Denmark } \\
\mathrm{N}=\mathbf{6 3 3}\end{array}$ & $\begin{array}{c}\text { Finland } \\
\mathrm{N}=\mathbf{6 3 6}\end{array}$ & $\begin{array}{c}\text { Iceland } \\
\mathrm{N}=\mathbf{6 0 3}\end{array}$ & $\begin{array}{c}\text { Norway } \\
\mathbf{N}=\mathbf{6 3 2}\end{array}$ & $\begin{array}{c}\text { Sweden } \\
\mathrm{N}=\mathbf{5 6 4}\end{array}$ \\
\hline Don't know & 44 & 64 & 22 & 43 & 45 & 44 \\
\hline
\end{tabular}

- The mean Nordic score for this question was 4.4. Finns rated the opportunities for comparing price levels significantly highest with a mean score of 5.4; while Swedes, Danes and Norwegians rated them significantly lower with mean scores of 4.2, 3.3 and 3.9 respectively.

- A total of $44 \%$ in the Nordic countries felt they couldn't answer this question. Significantly more Danes (64\%) were unable to answer than their Nordic counterparts while the same was true for significantly fewer Finns (22\%). The high share of “don't know” in Denmark indicates a low interest in price, an understandable attitude given that the service is free.

- Iceland also scored low here with a mean score of 3.5, though this score is not significantly different in terms of the Nordic average.

- Looking at the individual countries we see that in Sweden widowers, people in households with 3 adults and those with 1 or 5 children rated the possibilities for comparing the price levels significantly higher. However single people, those between 30 -39 years, those living in smaller towns and those with between 2 and 4 children living in the household rated them significantly lower.

- In Norway widowers, those between the ages of 50-59 years and those living in mid sized towns rated the possibilities significantly higher while those living in households with 2 children rated them significantly lower.

- In Finland 18-29 year olds and those living with their partners rated the possibilities for comparing the price levels significantly lower.

- In Denmark 60-69 year olds and widowers rated the possibilities for comparison of the price levels significantly higher while those living in metropolitan areas and those with 2 children in their household rated them significantly lower.

- For Iceland it is worth noting that those between 40-49 years rated the possibilities for comparing the price levels low (mean score of 2.6) and those living in a household with an income of less the $€ 30.000$ rated them higher (4.5). 
Figure 9: Satisfaction with possibilities of comparing the quality of the treatment of doctors ( 0 is 'not at all satisfied' and 10 is 'very satisfied')

Q15: How would you assess the possibilities for comparing the quality of the medical treatment of different doctors? Scale from 0-10, where 0 is "Very poor" and 10 is "Very good"

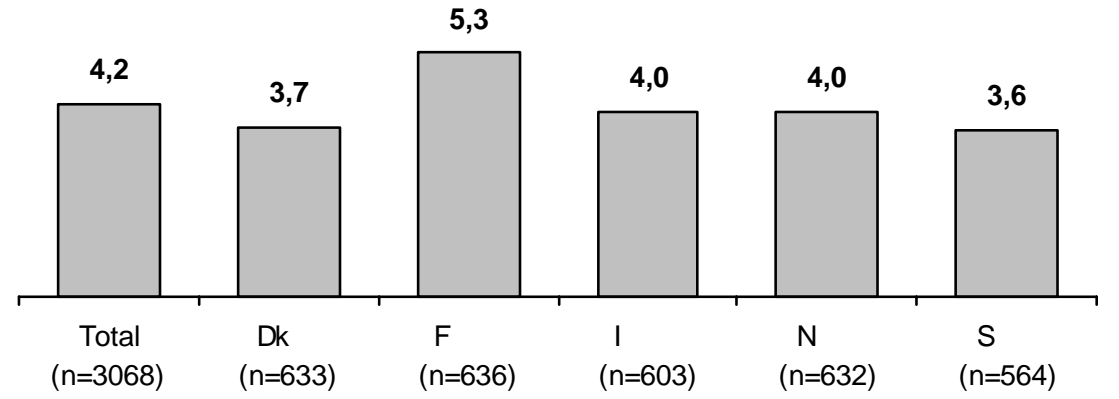

$\square$ Mean value

Table 11: \% unable to assess the possibilities for comparing quality of treatment

\begin{tabular}{ccccccc}
\hline & $\begin{array}{c}\text { Total } \\
\mathrm{N}=\mathbf{3 0 6 8}\end{array}$ & $\begin{array}{c}\text { Denmark } \\
\mathrm{N}=6 \mathbf{6 3 3}\end{array}$ & $\begin{array}{c}\text { Finland } \\
\mathrm{N}=636\end{array}$ & $\begin{array}{c}\text { Iceland } \\
\mathrm{N}=603\end{array}$ & $\begin{array}{c}\text { Norway } \\
\mathrm{N}=632\end{array}$ & $\begin{array}{c}\text { Sweden } \\
\mathrm{N}=564\end{array}$ \\
\hline Don't know & 34 & 39 & 18 & 28 & 33 & 41 \\
\hline
\end{tabular}

- The mean Nordic score for this question was 4.2. The Finns rated the possibilities for comparison of the quality of medical treatment significantly higher with a mean score of 5.3. Both the Danes (3.7) and the Swedes (3.6) rated them significantly lower.

- Significantly more Danes rated the possibilities for comparing the quality of the medical treatment of different doctors as "very poor" (13\% versus a Nordic average of $10 \%)$

- Iceland lies just below the Nordic average with a mean score of 4.0 on this question.

- A total of 34\% in the Nordic countries felt they couldn't answer this question. Significantly more Danes (39\%) and Swedes (41\%) were unable to answer than their Nordic counterparts while the same was true for significantly fewer Finns (18\%).

- Looking at the individual countries we see that in Sweden, Norway and Denmark 30-49 year olds rated the possibilities for comparing the quality of the medical treatment significantly lower.

- In Finland and Denmark those living in metropolitan areas rate the possibilities for comparing the quality of the medical treatment significantly lower.

- In Norway and Denmark widowers rate the possibilities for comparing the quality of the medical treatment significantly higher. 
- In Sweden and Denmark people with 2 children in the household rate the possibilities for comparing the quality of the medical treatment significantly lower.

- In Norway and Sweden people living with their partner rate the possibilities for comparing the quality of the medical treatment significantly lower.

- It is worth noting that in Iceland widowers rate the possibilities for comparing the quality of the medical treatment higher while those with four children in the household rate them lower.

Figure 10: Satisfaction with possibilities for comparing waiting time at doctors ( 0 is 'very poor' and 10 is 'very good')

Q16: How would you assess the possibilities for comparing different doctors with respect to waiting time? Please answer on the basis of a scale from 0-10, where 0 is "Very poor" and 10 is "Very good"

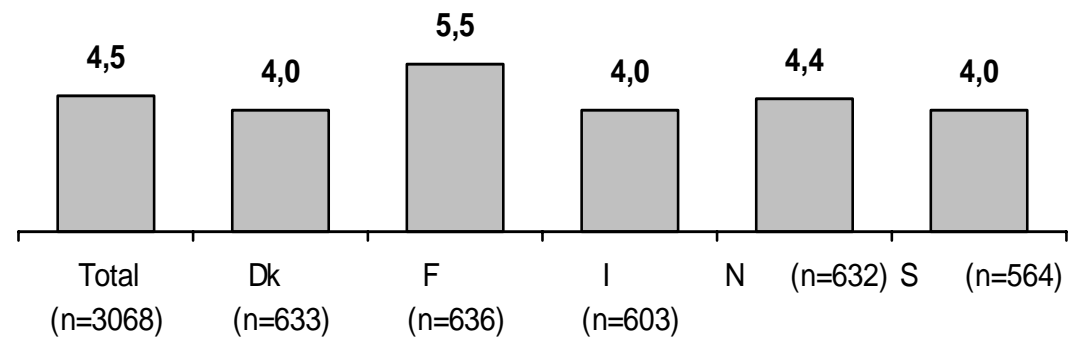

$\square$ Mean value

Table 11: \% unable to assess the possibilities for comparing waiting times at doctors

\begin{tabular}{ccccccc}
\hline & $\begin{array}{c}\text { Total } \\
\mathrm{N}=\mathbf{3 0 6 8}\end{array}$ & $\begin{array}{c}\text { Denmark } \\
\mathrm{N}=\mathbf{6 3 3}\end{array}$ & $\begin{array}{c}\text { Finland } \\
\mathrm{N}=\mathbf{6 3 6}\end{array}$ & $\begin{array}{c}\text { Iceland } \\
\mathbf{N}=\mathbf{6 0 3}\end{array}$ & $\begin{array}{c}\text { Norway } \\
\mathrm{N}=\mathbf{6 3 2}\end{array}$ & $\begin{array}{c}\text { Sweden } \\
\mathrm{N}=\mathbf{5 6 4}\end{array}$ \\
\hline Don't know & 35 & 43 & 20 & 27 & 33 & 41 \\
\hline
\end{tabular}

- The mean Nordic score for this question was again under the middle score at 4.5. Again the Finns rated the possibilities for comparing different doctors with respect to waiting time significantly higher with a mean score of 5.5. Both the Swedes (4) and the Danes (4) rated the possibilities significantly lower. Icelanders also scored 4, though this is not significantly different in terms of the Nordic average.

- A total of 35\% in the Nordic countries felt they couldn't answer this question. Significantly more Danes (43\%) and Swedes (41\%) were unable to answer than their Nordic counterparts while the same was true for significantly fewer Finns (20\%). 
Figure 11: Satisfaction with the information available concerning doctors' age ( 0 is 'very poor' and 10 is 'very good')

Q17: How would you assess the availability of information about a certain doctor's age? Please answer on the basis of a scale from 0-10, where 0 is "Very poor" and 10 is "Very good"

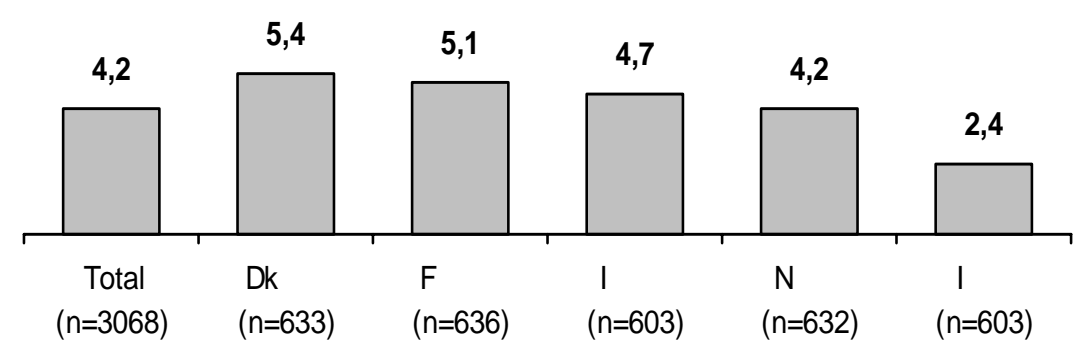

$\square$ Mean value

Table 13: \% unable to assess the possibilities for comparing doctors' age

\begin{tabular}{ccccccc}
\hline & $\begin{array}{c}\text { Total } \\
\mathrm{N}=\mathbf{3 0 6 8}\end{array}$ & $\begin{array}{c}\text { Denmark } \\
\mathbf{N}=\mathbf{6 3 3}\end{array}$ & $\begin{array}{c}\text { Finland } \\
\mathrm{N}=\mathbf{6 3 6}\end{array}$ & $\begin{array}{c}\text { Iceland } \\
\mathbf{N}=\mathbf{6 0 3}\end{array}$ & $\begin{array}{c}\text { Norway } \\
\mathbf{N}=\mathbf{6 3 2}\end{array}$ & $\begin{array}{c}\text { Sweden } \\
\mathrm{N}=\mathbf{5 6 4}\end{array}$ \\
\hline \multirow{2}{*}{ Don't know } & 43 & 44 & 25 & 36 & 45 & 53 \\
\hline
\end{tabular}

- The mean Nordic score for this question was a 4.2. However both Finns and Danes rated the availability of information about a certain doctor's age significantly higher with respective mean scores of 5.4 and 5.1. The higher Danish score could be due to the fact that when Danes move to a new address the local authority automatically sends them information about doctors working within that local authority. This information includes the doctors' age.

- Swedes however rated the availability of information on a certain doctor's age significantly lower registering a mean score of just 2.4.

- Significantly fewer Finns gave a rating of "very good" (3\%) than was average for the Nordic countries (5\%).

- Again a high percentage of people in the Nordic countries felt unable to answer this question (43\%). Significantly more Swedes (53\%) and significantly fewer Finns (25\%) felt this way.

\subsection{User rights and complaints}

\subsubsection{A summary of survey findings}

People in the Nordic region are averagely satisfied with their rights as far as a doctor's service is concerned with mean scores of over 5 but under 6 on all questions. Yet again Finns are the most satisfied and the Swedes 
the least satisfied. Again a sizeable minority in the Nordic region simply do not feel able to answer questions concerning the possibilities of comparison.

$85 \%$ of people in the Nordic region say that they have not had cause to complain though the Swedes are the most likely to have complained (7\%). In Sweden and Finland more 18-29 year olds have felt the need to complain although they haven't actually done it.

As far as feeling that they have sufficient protection from defective treatment in Norway, Sweden and Denmark it is yet again the widowers who are more satisfied while younger people tend to be less satisfied. In Finland, Norway and Sweden those living with 2 children in the household are less satisfied.

Looking at the possibility for complaint about their doctor or treatment in Finland, Sweden, Norway and Denmark it is the younger and single people who rate the possibilities lower while in Sweden and Denmark people over 60 rate them higher.

Looking at the possibilities for acquiring information about the complaints process we see again that in Finland, Sweden, Norway and Denmark it is the younger people who are less positive here.

If we compare perceptions about the possibilities for complaint across the three markets in the Nordic countries we see that satisfaction is average when it comes to doctors and dentists and a little better than average for day care facilities. Finns are the most satisfied with their possibilities for complaint in all three markets while Swedes are least satisfied as far as doctors are concerned and Icelanders (not significant) as far as dentists concerned. As far as day care facilities are concerned it is again the Swedes and Icelanders who are least satisfied with their opportunities for complaint.

Again we see sizeable minorities who feel incapable of answering questions about the possibilities they have for complaint across all three markets, though this is less the case for day care facilities than for the other two markets. It is the Swedes who are most likely to be unable to answer these questions when it comes to doctors and dentists.

A large majority in all three markets have not made a complaint about their doctor, dentist or child's day care facility. 


\subsubsection{Survey findings}

Figure 12: Satisfaction with protection against defective advice/treatments ( 0 is 'to a very poor extent' and 10 is 'to a great extent')

Q18: To what extent do you feel that sufficient protection from wrong or defective advice or treatment in relation to a medical visit exists? Please answer on the basis of a scale from 0-10, where 0 is "To a very poor extent" and 10 is "To a great extent"

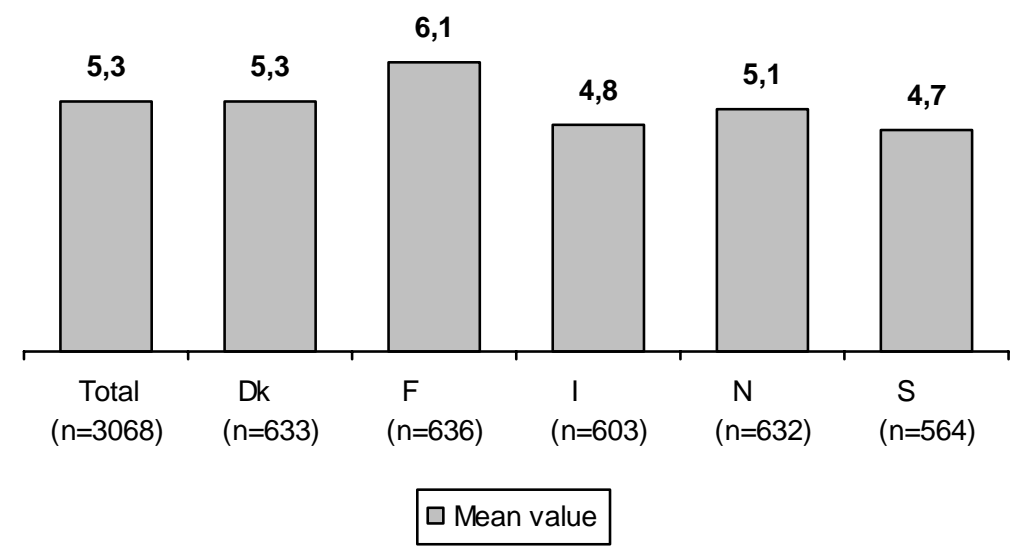

Table 12: \% unable to assess the possibilities for protection from wrong or defective advice/treatment

\begin{tabular}{ccccccc}
\hline & $\begin{array}{c}\text { Total } \\
\mathbf{N}=\mathbf{3 0 6 8}\end{array}$ & $\begin{array}{c}\text { Denmark } \\
\mathbf{N}=\mathbf{6 3 3}\end{array}$ & $\begin{array}{c}\text { Finland } \\
\mathbf{N}=\mathbf{6 3 6}\end{array}$ & $\begin{array}{c}\text { Iceland } \\
\mathbf{N}=\mathbf{6 0 3}\end{array}$ & $\begin{array}{c}\text { Norway } \\
\mathbf{N}=632\end{array}$ & $\begin{array}{c}\text { Sweden } \\
\mathbf{N}=564\end{array}$ \\
\hline Don't know & 21 & 21 & 14 & 27 & 21 & 26 \\
\hline
\end{tabular}

- The mean Nordic score for this question was 5.3. Finns felt significantly more that they had sufficient protection from defective treatment with a mean score of 6.1. However the Swedes were significantly less sure about this with a mean score of 4.7. Icelanders were also less satisfied registering a mean score of 4.8 , though this score is not significantly different in terms of the Nordic average.

- Over one fifth across the five countries felt that they could not answer this question (21\%). Significantly more Swedes (26\%) and significantly fewer Finns (14\%) felt this way. Although not significantly different in terms of the Nordic average, it should also be noted that $27 \%$ of Icelanders also said they were unable to assess whether they had sufficient protection against defective treatment.

- Looking at the individual countries we see that in Sweden 50-59 year olds and widowers are significantly more satisfied while 18-49 year olds, those living with their partner, those living in a metropolitan area and those with 2 and 3 children in the household are significantly less satisfied with their protection from defective treatment. 
- In Norway 30-39 year olds and those living with 2 children in the households are significantly less satisfied while widowers are significantly more satisfied.

- In Finland those living with their partner and those living with 2 children in the households are significantly less satisfied with their protection from defective treatment.

- In Denmark widowers are significantly more satisfied whilst those between 18-39 years are significantly less satisfied.

Figure 12: Satisfaction with the possibilities for complaint ( 0 is 'very poor' and 10 is 'very good')

Q19: How would you assess the possibility for complaining to a complaints board about your doctor or medical treatment? Please answer on the basis of a scale from $0-10$, where 0 is "Very poor" and 10 is "Very good"

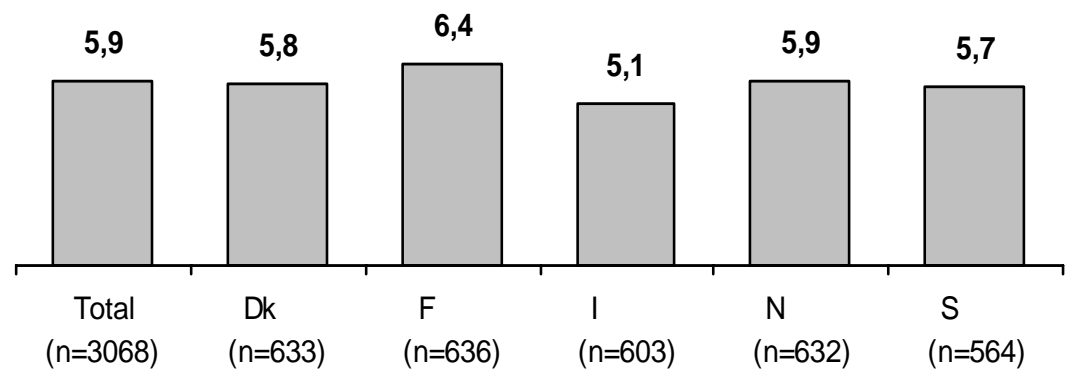

$\square$ Mean value

Table 13: \% unable to assess the possibilities for complaint

\begin{tabular}{ccccccc}
\hline & $\begin{array}{c}\text { Total } \\
\mathrm{N}=\mathbf{3 0 6 8}\end{array}$ & $\begin{array}{c}\text { Denmark } \\
\mathrm{N}=\mathbf{6 3 3}\end{array}$ & $\begin{array}{c}\text { Finland } \\
\mathrm{N}=\mathbf{6 3 6}\end{array}$ & $\begin{array}{c}\text { Iceland } \\
\mathrm{N}=\mathbf{6 0 3}\end{array}$ & $\begin{array}{c}\text { Norway } \\
\mathrm{N}=\mathbf{6 3 2}\end{array}$ & $\begin{array}{c}\text { Sweden } \\
\mathrm{N}=\mathbf{5 6 4}\end{array}$ \\
\hline Don't know & 22 & 23 & 11 & 42 & 25 & 26 \\
\hline
\end{tabular}

- The mean Nordic score for this question was 5.9. Again Finns felt significantly more that they had good opportunities for complaint with a mean score of 6.4. And yet again the Swedes were significantly less sure about this with a mean score of 5.7. It is also worth noting that Iceland scored low at 5.1, though this score is not significantly different in terms of the Nordic average.

- However, significantly more Swedes (11\%) and significantly fewer Finns (5\%) rated their possibilities for complaint as "very good" than was average for the Nordic countries (8\%)

- $22 \%$ across the five countries felt unable to answer this question. Significantly more Icelanders (42\%) and Swedes (26\%) felt this way whilst the same was true for significantly fewer Finns (11\%).

- Looking at the individual countries we see that in Sweden 18-39 year olds and those living with their partner are significantly less satisfied 
with the opportunities for complaint. However those over 60 years and those living in households of more than 3 adults are significantly more satisfied.

- In Norway single people are significantly less satisfied.

- In Finland 18-29 year olds and single people are significantly less satisfied with the opportunities for complaint while 40-49 year olds and those living in a household with 2 children are significantly more satisfied.

- In Denmark those over 60 and those living in mid sized towns are significantly more satisfied with the opportunities for complaint whole those between18-29 are significantly less satisfied.

- For Iceland it is worth noting that those living in large provincial towns and those with 3 children in the household rate the possibilities for complaint higher.

Figure 13: Satisfaction with possibility for acquiring information about how to complain ( 0 is 'very poor' and 10 is 'very good')

Q20: How would you asses the possibilities for acquiring information about how to complain e.g. information about complaint deadline, information about what the complaint should include and information about who you can complain to? Scale of 0-10, where 0 is "Very poor" and 10 is "Very good"

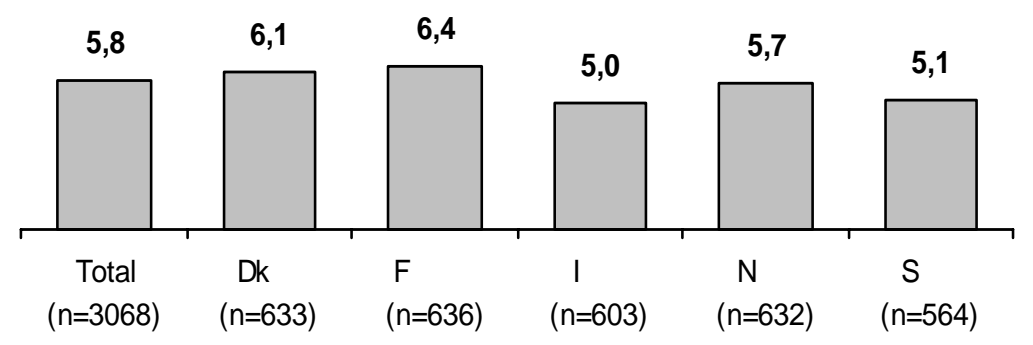

$\square$ Mean value

Table 14: \% unable to assess the possibilities for acquiring information about how to complain

\begin{tabular}{ccccccc}
\hline & $\begin{array}{c}\text { Total } \\
\mathrm{N}=\mathbf{3 0 6 8}\end{array}$ & $\begin{array}{c}\text { Denmark } \\
\mathrm{N}=\mathbf{6 3 3}\end{array}$ & $\begin{array}{c}\text { Finland } \\
\mathrm{N}=\mathbf{6 3 6}\end{array}$ & $\begin{array}{c}\text { Iceland } \\
\mathbf{N}=603\end{array}$ & $\begin{array}{c}\text { Norway } \\
\mathrm{N}=632\end{array}$ & $\begin{array}{c}\text { Sweden } \\
\mathrm{N}=564\end{array}$ \\
\hline Don't know & 22 & 25 & 9 & 32 & 22 & 30 \\
\hline
\end{tabular}

- The mean Nordic score for this question was 5.8. Again Finns felt significantly more that they had good opportunities to get information about the complaints process with a mean score of 6.4. Danes are also significantly more positive than Norwegians, Icelanders and Swedes with a mean score of 6.1. Swedes were significantly less sure about being able to acquire information about how to complain with a mean score of 5.1, while it should be also noted that, although not 
significantly different from the Nordic average, Iceland registered the lowest mean score of 5.0.

- $22 \%$ across the five countries felt unable to answer this question. Significantly more Swedes (30\%) felt this way whilst the same was true for significantly fewer Finns (9\%). However, though the percentage is not significantly different in terms of the Nordic average, it was in Iceland that most people felt unable to answer this question (32\%).

- Looking at the individual countries we see that in Sweden 18-49 year olds, those living with their partner and those in households with 2 children are significantly less positive about being able to acquire information about how to complain. Married people, those between 50-69 years, and those living in households with more than 4 children were significantly more positive.

- In Norway 18-29 year olds and single people are significantly less positive about being able to acquire information about how to complain.

- In Finland 18-29 year olds and those living with their partner are significantly less positive while married people and those between the ages of 40-49 years are significantly more positive about being able to acquire information about how to complain.

- In Denmark 18-29 year olds and those living with their partner are significantly less positive about being able to acquire information about how to complain while those over 60 years old are significantly more positive.

- It is worth noting that in Iceland people over 50 years are more positive about being able to acquire information about being able to complain.

\section{Figure 12: The need to complain about a doctor in the last 12 months}

Q21: Have you, within the past 3 years, had the need to complain to a complaints board about a doctor or specialist you have consulted in your country?

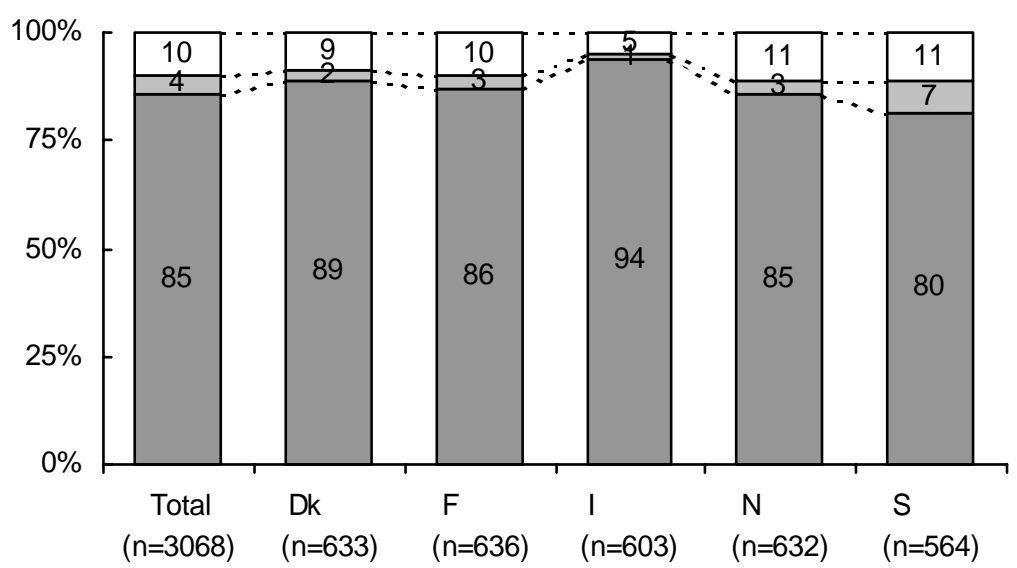

$\square$ No $\square$ Yes $\square$ Felt the need, but not done it 
- Looking at the Nordic countries as a whole we see that 85\% have not had cause to complain about their doctor or specialist in the last 3 years. Significantly more Danes (89\%) and Icelanders (94\%) have had no cause for complaint while the same is true for significantly fewer Swedes (80\%).

- Significantly more Swedes had actually complained (7\% versus a Nordic average of $4 \%$ ).

- Looking at the individual countries we see that in Sweden, Finland significantly more 18-29 year olds have felt the need to complain but haven't done it.

- In Sweden and Denmark those living with 3 children in the household are significantly less likely to complain. 



\section{Chapter 3 - Survey: Dental services}

\subsection{Introduction}

This chapter will look at all survey findings within the area of dental services. Findings on a Nordic level, a country level and a market level are summarised before the findings for each area of investigation are detailed.

\subsection{Usage of dentists}

\subsubsection{Summary of survey findings}

Most people in the Nordic countries (73\%) have visited a dentist in the past 12 months. Around one half of them have consulted their dentist once, and $68 \%$ of them consulted a private dentist. Generally speaking the majority are likely to have a long term (over 5 years) relationship with their dentist.

In Denmark men are significantly more likely to go to a private dentist than women while in Finland and Norway 18-29 year olds are more likely to go to a public dentist.

Danes are also more likely to have had their dentist for over 15 years. However we also see that in Denmark, Norway, Sweden and Finland people over 50 years of age and those who are married are more likely to have had their dentist for over 15 years.

If we compare usage of doctors and usage of dentists across the Nordic region we see that the visiting pattern is similar with nearly three quarters visiting a doctor and a dentist at least once in the last 12 months. More people visit their doctor more than once a year than visit their dentist more than once a year.

When it comes to type of doctor $68 \%$ have visited a GP while the same percentage has visited a private dentist.

We see some differences when it comes to length of relationship with their current doctor and dentist. Nearly $40 \%$ say that they have either had the doctor for less than a year or that they have no regular doctor while the majority reports a relationship of over 5 years with their current dentist. Danes have the longest relationship with both their doctors and dentist. 


\subsubsection{Survey findings}

Figure 13: \% consulting a dentist within the past 12 months

Q25: Have you and how often have you consulted a dentist within the past 12 months?

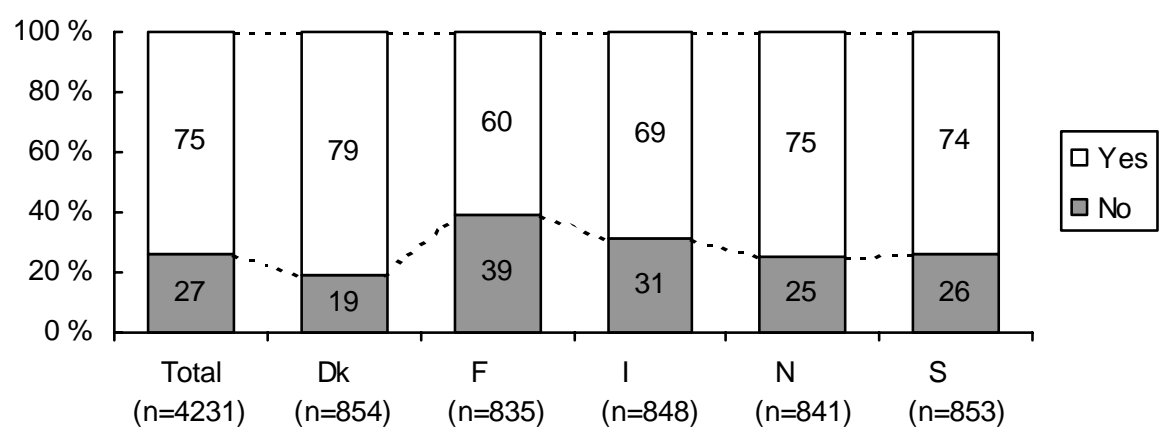

Table 15: Frequency of dentist consultation within the past 12 month, \% answering

\begin{tabular}{lrrrrrr}
\hline & $\begin{array}{r}\text { Total } \\
\mathbf{N}=\mathbf{3 0 2 7}\end{array}$ & $\begin{array}{r}\text { Denmark } \\
\mathbf{N}=\mathbf{6 8 1}\end{array}$ & $\begin{array}{r}\text { Finland } \\
\mathbf{N = 5 0 0}\end{array}$ & $\begin{array}{r}\text { Iceland } \\
\mathbf{N}=\mathbf{5 6 7}\end{array}$ & $\begin{array}{r}\text { Norway } \\
\mathbf{N = 6 5 1}\end{array}$ & $\begin{array}{r}\text { Sweden } \\
\mathbf{N}=\mathbf{6 2 8}\end{array}$ \\
\hline Once & 48 & 39 & 44 & 44 & 54 & 52 \\
Twice & 30 & 41 & 23 & 27 & 32 & 27 \\
3 times & 9 & 9 & 14 & 14 & 8 & 9 \\
4 times & 5 & 6 & 7 & 6 & 2 & 5 \\
5 times & 7 & 5 & 12 & 8 & 4 & 7 \\
Don't know & 0 & 0 & 0 & 1 & 0 & 1 \\
\hline
\end{tabular}

- Looking at the Nordic countries as a whole, we see that nearly three quarters (73\%) have consulted a dentist in the last 12 months.

Significantly more Danes (79\%) and significantly fewer Finns (60\%) have consulted their dentist. The latter may be due to a lag effect 2002 reform.

- Half (48\%) of those living in the Nordic region have consulted their dentist once within the past 12 months.

- There are a significantly higher percentage of Swedes (52\%) and Norwegians (54\%) who have visited their dentist once within the past 12 months than the Nordic average (48\%).

- A significantly lower percentage of Danes (39\%) have visited the dentist once within the past 12 months compared to the Nordic average (48\%).

- $41 \%$ of Danes have visited their dentist twice during the past 12 month. This is a significantly higher proportion than the average for the Nordic countries (30\%).

- $12 \%$ of Finns have visited their dentist 5 times or more in the past 12 months. This is a significantly higher proportion than the average for the Nordic countries (7\%), and may be a result of the right to dental care at a low, fixed price. 
- Norwegians are least likely of all Nordic people to have visited their dentist more than 3 times in the past 12 months.

- If we look more closely at the individual countries we see that in Denmark, Sweden and Norway people with 3 children are significantly more likely to have visited the dentist just once within the last 12 months.

- Furthermore in Sweden and Finland 18-29 year olds are significantly more likely to have visited the dentist just once while in Norway this is true for 30-39 year olds.

- In Iceland it is worth noting that those living in households with 2 children, those aged between 30-39 years and people with a household income of over $€ 65.000$ are most likely to visit their dentist just once.

Table 14: Type of dentist last visited, \% answering

Q26: Which kind of dentist did you visit at your last visit to a dentist?

\begin{tabular}{lrrrrrr}
\hline & $\begin{array}{r}\text { Total } \\
\mathbf{N}=\mathbf{3 0 2 7}\end{array}$ & $\begin{array}{r}\text { Denmark } \\
\mathbf{N}=\mathbf{6 8 1}\end{array}$ & $\begin{array}{r}\text { Finland } \\
\mathbf{N}=\mathbf{5 0 0}\end{array}$ & $\begin{array}{r}\text { Iceland } \\
\mathbf{N}=\mathbf{5 6 7}\end{array}$ & $\begin{array}{r}\text { Norway } \\
\mathbf{N}=\mathbf{6 5 1}\end{array}$ & $\begin{array}{r}\text { Sweden } \\
\mathbf{N}=\mathbf{6 2 8}\end{array}$ \\
\hline Private practising dentist & 68 & 85 & 52 & 92 & 82 & 58 \\
Public dentist & 30 & 12 & 47 & 7 & 17 & 42 \\
Don't know & 1 & 3 & 1 & 1 & 1 & 0 \\
Other & 1 & 0 & 0 & 0 & 0 & 0 \\
\hline
\end{tabular}

- Looking at the Nordic countries as a whole, we see that the majority consulted a private practising dentist on their last visit to a dentist (68\%).

- However here it is worth noting that we see significant differences in all five countries. There is a significantly higher percentage of Danes (85\%), Norwegians (82\%) and Icelanders (92\%) than Swedes (58\%) or Finns (52\%) who have visited a private practitioner. Structural similarities between Sweden and Finland in terms of share between public and private dentists are reflected in these findings, as well as the fact that dentists are most often private practitioners in Denmark.

- Looking at the individual countries we see that in Denmark men are significantly more likely to have visited a private dentist than women.

- In Finland and Sweden people over 50 are significantly more likely to have visited a private dentist.

- In Finland and Norway people under 30 are significantly more likely to go to a public dentist while it is people living in metropolitan areas who are significantly more likely to have visited a private practitioner.

- In Sweden people with 3 children are significantly more likely to have visited a public dentist.

- In Iceland it is worth noting that people living in a household of 3 adults are more likely to go to a private dentist. 
Figure 14: Length of relationship with dentist

Q27: For how long have you had the dentist you used at your last visit?

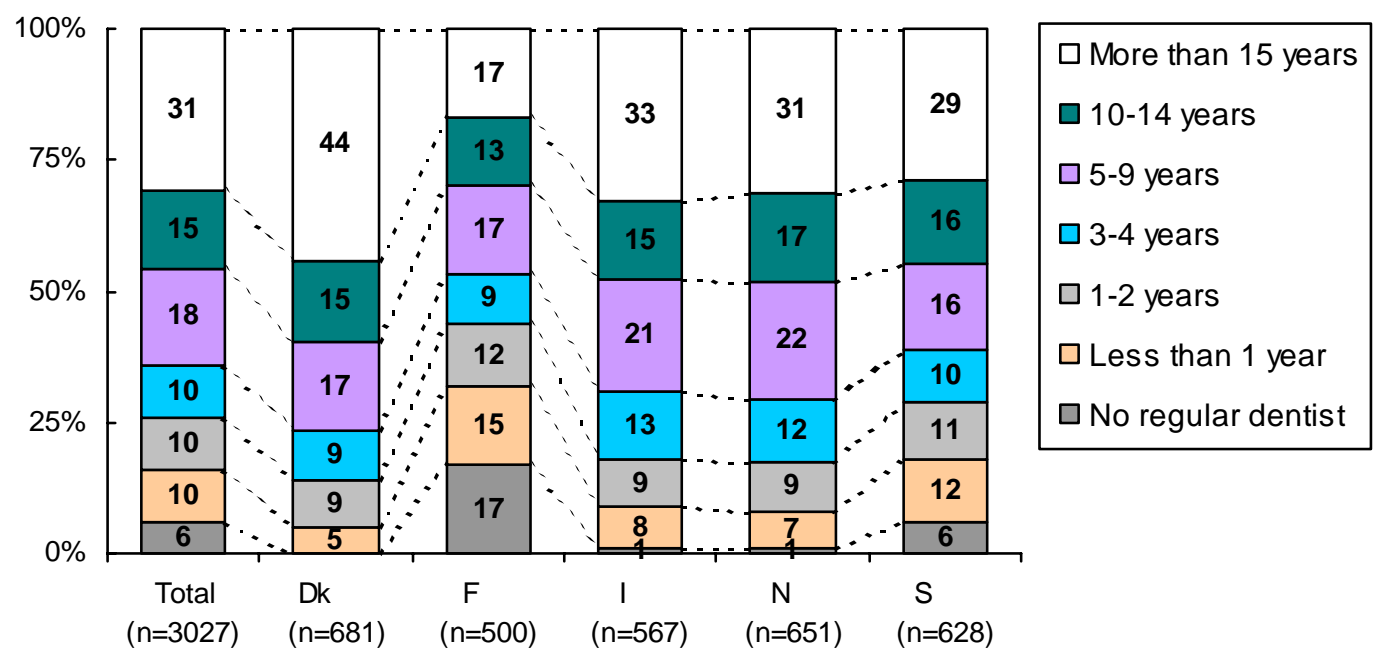

- If we look at the Nordic as a whole, we see that three out of ten (31\%) state that they have had their dentist for more than 15 years.

Generally, we see that the majority have a long term (5 years or over) relationship with their current dentist.

- There are significantly more Danes who have kept their dentist for more than 15 years (44\%) than the average for the Nordic countries as a whole (31\%).

- There are significantly fewer Finns who have kept their dentist for more than 15 years $(17 \%)$.

- There are more Finns who either have had their current dentist for less than one year (15\%) or who have no regular dentist (17\%), than the average for the Nordic countries (10\% and 6\% respectively). This may be explained by the 2002 reform.

- There are significantly fewer Danes (5\%) and Norwegians (7\%) who have had their current dentist for less than a year than the average for the Nordic countries (10\%). A similar pattern is found for Iceland, though this is not significant on a Nordic level. In all these three countries the desk research findings indicate that users are more strongly connected to a specific dentist.

- Looking at the individual countries we see that it is people over 50 years of age and people who are married who are most likely to have had their current dentist for 15 years or more. This is true in Denmark, Sweden, Norway and Finland.

- In Denmark we also see that people living in metropolitan areas are significantly less likely to have had their current dentist for 15 years or more.

- For Iceland it is worth noting that older people (over 50 years) are more likely to have had their dentist for more than 15 years while 
people living in households with 4 children are most likely to have had their current dentist for less than one year.

\subsection{User motives and information gathering}

\subsubsection{Summary of survey findings}

"Recommended by a friend" was the most mentioned reason across the Nordic countries for choosing their current dentist, followed by "location” which was more likely to be mentioned by Danes.

In Finland, Sweden and Denmark 18-29 years old are more likely to say that the primary reason for choosing their dentist was that the dentist was the family dentist. In Norway however this age group was significantly more likely to have chosen their dentist by chance.

$85 \%$ of people in the Nordic countries did not gather information before the first visit to their dentist. In Finland men are less likely to gather information than women.

Of those who did gather information before the first visit to their dentist almost three quarters (73\%) of them used family friends as a source of information.

Over a quarter (28\%) of those who did not gather information prior to their first visit to the dentist excused this by saying that the dentist had been recommended by family and friends. Almost half of those living in Denmark gave this as a reason. However it is worth noting that over 1 out of 10 people in the Nordic region said that they simply didn't want to spend time gathering information. In Sweden younger people were most likely to say this.

If we compare motives for choice of provider and user information gathering patterns across the markets in the Nordic region we see that location and recommendations from either friends or from professionals were also important reasons for choice of provider for all three markets. However it should be noted that the most popular reason for choice of doctor (given by $17 \%$ of people) was "by chance".

Most people did not gather information about different doctors and dentists; however $61 \%$ did gather information about different day care facilities. For people who did gather information most cited friends and family as their main source of information in all three markets. Not surprisingly, the fact that they had a recommendation was the main reason cited for not gathering information about different doctors and dentists before choice. However when it came to day care provider "other" reasons were most cited when people were asked why they did not gather information. 


\subsubsection{Survey findings}

Table 15: Primary reason for choice of dentist, $\%$ answering

Q28: Now I ask you to think of the first time you visited this dentist. Do you remember the primary reason why you chose this dentist?

\begin{tabular}{lrrrrrr}
\hline & $\begin{array}{r}\text { Total } \\
\mathbf{N = 3 0 2 7}\end{array}$ & $\begin{array}{r}\text { Denmark } \\
\mathbf{N = 6 8 1}\end{array}$ & $\begin{array}{r}\text { Finland } \\
\mathbf{N = 5 0 0}\end{array}$ & $\begin{array}{r}\text { Iceland } \\
\mathbf{N = 5 6 7}\end{array}$ & $\begin{array}{r}\text { Norway } \\
\mathbf{N = 6 5 1}\end{array}$ & $\begin{array}{r}\text { Sweden } \\
\mathbf{N = 6 2 8}\end{array}$ \\
\hline Recommended by friends & 21 & 24 & 14 & 24 & 23 & 22 \\
Location & 14 & 19 & 11 & 10 & 16 & 11 \\
By chance & 11 & 5 & 16 & 7 & 12 & 12 \\
It is the family dentist & 10 & 19 & 4 & 17 & 12 & 8 \\
Recommended by dentist/dental & 7 & 3 & 10 & 6 & 5 & 9 \\
personnel & & & & & & \\
Transferred/old dentist stopped & 7 & 6 & 1 & 2 & 8 & 11 \\
Only dentist with available places & 5 & 2 & 7 & 7 & 5 & 6 \\
Previous experience/good reputation & 3 & 6 & 3 & 0 & 5 & 1 \\
The dentist's personal data (age, sex) & 2 & 2 & 3 & 4 & 5 & 0 \\
Good opening hours & 1 & 0 & 2 & 1 & 0 & 1 \\
Size of clinic & 0 & 0 & 1 & 0 & 0 & 0 \\
Suggested by health insurance & 0 & 0 & 0 & 0 & 0 & 0 \\
Other & 10 & 4 & 19 & 11 & 4 & 14 \\
Don't remember/don't know & 6 & 7 & 3 & 8 & 5 & 8 \\
\hline
\end{tabular}

- Across the Nordic countries "Recommended by friend" (21\%) and "location" (14\%) are the most common reasons for choosing a dentist.

- A significantly lower percentage of Finns (14\%) based their decision on recommendations from friends than was average for the Nordic countries (21\%).

- Location is significantly more important in Denmark (19\%) and significantly less important in Sweden and Finland (both 11\%) than was average for the Nordic countries (14\%). It should also be noted that only $10 \%$ of Icelanders based their decision on location, though this percentage is not significantly different in terms of the Nordic average.

- Significantly more Danes (19\%) and significantly fewer Swedes (8\%) and Finns (4\%) based their decision on the fact that it is the family dentist than was average for the Nordic countries as a whole (10\%). In Iceland the relevant percentage, though it is not significantly different from the Nordic average, is $17 \%$ here. It is worth noticing that even in Norway family dentists play a more important role than in Sweden and Finland.

- A significantly higher percentage of Finns (16\%) choose dentists by chance, a result that may be linked to the 2002 reform. In Denmark only $5 \%$ choose their dentist by chance (significantly lower than the average for the Nordic countries $11 \%$ ). In Iceland only $7 \%$ stated that they chose their dentist by chance; again this percentage is not significantly different in terms of the Nordic countries as a whole.

- Other interesting findings were that significantly more Finns gave price as a reason for their choice of dentist (7\%) than was average for the Nordic countries (2\%). And that previous experience/good 
reputation is significantly more important in Norway (5\%) and Denmark (6\%) and significantly less important in Sweden (1\%) than was average for the Nordic countries (3\%).

- Looking at the individual countries we see that in Finland, Sweden and Denmark 18-29 years old are significantly more likely to say that the primary reason for choosing their dentist was that the dentist was the family dentist. In Norway however this age group was significantly more likely to have chosen their dentist by chance.

- In Iceland we also see that 18-29 year olds are more likely to say that the primary reason for choosing their dentist was that the dentist was the family dentist.

Figure 15: \% gathering information prior to their visit to their dentist

Q29: Did you gather information about various dentists prior to your first visit to this dentist?

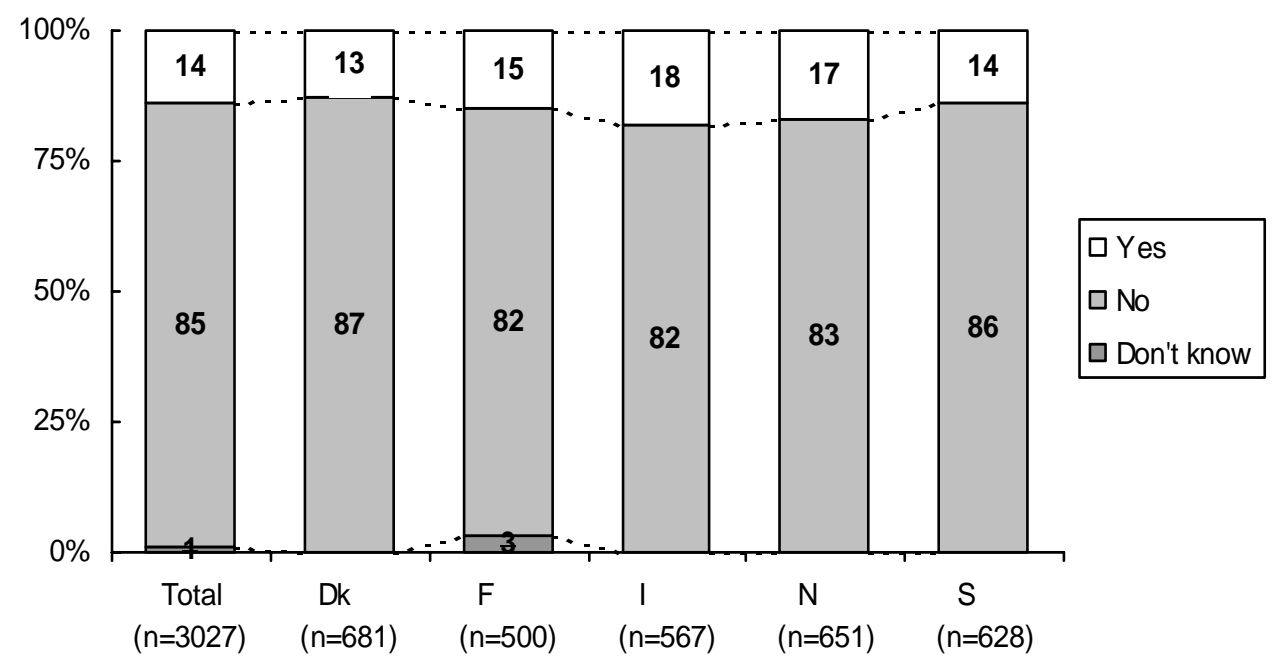

- Looking at the Nordic countries as a whole we see that a total of $85 \%$ did not gather information prior to their first visit to their dentist.

- There are no significant differences between countries.

- Looking at the individual countries we see that in Finland men, those between 18-29 years of age and single people are significantly less likely to gather information prior to their first visit to their dentist.

- In Norway people living by themselves are significantly less likely to have gathered information. 
Table 16: Sources of information about dentists, $\%$ answering

Q30: Which sources did you use to gather information about the different dentists? (asked to those who gathered information)

\begin{tabular}{|c|c|c|c|c|c|c|}
\hline & $\begin{array}{r}\text { Total } \\
\mathrm{N}=485\end{array}$ & $\begin{array}{r}\text { Denmark } \\
\qquad \mathrm{N}=\mathbf{8 8}\end{array}$ & $\begin{array}{l}\text { Finland } \\
\qquad \mathrm{N}=87\end{array}$ & $\begin{array}{r}\text { Iceland } \\
\mathrm{N}=108\end{array}$ & $\begin{array}{r}\text { Norway } \\
\mathrm{N}=113\end{array}$ & $\begin{array}{r}\text { Sweden } \\
\mathrm{N}=89\end{array}$ \\
\hline Spoke to family friends & 73 & 79 & 51 & 74 & 79 & 77 \\
\hline $\begin{array}{l}\text { Contacted one dentists and gained } \\
\text { information }\end{array}$ & 8 & 2 & 7 & 12 & 6 & 13 \\
\hline $\begin{array}{l}\text { Saw advertising material in phone } \\
\text { books/newspapers/magazines }\end{array}$ & 8 & 3 & 12 & 5 & 3 & 12 \\
\hline $\begin{array}{l}\text { Contacted several dentists and } \\
\text { gained information }\end{array}$ & 7 & 9 & 9 & 16 & 5 & 4 \\
\hline Surfed the internet & 6 & 7 & 3 & 0 & 6 & 7 \\
\hline $\begin{array}{l}\text { Read article in newspaper/ } \\
\text { magazine }\end{array}$ & 3 & 1 & 9 & 0 & 4 & 1 \\
\hline Contacted public authorities & 2 & 0 & 3 & 2 & 2 & 2 \\
\hline $\begin{array}{l}\text { Received information without } \\
\text { asking for it }\end{array}$ & 1 & 0 & 1 & 1 & 1 & 1 \\
\hline Other & 6 & 6 & 19 & 5 & 2 & 1 \\
\hline Don't remember/don't know & 1 & 0 & 2 & 0 & 3 & 0 \\
\hline
\end{tabular}

- On average across the Nordic countries, the majority of those who gathered information stated that they collected their information from family/friends (73\%). A significantly lower percentage in Finland (51\%) gathered information from family and friends.

- In Finland significantly more read an article in newspaper/magazine (9\%) than was average for the Nordic countries (3\%) while in Denmark significantly fewer simply contacted one dentist (2\%) than was average for the Nordic countries (8\%)

- In Denmark and Norway only 3\% had seen advertising material in phone books/newspapers/magazines - a significantly lower percentage than the average for the Nordic countries (8\%).

- For Iceland it is worth noting that $12 \%$ and $16 \%$ gather information by contacting one or more dental clinics respectively. It is also worth noting that the internet is not reported to be a source of information. Neither finding represents a significant difference from the Nordic average.

- Looking at the individual countries we see that in Sweden and Denmark 18-29 year olds are significantly more likely to surf the internet for information; and in Denmark and Norway the same age group were significantly less likely to ask family and friends for information.

- In Sweden 30-39 year olds are significantly less likely to ask friends and family for information while 50-59 years olds are significantly more likely to do the same. 
Table 17: Reasons for not gathering information, $\%$ answering

Q31: What is the reason for not gathering information about various dentists prior to your first visit to this dentist? (asked to those who answered that they did not gather information)

\begin{tabular}{|c|c|c|c|c|c|c|}
\hline & $\begin{array}{r}\text { Total } \\
\mathrm{N}=2527\end{array}$ & $\begin{array}{r}\text { Denmark } \\
\qquad N=593\end{array}$ & $\begin{array}{r}\text { Finland } \\
\mathrm{N}=398\end{array}$ & $\begin{array}{r}\text { Iceland } \\
\mathrm{N}=459\end{array}$ & $\begin{array}{r}\text { Norway } \\
\mathrm{N}=538\end{array}$ & $\begin{array}{r}\text { Sweden } \\
\mathrm{N}=539\end{array}$ \\
\hline $\begin{array}{l}\text { Other friends/relatives had } \\
\text { recommended the dentist }\end{array}$ & 28 & 44 & 17 & 30 & 28 & 22 \\
\hline $\begin{array}{l}\text { Did not want to spend time gathering } \\
\text { the information }\end{array}$ & 13 & 10 & 20 & 13 & 14 & 12 \\
\hline $\begin{array}{l}\text { Dentist/dental personnel had } \\
\text { recommended the dentist }\end{array}$ & 11 & 6 & 15 & 6 & 7 & 15 \\
\hline $\begin{array}{l}\text { I have good experiences with the dentist } \\
\text { The dentist is the only one close to }\end{array}$ & 9 & 12 & 5 & 15 & 8 & 8 \\
\hline my home/work & 9 & 11 & 7 & 14 & 12 & 7 \\
\hline Chosen accidentally & 3 & 4 & 0 & 1 & 3 & 3 \\
\hline Difficult to find information & 2 & 2 & 3 & 3 & 1 & 2 \\
\hline Know dentist personally & 2 & 3 & 1 & 6 & 2 & 2 \\
\hline Other & 12 & 4 & 20 & 10 & 5 & 16 \\
\hline Don't remember/don't know & 16 & 12 & 14 & 9 & 19 & 19 \\
\hline
\end{tabular}

- The most common reason for not gathering information before visiting a dentist is the fact that other friends/relatives had recommended the dentist (28\% across the Nordic countries). Significantly more Danes gave this as their reason for not gathering information (44\%), while significantly fewer Swedes (22\%) and Finns (17\%) gave this as a reason for not gathering information.

- The second most common reason for not gathering information was that people did not want spend time doing it (13\%). Significantly fewer Danes (10\%) and significantly more Finns (20\%) answered that they didn't want to spend the time gathering information when compared to the average for the Nordic countries (13\%).

- In Sweden and Finland significantly more (both $15 \%$ ) reported that they did not gather information because they had a recommendation from a dentist or dentist personnel than was average for the Nordic countries (11\%).

- It is worth noting that in Iceland 15\% reported that the reason they did not gather information was that they had good experience with the dentist (against a Nordic average of $9 \%$ ) and $14 \%$ said that their dentist was the only one close to their home (against a Nordic average of $9 \%)$. Neither finding represents a significant difference from the Nordic average.

- In Sweden 18-29 year olds are significantly more likely to say that they cannot be bothered to gather information while in Denmark significantly more of this age group say that the reason they do not gather information is that they have had recommendations from friends and relatives.

- In Norway people with 1 child in the household were significantly more likely to say that they did not want to spend time gathering information. 
- In Denmark people living in small towns were significantly more likely to say that they did not gather information because the dentist had a good reputation.

- In Iceland 30-39 year olds were the most likely to report that they had had their dentist recommended by friends or family, and those living with their partner were the most likely to report that they did not want to spend the time gathering information.

\subsection{User satisfaction}

\subsubsection{A summary of survey findings}

The overall impression concerning user satisfaction is that people in the Nordic region are averagely satisfied with the possibility for acquiring general information about dental services (mean Nordic score of 5.9) and they are very satisfied when it comes to the total service they received on their last dental visit (mean Nordic score of 8.5). Finns are, overall, the most satisfied of the Nordic people.

If we compare satisfaction with the possibility for acquiring information in all three markets across the Nordic region we see that satisfaction is greatest with day care facilities with mean scores of over 7 in all countries except Sweden. Doctors scored over average while satisfaction with dentists was only a little better than average.

Satisfaction with total service scored high in all three markets.

\subsubsection{Survey findings}

Figure 15: Satisfaction with the possibilities for acquiring general information about dental services ( 0 is 'not at all satisfied and $\mathbf{1 0}$ is 'very satisfied')

Q32: Based on your experiences, how satisfied are you with the possibilities for acquiring general information about dental services? (scale of 0-10, where 0 is "not at all satisfied" and 10 is "very satisfied").

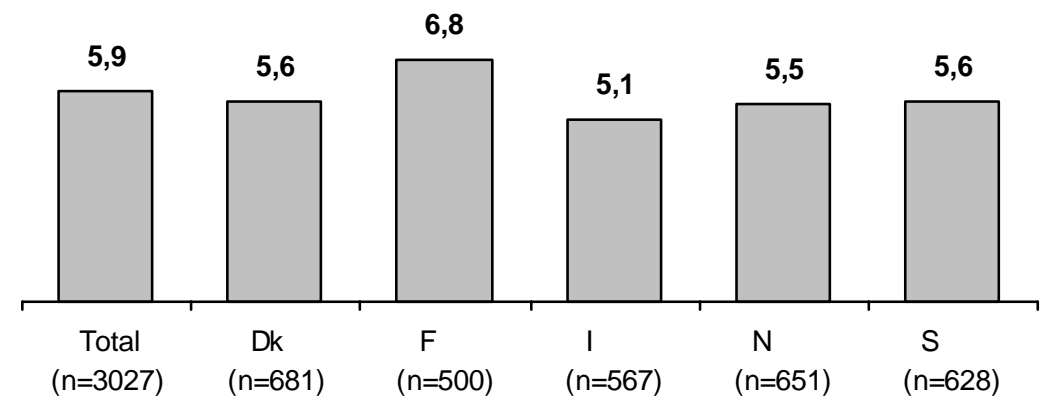

$\square$ Mean value 
Table 18: \% unable to assess their satisfaction with the possibilities for acquiring general information about dental services

\begin{tabular}{ccccccc}
\hline & $\begin{array}{c}\text { Total } \\
\mathrm{N}=\mathbf{3 0 2 7}\end{array}$ & $\begin{array}{c}\text { Denmark } \\
\mathrm{N}=\mathbf{6 8 1}\end{array}$ & $\begin{array}{c}\text { Finland } \\
\mathrm{N}=\mathbf{5 0 0}\end{array}$ & $\begin{array}{c}\text { Iceland } \\
\mathrm{N}=\mathbf{5 6 7}\end{array}$ & $\begin{array}{c}\text { Norway } \\
\mathrm{N}=\mathbf{6 5 1}\end{array}$ & $\begin{array}{c}\text { Sweden } \\
\mathrm{N}=\mathbf{6 2 8}\end{array}$ \\
\hline Don't know & 25 & 32 & 8 & 31 & 29 & 25 \\
\hline
\end{tabular}

- Over all it seems that people in the Nordic Countries are more satisfied than dissatisfied with the possibilities for acquiring general information on dental services.

- Finns were significantly more satisfied than their Nordic counterparts with a mean score of 6.8 as against a mean Nordic score of 5.9.

Although not significantly lower than the Nordic average it is worth noting that Iceland scored lowest on satisfaction with the possibilities for acquiring general information about dental services with a mean score of 5.1 .

- A further finding worth noting is that $25 \%$ of people in the Nordic countries felt that they were unable to give a rating. While in Finland the percentage here was significantly lower (8\%), in both Denmark and Norway the percentages were significantly higher at 32\% and $29 \%$ respectively.

- In Iceland 31\% reported that they were unable to assess how satisfied they were with the possibilities for acquiring general information. This finding does not represent a significant difference from the Nordic average.

- Looking at the individual countries we see that in Finland 18-39 year olds and people living alone are less likely to be satisfied with the possibilities for acquiring general information.

- In Sweden people living with their partner and people with 1 or 3 children in the household are less likely to be satisfied while those who are either married or widowed are more likely to be satisfied.

- In Denmark 30-39 year olds and people with 2 children in the household are less likely to be satisfied with the possibilities for acquiring general information while widowers are more likely to be satisfied. 
Figure 16: Satisfaction with the total service after last dental visit ( $0=$ 'not at all satisfied, $10=$ 'very satisfied')

Q33: On a scale from 0-10, where 0 is "not at all satisfied" and 10 is "very satisfied", how satisfied were you with the total service after your last dental visit?

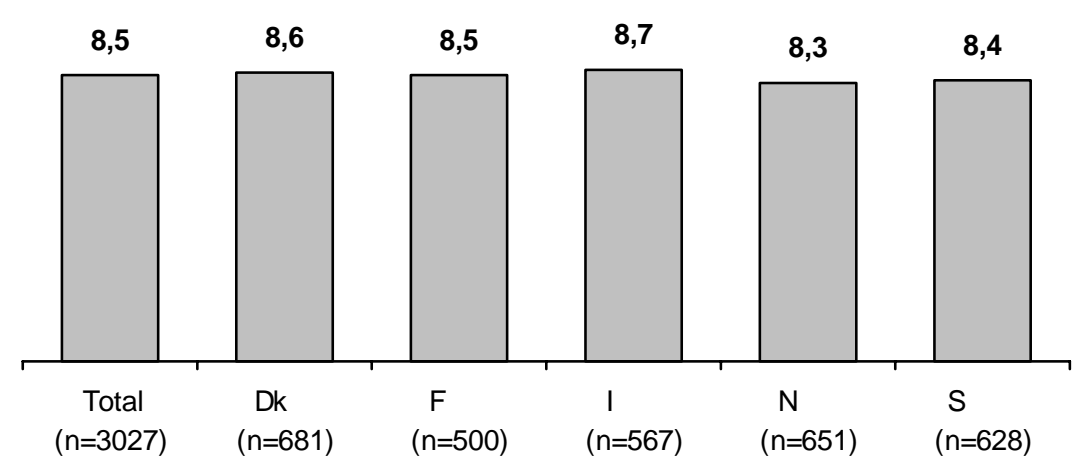

$\square$ Mean value

- Over all it seems that people in the Nordic Countries are mostly satisfied with the total service after their last dental visit. The mean score for all countries was 8.5.

- Norwegians were significantly less satisfied than their Nordic counterparts but were still mostly satisfied registering a mean score of 8.3. Danes were significantly more satisfied registering a mean score of 8.6.

- Icelanders rated satisfaction with total service highest with a mean score of 8.7, though this score was not significantly different in terms of the Nordic average.

- In Sweden and Denmark significantly more people (44\% and $41 \%$ ) were "very satisfied" than was average for the Nordic countries, while in Finland and Norway significantly fewer (24\% and 31\%) were "very satisfied".

- Looking at the individual countries we see that the age group 18-29 were significantly less satisfied with the total service in Denmark, Sweden, Norway and Finland.

- 60-69 year olds are significantly more satisfied in Denmark and Sweden.

- People living with their partner are significantly less satisfied in Denmark, Sweden and Finland while in Norway widowers are significantly more satisfied with the total service.

\subsection{Change of dentist}

\subsubsection{A summary of survey findings}

Three quarters of people in the Nordic countries have not changed or considered changing their dentist within the past three years. Finns are 
more likely to have changed their dentist and Norwegians least likely to have done the same.

Of those who say they have changed or have considered changing their doctor, relocation and price were the most mentioned reasons, the first being most mentioned by the Danes (30\%). Other important reasons were that their former dentist had moved, dissatisfaction with information/services and concerns regarding quality (particularly important in Norway where 28\% mentioned it). In Finland 37\% gave "other" reasons for a switch of dentist; this is most likely linked to the dental care reform of 2002 which gave everyone the right to public dental care.

If we look at the reasons people in the Nordic region give for staying with their dentist, satisfaction with their current dentist is a clear winner with $80 \%$ of people citing this. $21 \%$ mentioned that changing dentist would mean having to build up a personal relationship with a new dentist.

18-29 year olds in Sweden, Norway and Denmark are less likely to give satisfaction as a reason for staying with their current dentist.

If we compare how often people change their provider across the three markets in the Nordic region we see that over $70 \%$ of people have neither considered changing or have changed provider in all three markets. More people have considered changing their child's day care facility than have considered changing either their doctor or dentist.

For those who have either changed or considered changing provider relocation was an important reason in all three markets, together with concerns about quality of (and dissatisfaction with) the service; satisfaction was the main reason for staying with their current provider in all three markets. 


\subsubsection{Survey findings}

Figure 17: \% changing/considering changing dentist

Q34: Have you changed or considered to change your dentist within the past three years?

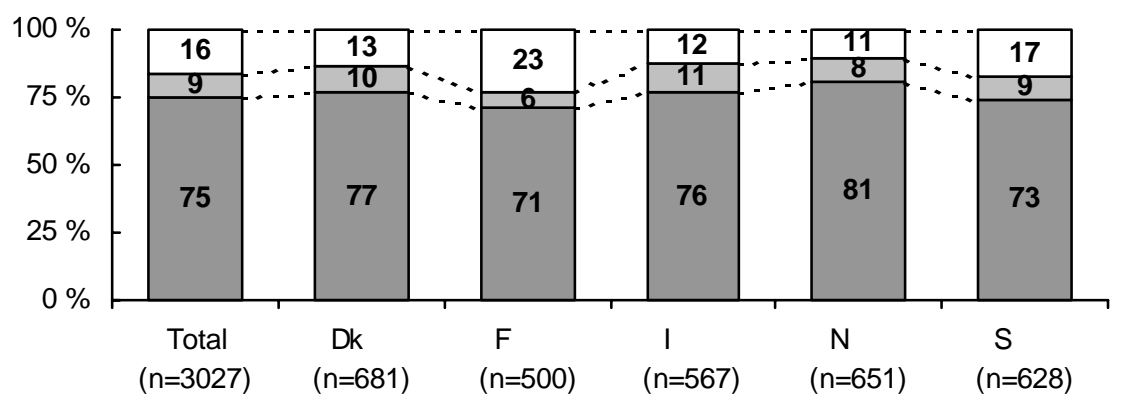

$\square$ No, have not changed $\square$ Yes, have considered to change $\square$ Yes, have changed

- $75 \%$ of people across the Nordic countries have not changed their dentist in the past three years.

- Norwegians are significantly more likely not to have changed their dentist (81\%) than the Nordic average (75\%).

- Finns are significantly more likely to have changed their dentist (23\%) than the Nordic average (16\%), again a finding that may be linked to the 2002 reform.

- Looking at the individual countries we see that in Finland, Norway and Denmark significantly fewer 18-29 year olds have not changed their dentist within the past 3 years; and in Sweden significantly more 18-29 year olds have changed their dentist within the past 3 years.

Table 19: Most important reasons for change/ considering change of dentist, $\%$ answering - more than one answer allowed

Q35: What are the three most important reasons for your change or consideration of change of dentist? Asked to those who said they had either changed, or considered changing their dentist.

\begin{tabular}{|c|c|c|c|c|c|c|}
\hline & $\begin{array}{r}\text { Total } \\
\mathrm{N}=713\end{array}$ & $\begin{array}{r}\text { Denmark } \\
\mathrm{N}=154\end{array}$ & $\begin{array}{r}\text { Finland } \\
\mathrm{N}=138\end{array}$ & $\begin{array}{l}\text { Iceland } \\
\mathrm{N}=134\end{array}$ & $\begin{array}{r}\text { Norway } \\
\mathrm{N}=119\end{array}$ & $\begin{array}{r}\text { Sweder } \\
\mathrm{N}=168\end{array}$ \\
\hline Price considerations & 22 & 23 & 22 & 26 & 22 & 22 \\
\hline Want dentist with different location & 22 & 30 & 5 & 27 & 23 & 25 \\
\hline My former dentist moved/closed & 20 & 11 & 17 & 13 & 19 & 27 \\
\hline $\begin{array}{l}\text { Dissatisfied with dentist's } \\
\text { information/service }\end{array}$ & 19 & 18 & 13 & 17 & 11 & 20 \\
\hline Concern regarding quality & 18 & 21 & 19 & 19 & 28 & 13 \\
\hline Lack of trust in former dentist & 13 & 13 & 4 & 11 & 11 & 19 \\
\hline $\begin{array}{l}\text { A wish to avoid waiting hours at former } \\
\text { dentist }\end{array}$ & 5 & 2 & 11 & 2 & 1 & 4 \\
\hline Recommendation from others & 4 & 3 & 6 & 3 & 2 & 4 \\
\hline A wish for a specialist & 2 & 1 & 5 & 1 & 2 & 0 \\
\hline A wish for different opening hours & 1 & 0 & 2 & 2 & 1 & 1 \\
\hline I turned 18 & 1 & 5 & 1 & 0 & 0 & 0 \\
\hline Other & 12 & 10 & 37 & 10 & 3 & 4 \\
\hline Don't know/don't remember & 0 & 0 & 0 & 0 & 2 & 0 \\
\hline
\end{tabular}


- Across the five countries the most mentioned reasons for changing or considering changing dentist are: price (22\%), relocation (22\%), former dentist moved/closed (20\%), dissatisfaction with information/service (19\%) and concerns regarding quality (18\%).

- A significantly higher proportion of Danes (30\%) gave relocation as a reason for change while significantly fewer Finns gave the same reason (5\%).

- A significantly higher proportion of Norwegians (28\%) gave concerns regarding quality as a reason for change while significantly fewer Swedes gave the same reason (13\%).

- Significantly fewer Finns (13\%) cited dissatisfaction with information/service as a reason for change while significantly more Finns gave "other" reasons (37\% versus a Nordic average of 12\%).

- Other differences worth noting on a Nordic level are that significantly more Swedes give a lack of trust in their former dentist as a reason for change while significantly more Finns give the desire to reduce waiting time as a reason for change.

- Although not significantly different in terms of the Nordic countries as a whole, it should be noted that in Iceland 26\% cite price as a reason for changing or considering a change of dentist (as against a Nordic average of 22\%) and 27\% cited relocation as a reason (as against a Nordic average of 22\%).

- Looking at the individual countries we see that in Denmark and Sweden 18-29 year olds are significantly more likely to give their own relocation as a reason for changing or considering a change of dentist. We also see that married people in both these countries are significantly less likely to cite location as a reason while people living with their partners are significantly more likely to cite location.

- In Sweden men are significantly more likely to cite location and women are more likely to cite a lack of trust in their current dentist.

- In Norway dissatisfaction with information/service is significantly more likely to be cited as a reason for changing or considering a change of dentist by 18-29 year olds and single people while it is significantly less likely to be cited by people between 40-49 and 60-69 years and by people in households with 2 adults.

- In Finland 18-29 year olds are significantly more likely to give "other" reasons for changing or considering a change of dentist and significantly less likely to cite price as a reason. 50-59 year olds are significantly more likely to cite the fact that their dentist had moved.

- Finns living in larger towns were significantly more likely to give price as a reason for changing or considering a change of dentist.

- In Iceland it is worth noting that people living with their partner are most likely to cite concerns over quality as a reason for changing or considering a change of dentist. 
Table 20: The most important reasons for staying with current dentist, $\%$ answering - more than one answer allowed

Q36: What are the three most important reasons for you staying with your current dentist?

\begin{tabular}{|c|c|c|c|c|c|c|}
\hline & $\begin{array}{r}\text { Total } \\
\mathrm{N}=2587\end{array}$ & $\begin{array}{r}\text { Denmark } \\
\mathrm{N}=594\end{array}$ & $\begin{array}{r}\begin{array}{r}\text { Finland } \\
\mathrm{N}=395\end{array}\end{array}$ & $\begin{array}{r}\text { Iceland } \\
\mathrm{N}=495\end{array}$ & $\begin{array}{r}\text { Norway } \\
\mathrm{N}=582\end{array}$ & $\begin{array}{r}\text { Sweden } \\
\mathrm{N}=521\end{array}$ \\
\hline $\begin{array}{l}\text { Satisfied with my current dentist } \\
\text { Have to built up personal relationship } \\
\text { between dentist and patient again if I }\end{array}$ & 80 & 89 & 71 & 86 & 84 & 76 \\
\hline $\begin{array}{l}\text { change } \\
\text { The clinic has the most convenient }\end{array}$ & 21 & 20 & 14 & 21 & 26 & 22 \\
\hline location (of many clinics in the area) & 12 & 10 & 11 & 4 & 15 & 13 \\
\hline Money - cannot afford to change & 5 & 5 & 9 & 21 & 6 & 3 \\
\hline $\begin{array}{l}\text { Haven't had the time } \\
\text { Superfluous trouble to change because }\end{array}$ & 4 & 2 & 6 & 2 & 2 & 5 \\
\hline I seldom go to the dentist & 4 & 4 & 7 & 3 & 3 & 4 \\
\hline $\begin{array}{l}\text { Difficult to find information on other } \\
\text { dentists }\end{array}$ & 3 & 1 & 2 & 2 & 1 & 4 \\
\hline The clinic is the only one nearby & 3 & 2 & 7 & 2 & 3 & 1 \\
\hline Difficult/bureaucratic to change & 2 & 2 & 1 & 2 & 0 & 3 \\
\hline The waiting time at the dentist I want & 2 & 1 & 2 & 6 & 3 & 2 \\
\hline Am afraid to lose my journal if I change & 1 & 1 & 1 & 0 & 1 & 1 \\
\hline $\begin{array}{l}\text { Under treatment (want treatment prior to } \\
\text { change) }\end{array}$ & 1 & 1 & 2 & 1 & 0 & 2 \\
\hline Other & 9 & 3 & 27 & 8 & 7 & 6 \\
\hline Don't know/don't remember & 1 & 0 & 0 & 0 & 4 & 0 \\
\hline
\end{tabular}

- The reason most people in the Nordic region give for remaining with their current dentist is satisfaction with their current dentist (80\%).

- Significantly more Norwegians (84\%) and Danes (89\%) give satisfaction as a reason for remaining with their current dentist, while significantly fewer Finns (71\%) and of Swedes (76\%) cite satisfaction as a reason.

- Although not significantly different in terms of the Nordic average it should be noted here that $86 \%$ of Icelanders also cite satisfaction as a reason for remaining with their current dentist.

- The next most mentioned reason for remaining with a current dentist is that it would mean having to build up a personal relationship with their new dentist (21\%). Finns are significantly less likely to give this as a reason (14\%), while significantly more Norwegians gave this as a reason for remaining with their current dentist (26\%).

- The third most mentioned reason is convenience of location. On average $12 \%$ of people in the Nordic countries cite this as a reason for remaining with their dentist, though significantly fewer Icelanders mention this (4\%).

- Other differences between the countries worth noting are that significantly more Icelanders state that they cannot afford to change dentist (21\% versus a Nordic average of 5\%), while significantly more Finns state that their clinic is the only one nearby (7\% versus a Nordic average of $3 \%$ ). 
- Looking at the individual countries we see that in Denmark, Sweden and Norway 18-29 year olds are significantly less likely to give satisfaction with their current dentist as a reason for staying with their current dentist.

- In Norway single people and people in households with more than 3 children are significantly less likely to cite satisfaction as a reason for staying with their current dentist while in Sweden and Denmark this is true for people living with their partner.

- The need to build a new relationship with the dentist was significantly more likely to be cited as a reason for staying with a current dentist by 40-49 year olds in Norway, by 50-59 year olds and people living in metropolitan areas in Sweden and by people living in households with one child in Denmark.

\subsection{Possibilities of comparison and information}

\subsubsection{A summary of survey findings}

People in the Nordic region are not satisfied with the possibilities for comparison of dentists' service (rated on price, quality of treatment, waiting times and age of dentist); mean Nordic scores for all questions were below 5. We see that the Finns are the most satisfied of the Nordic people and Swedes and Danes the most dissatisfied. We also see that there is a sizeable minority in the Nordic region who simply do not feel able to answer questions concerning the possibilities of comparison.

Widowers in Norway, Sweden and Denmark are more likely to rate the possibilities for price comparison higher while Swedish men are more likely to rate them lower.

Looking at the possibilities for comparing the quality of dental treatment again widowers in Norway, Sweden and Denmark are less dissatisfied, together with 18-29 year olds in Sweden and Norway.

Looking at the possibilities for comparing dentists based on waiting times, women in Norway and Denmark are less dissatisfied and in Sweden, Finland and Denmark the same is true for people living in smaller communities.

If we compare the three markets with regard to ratings given to the possibilities for comparison of the service provided across the Nordic countries we see that there is a basic level of dissatisfaction when it comes to doctors and dentists and that people are more satisfied with the possibilities of comparison of day care facilities' service (opening hours, number of children, number of employees). Finns are most satisfied as far as doctors and dentists are concerned and Danes are most satisfied as far as their child's day care facilities are concerned. 
Furthermore we see that across all markets there is a sizeable minority that feels incapable of answering questions about the possibilities for comparison of these aspects of service. This is particularly true for Swedes.

\subsubsection{Survey findings}

Figure 18: Satisfaction with the possibility to compare prices of dentists ( 0 is 'very poor' and 10 is 'very good')

Q37: If you usually pay for your dental service, how would you assess the possibilities for comparing the price level of different dentists e.g. via the internet, pamphlets, newspapers or magazines? A scale from 0-10, where 0 is "Very poor" and 10 is "Very good"

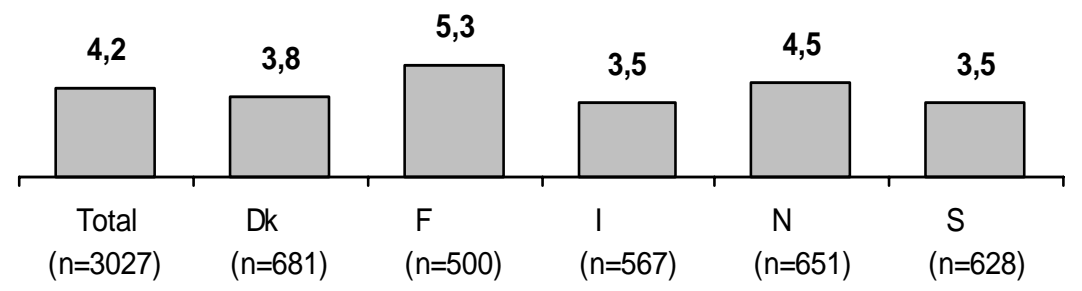

$\square$ Mean value

Table 21: \% unable to assess the possibilities for comparing prices of dentists

\begin{tabular}{ccccccc}
\hline & $\begin{array}{c}\text { Total } \\
\mathbf{N}=\mathbf{3 0 2 7}\end{array}$ & $\begin{array}{c}\text { Denmark } \\
\mathbf{N}=\mathbf{6 8 1}\end{array}$ & $\begin{array}{c}\text { Finland } \\
\mathbf{N}=\mathbf{5 0 0}\end{array}$ & $\begin{array}{c}\text { Iceland } \\
\mathbf{N}=\mathbf{5 6 7}\end{array}$ & $\begin{array}{c}\text { Norway } \\
\mathbf{N}=\mathbf{6 5 1}\end{array}$ & $\begin{array}{c}\text { Sweden } \\
\mathbf{N}=\mathbf{6 2 8}\end{array}$ \\
\hline Don't know & 37 & 39 & 19 & 32 & 34 & 45 \\
\hline
\end{tabular}

- The mean Nordic score for this question was 4.2. Finns and Norwegians were significantly less dissatisfied with the opportunities for comparing price levels registering mean scores of 5.3 and 4.5 respectively; while Swedes and Danes were significantly more dissatisfied registering mean scores of 3.5 and 3.8. The principle of free pricing found in Sweden (desk research) may partly explain this.

- Though not significantly different in terms of the Nordic average, it should be noted that Icelanders also rated possibilities for comparison of price levels low registering a mean score of 3.5. The free market with price defined by supply and demand may explain this finding.

- A total of $37 \%$ in the Nordic countries felt they couldn't answer this question. Significantly more Swedes (45\%) were unable to answer than their Nordic counterparts while the same was true for significantly fewer Finns (19\%). The fixed price level for dental services may partly explain this. 
- $12 \%$ of Swedes rate the possibilities for comparing price levels as "very poor" while the same can be said of $4 \%$ of Finns against a Nordic average of $9 \%$.

- Looking at the individual countries we see that in Denmark, Norway and Sweden widowers are significantly more likely to rate the possibilities for comparison of prices lower.

- In Sweden men are significantly more likely to rate the possibilities for comparison of prices lower than women and 18-29 year olds are significantly more likely to rate the possibilities higher than other age groups.

- In Denmark and Finland people living in smaller towns are significantly more likely to rate the possibilities for comparison of prices higher.

- In Sweden people in households with 2 children are significantly more likely to rate the possibilities for comparison of prices lower while in Finland they are significantly more likely to rate them higher.

- It is worth noting that in Iceland 40-49 year olds rate possibilities for comparison of prices very low registering a mean score of just 2.5 .

Figure 19: Satisfaction with possibilities for comparing the quality of dental treatment

Q38: How would you assess the possibilities for comparing the quality of the dental treatment of different dentists? Please answer on the basis of a scale from 0-10, where 0 is "Very poor" and 10 is "Very good"

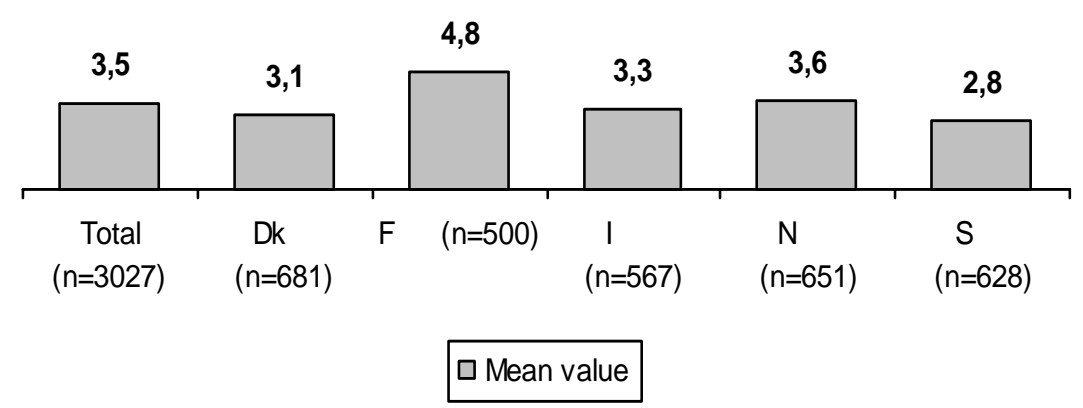

Table 21: \% unable to assess the possibilities for comparing quality of dental treatment

\begin{tabular}{ccccccc}
\hline & $\begin{array}{c}\text { Total } \\
\mathbf{N}=\mathbf{3 0 2 7}\end{array}$ & $\begin{array}{c}\text { Denmark } \\
\mathbf{N}=\mathbf{6 8 1}\end{array}$ & $\begin{array}{c}\text { Finland } \\
\mathbf{N}=\mathbf{5 0 0}\end{array}$ & $\begin{array}{c}\text { Iceland } \\
\mathbf{N}=\mathbf{5 6 7}\end{array}$ & $\begin{array}{c}\text { Norway } \\
\mathbf{N}=\mathbf{6 5 1}\end{array}$ & $\begin{array}{c}\text { Sweden } \\
\mathbf{N}=\mathbf{6 2 8}\end{array}$ \\
\hline Don't know & 35 & 35 & 17 & 32 & 31 & 45 \\
\hline
\end{tabular}

- The mean Nordic score for this question was well below the middle score at 3.5. While they could hardly be described as satisfied, the Finns were significantly less dissatisfied than their Nordic counterparts with a mean score of 4.8. Both the Swedes (2.8) and the Danes (3.1) were significantly more dissatisfied. 
- $15 \%$ of Swedes (significantly more than the Nordic average of $12 \%$ ) rated their possibilities for comparing the quality of dental treatment as "very poor".

- A total of 35\% answered that they don't know or cannot assess the possibilities. Significantly more Swedes (45\%) answered this while the same was true for significantly fewer Finns (17\%).

- Looking at the individual countries we see that in Denmark, Norway and Sweden widowers are significantly less dissatisfied with the possibilities for comparing quality of treatment.

- 18-29 year olds in Sweden and Norway are significantly less dissatisfied with the possibilities for comparing quality of treatment, while 40-49 year olds in Norway and 30-59 year olds in Sweden are significantly more dissatisfied with the possibilities for comparing quality of treatment lower.

- In Finland and Norway people living in metropolitan areas are significantly more dissatisfied with the possibilities for comparing quality of treatment.

- In Sweden and Norway single dwellers are significantly less dissatisfied with the possibilities for comparing quality of treatment.

Figure 20: Satisfaction with the possibility to compare waiting time at dentists

Q39: How would you assess the possibilities for comparing different dentists with respect to waiting time? Please answer on the basis of a scale from $0-10$, where 0 is "Very poor" and 10 is "Very good"

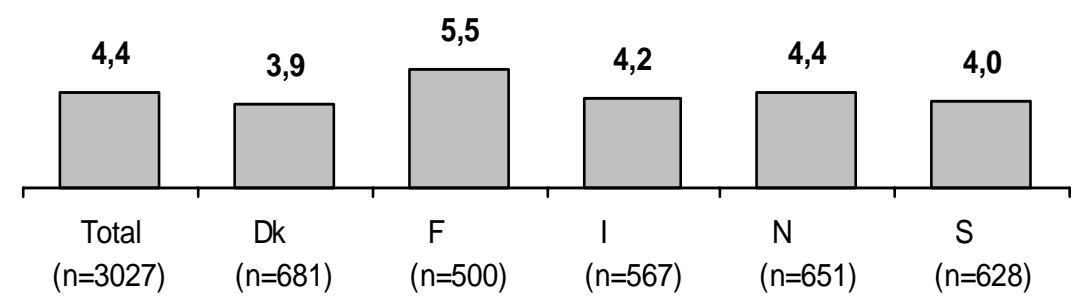

$\square$ Mean value

Table 22: \% unable to assess the possibilities for comparing waiting time at dentists

\begin{tabular}{lcccccc}
\hline & $\begin{array}{c}\text { Total } \\
\mathrm{N}=\mathbf{3 0 2 7}\end{array}$ & $\begin{array}{c}\text { Denmark } \\
\mathrm{N}=\mathbf{6 8 1}\end{array}$ & $\begin{array}{c}\text { Finland } \\
\mathrm{N}=\mathbf{5 0 0}\end{array}$ & $\begin{array}{c}\text { Iceland } \\
\mathrm{N}=567\end{array}$ & $\begin{array}{c}\text { Norway } \\
\mathrm{N}=651\end{array}$ & $\begin{array}{c}\text { Sweden } \\
\mathrm{N}=\mathbf{6 2 8}\end{array}$ \\
\hline Don't know & 42 & 47 & 21 & 39 & 36 & 51 \\
\hline
\end{tabular}

- The mean Nordic score for this question was again under the middle score at 4.4. Again the Finns were significantly more satisfied with the possibilities for comparing dentists vis à vis waiting time than their Nordic counterparts with a mean score of 5.5. Both the Swedes (4) and the Danes (3.9) were significantly more dissatisfied. 
- A total of $42 \%$ in the Nordic countries say they don't know or cannot assess the possibilities for comparison here. Significantly more Swedes and Danes answered this (51\% and $47 \%$ respectively) while significantly fewer Norwegians and Finns did the same (36\% and $21 \%)$.

- Looking at the individual countries we see that in Sweden, Norway and Finland 18-29 year olds are significantly more likely to rate the possibilities for comparing dentists on the basis of waiting times lower.

- In both Sweden and Denmark widowers are significantly more likely rate the possibilities for comparing dentists on the basis of waiting times higher whilst those living with partners are less likely to do the same.

- In both Norway and Denmark women are significantly more likely to rate the possibilities for comparing dentists on the basis of waiting times higher than men.

- In Sweden, Finland and Denmark people living in smaller towns or villages are significantly more likely to rate the possibilities for comparing dentists on the basis of waiting times higher.

Figure 21: Satisfaction with the available information about a dentist's age ( 0 is 'very poor' and 10 is 'very good')

Q40: How would you assess the availability of information about a certain dentist's age? Please answer on the basis of a scale from $0-10$, where 0 is "Very poor" and 10 is "Very good"

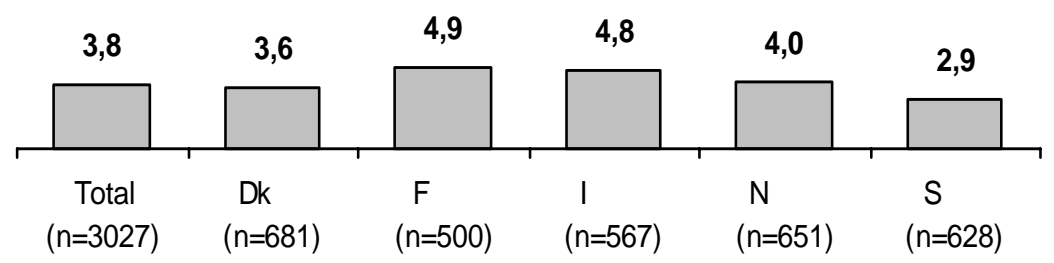

$\square$ Mean value

Table 23: \% unable to assess the possibilities for comparing dentists' age

\begin{tabular}{ccccccc}
\hline & $\begin{array}{c}\text { Total } \\
\mathrm{N}=\mathbf{3 0 2 7}\end{array}$ & $\begin{array}{c}\text { Denmark } \\
\mathbf{N}=\mathbf{6 8 1}\end{array}$ & $\begin{array}{c}\text { Finland } \\
\mathbf{N}=\mathbf{5 0 0}\end{array}$ & $\begin{array}{c}\text { Iceland } \\
\mathbf{N}=\mathbf{5 6 7}\end{array}$ & $\begin{array}{c}\text { Norway } \\
\mathbf{N}=\mathbf{6 5 1}\end{array}$ & $\begin{array}{c}\text { Sweden } \\
\mathbf{N}=\mathbf{6 2 8}\end{array}$ \\
\hline Don't know & 47 & 51 & 27 & 35 & 45 & 55 \\
\hline
\end{tabular}

- The mean Nordic score for this question was a fairly poor 3.8 but again the Finns were significantly more satisfied with the availability of age data with a mean score of 4.9. The Swedes were significantly more dissatisfied with a mean score of 2.9. 
- The percentage answering “don't know/cannot assess” in response to this question is also high with a total of $47 \%$ across the Nordic countries giving this response. Significantly more Swedes (55\%) answered that they “didn’t know/couldn’t assess” while significantly fewer Finns (27\%) answered the same.

\subsection{User rights and complaints}

\subsubsection{A summary of survey findings}

People in the Nordic region are averagely satisfied with their rights as far as dentists' services are concerned with mean scores of over 5 , but under 5.5 on all questions. Yet again Finns are the most satisfied and the Swedes the least satisfied. Again a sizeable minority in the Nordic region simply do not feel able to answer questions concerning the possibilities of comparison.

93\% of people in the Nordic region say that they have not had cause to complain though the Swedes are the most likely to have complained (3\%). In Sweden and Norway 18-29 year olds are least likely to complain.

As far as user rights are concerned in Sweden and Denmark it is the widowers who are more satisfied while younger people tend to be less satisfied.

As far as the complaints procedure goes the Danes along with the Finns are more likely to rate the possibilities for complaint higher.

If we compare perceptions about the possibilities for complaint across the three markets in the Nordic countries we see that satisfaction is average when it comes to doctors and dentists and a little better than average for day care facilities. Finns are the most satisfied with their possibilities for complaint in all three markets while Swedes are least satisfied as far as doctors are concerned and Icelanders (non significant) as far as dentists concerned. As far as day care facilities are concerned it is again the Swedes and Icelanders who are least satisfied with their opportunities for complaint.

Again we see sizeable minorities who feel incapable of answering questions about the possibilities they have for complaint across all three markets, though this is less the case for day care facilities than for the other two markets. It is the Swedes who are most likely to be unable to answer these questions when it comes to doctors and dentists.

A large majority in all three markets have not made a complaint about their doctor, dentist or child's day care facility. 


\subsubsection{Survey findings}

Figure 22: Satisfaction with existence of protection from defective dental advice/treatment ( 0 is 'to a very poor extent' and 10 is'to a great extent)

Q41: To what extent do you feel that sufficient protection from wrong or defective advice or treatment in relation to a dental visit exists? Please answer on the basis of a scale from $0-10$, where 0 is "To a very poor extent" and 10 is "To a great extent"

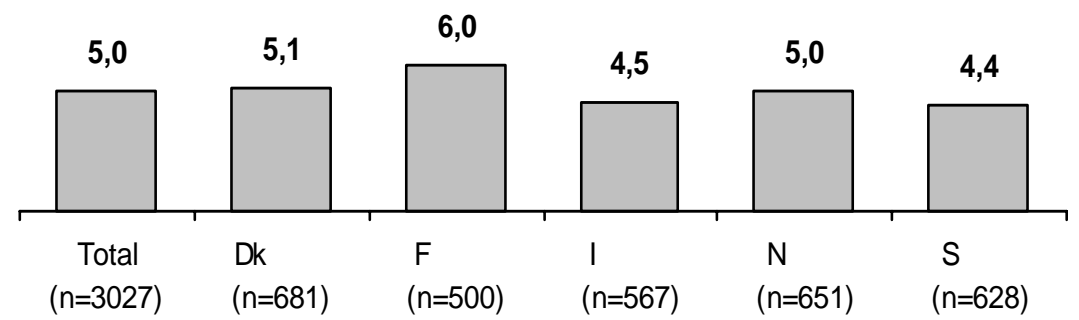

Mean value

Table 24: \% unable to assess their satisfaction with the existence of protection from defective dental advice / treatment

\begin{tabular}{ccccccc}
\hline & $\begin{array}{c}\text { Total } \\
\mathrm{N}=\mathbf{3 0 2 7}\end{array}$ & $\begin{array}{c}\text { Denmark } \\
\mathrm{N}=\mathbf{6 8 1}\end{array}$ & $\begin{array}{c}\text { Finland } \\
\mathrm{N}=500\end{array}$ & $\begin{array}{c}\text { Iceland } \\
\mathrm{N}=567\end{array}$ & $\begin{array}{c}\text { Norway } \\
\mathrm{N}=651\end{array}$ & $\begin{array}{c}\text { Sweden } \\
\mathrm{N}=6 \mathbf{6 2 8}\end{array}$ \\
\hline Don't know & 31 & 28 & 17 & 36 & 26 & 40 \\
\hline
\end{tabular}

- The mean Nordic score for this question was 5. Finns felt significantly more that they had sufficient protection from defective treatment with a mean score of 6 . However the Swedes were significantly less sure about this with a mean score of 4.4. It should be noted here that although the score was not significantly different in terms of the Nordic average, Icelanders registered a low mean score of 4.5 on this question.

- Norwegians were significantly more likely to answer that they felt they had sufficient protection against defective treatment "to a great extent” than their Nordic counterparts ( $7 \%$ versus a Nordic average of $4 \%)$

- As in earlier questions the proportion answering "Do not know/cannot assess" is relatively high. Across the Nordic countries $31 \%$ used this alternative with significantly more Swedes (40\%) and significantly fewer Norwegians (26\%) and Finns (17\%) answering that they did not feel able to answer the question.

- Although not significantly different in terms of the Nordic average, $36 \%$ of Icelanders felt unable to assess whether they have sufficient protection from defective treatment. 
- The unclear, complicated or bureaucratic procedures for complaints found in all countries may explain the large share of "Do not know"answers.

- Looking at the individual countries we see that in Sweden and Denmark widowers feel significantly more that they have sufficient protection from wrong or defective advice or treatment in relation to a dental visit.

- In Norway and Denmark people in households with 3 adults also feel significantly more that they have sufficient protection from wrong or defective advice or treatment in relation to a dental visit.

- In Sweden people between 40-49 years feel significantly less that they have sufficient protection from wrong or defective advice or treatment in relation to a dental visit while those between 60-69 years feel significantly more that they are protected.

- In Denmark those between 30-39 years feel significantly less that they have sufficient protection from wrong or defective advice or treatment in relation to a dental visit.

- In Iceland it is worth noting that 60-69 year olds, those with an income of under $€ 30.000$ and those living in households with 4 adults are more likely to feel that they have sufficient protection from defective treatment.

Figure 23: Satisfaction with the possibility for complaint about their dental treatment ( 0 is 'very poor, 10 is 'very good')

Q42: How would you assess the possibility for complaint to a complaints board about your dentist or dental treatment? A scale from 0-10, where 0 is "Very poor" and 10 is "Very good".

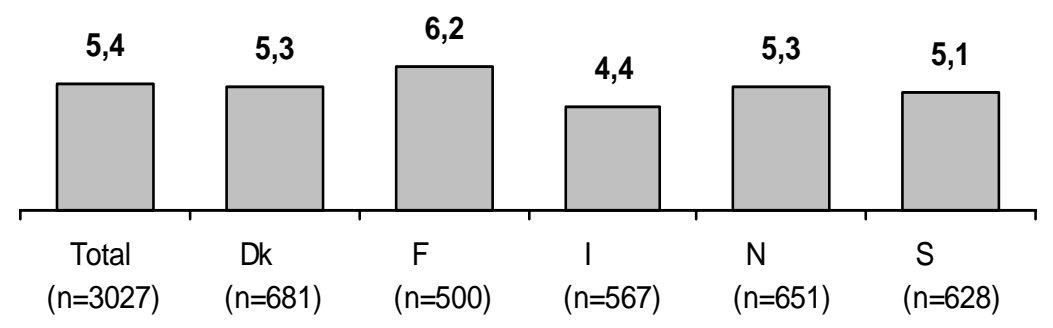

$\square$ Mean value

Table 25: \% unable to assess the possibilities for complaint about their dental treatment

\begin{tabular}{ccccccc}
\hline & $\begin{array}{c}\text { Total } \\
\mathrm{N}=\mathbf{3 0 2 7}\end{array}$ & $\begin{array}{c}\text { Denmark } \\
\mathrm{N}=\mathbf{6 8 1}\end{array}$ & $\begin{array}{c}\text { Finland } \\
\mathrm{N}=500\end{array}$ & $\begin{array}{c}\text { Iceland } \\
\mathrm{N}=567\end{array}$ & $\begin{array}{c}\text { Norway } \\
\mathrm{N}=651\end{array}$ & $\begin{array}{c}\text { Sweden } \\
\mathrm{N}=628\end{array}$ \\
\hline Don't know & 33 & 32 & 15 & 51 & 33 & 41 \\
\hline
\end{tabular}


- The mean Nordic score for this question was 5.4. Again Finns felt significantly more that they had good opportunities for complaint with a mean score of 6.2. And yet again the Swedes were significantly less sure about this with a mean score of 5.1. Here we should note that, although the score is not significant in terms of the average Nordic score, Iceland registers the lowest mean score of 4.4.

- $33 \%$ of people in the Nordic countries answered that they do not know/cannot assess. Significantly more Icelanders and Swedes feel this than their Nordic counterparts with $51 \%$ and $41 \%$ respectively stating they felt unable to answer the question. Significantly fewer Finns (15\%) felt this.

- Looking at the individual countries we see that in Sweden and Denmark widowers are significantly more satisfied with the possibility for complaint about their dentist or dental treatment together with those living in smaller towns.

- In Norway 18-29 years olds are significantly more satisfied with the possibility for complaint about their dentist or dental treatment while in Sweden 40-49 years olds are significantly less satisfied.

- In Sweden and Finland people living with their partners are significantly less satisfied with the possibility for complaint about their dentist or dental treatment.

- In Finland people living alone are significantly less satisfied with the possibility for complaint about their dentist or dental treatment while people in households with 3 adults in Sweden are significantly more satisfied.

- In Iceland 40-49 year olds rate possibilities for complaint low with a mean score of 3.6 while those living in households of three children rate them higher with a mean score of 6.0.

Figure 24: Satisfaction with the possibility for acquiring information about how to complain ( 0 is 'very poor' and $\mathbf{1 0}$ is 'very good')

Q43: How would you asses the possibilities for acquiring information about how to complain e.g. about complaint deadline, about what the complaint should include and about who you can complain to? A scale of 0-10, where 0 is "Very poor" and 10 is "Very good"

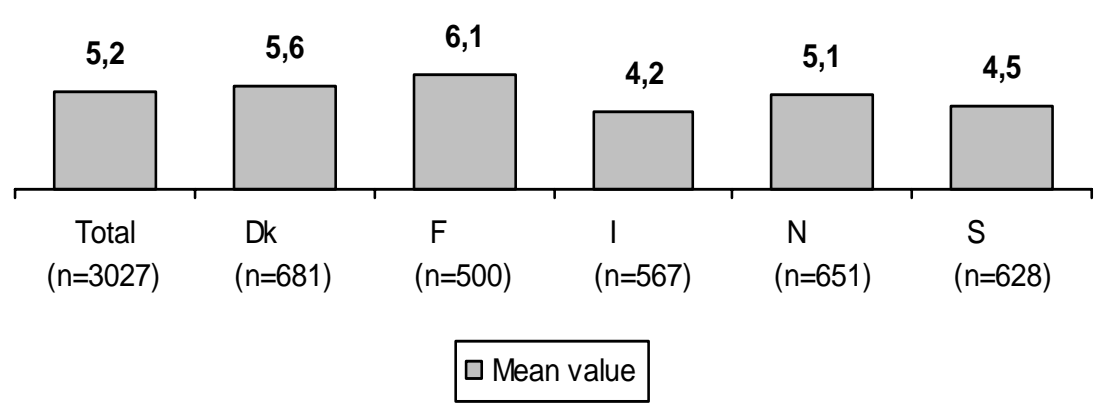


Table 26: \% unable to assess the possibilities for acquiring information about how to complain

\begin{tabular}{ccccccc}
\hline & $\begin{array}{c}\text { Total } \\
\mathrm{N}=\mathbf{3 0 2 7}\end{array}$ & $\begin{array}{c}\text { Denmark } \\
\mathrm{N}=\mathbf{6 8 1}\end{array}$ & $\begin{array}{c}\text { Finland } \\
\mathrm{N}=\mathbf{5 0 0}\end{array}$ & $\begin{array}{c}\text { Iceland } \\
\mathrm{N}=\mathbf{5 6 7}\end{array}$ & $\begin{array}{c}\text { Norway } \\
\mathbf{N}=651\end{array}$ & $\begin{array}{c}\text { Sweden } \\
\mathbf{N}=\mathbf{6 2 8}\end{array}$ \\
\hline Don't know & 29 & 26 & 15 & 37 & 27 & 39 \\
\hline
\end{tabular}

- The mean Nordic score for this question was 5.2. Again Finns felt significantly more that they had good opportunities to get information about the complaints process with a mean score of 6.1. Danes are also significantly more positive than Norwegians, Icelanders and Swedes with a mean score of 5.6. Swedes rated opportunities to get information about the complaints process significantly lower registering a mean score of 4.5 .

- We should note here that in Iceland the mean score registered was the lowest at 4.2, though this score is not significant with respect to the Nordic average.

- On average a total of $29 \%$ of people in the Nordic countries felt unable to answer this question. As before, significantly more Swedes (39\%) felt this way than people in the other Nordic countries and Finns were least likely feel this.

- Looking at the individual countries we see that in Sweden and Denmark 30-39 year olds are significantly less satisfied with the opportunities to get information about the complaints process while 50-60 year olds in Sweden are significantly more satisfied.

- In Finland 18-29 year olds are less satisfied with the opportunities to get information about the complaints process.

- In Sweden, Denmark and Finland those living with partners are significantly less satisfied with the opportunities to get information about the complaints process.

- In Sweden people living with 2 and 3 children are significantly less satisfied with the opportunities to get information about the complaints process while in Finland the same is true of those living in households with 1 child.

- In Finland married people are significantly more satisfied with the opportunities to get information about the complaints process while in Sweden the same is found for widowers.

- In Iceland it is worth noting that 60-69 year olds are more satisfied with the possibilities of gathering information pertaining to the complaints process registering a mean score of 5.9. 
Figure 25: The need to complain within the past 3 years

Q44: Have you, within the past 3 years, had the need to complain about a dentist you have consulted?

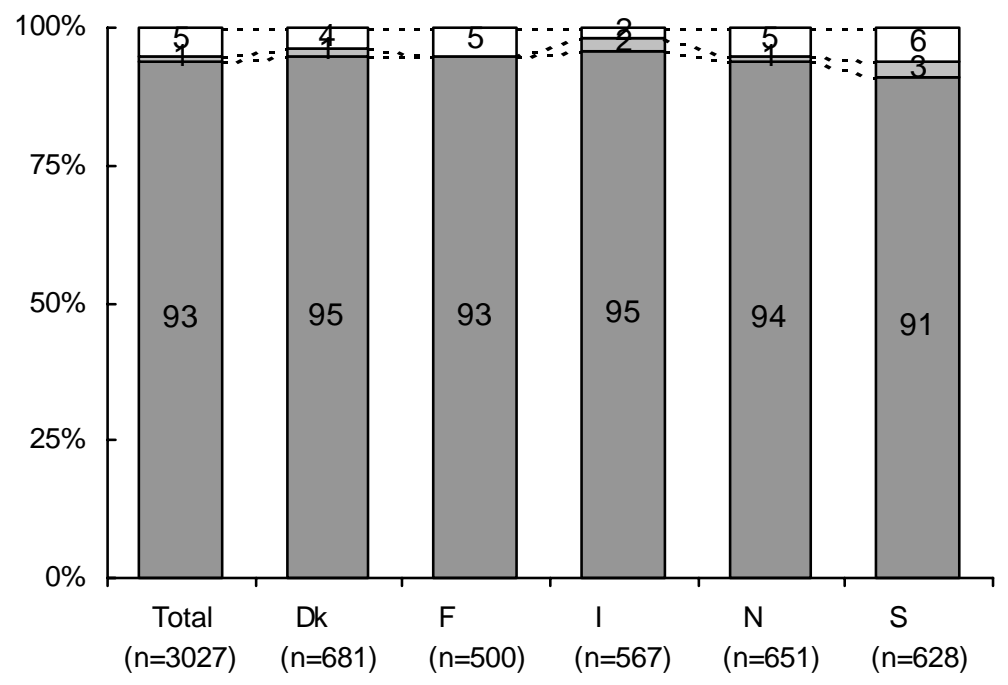

$\square$ No $\square$ Yes $\square$ Yes, felt the need, but not done it

- On average, a total of $93 \%$ of people in the Nordic countries feel that it hasn't been relevant to make a complaint during the past three years. Significantly more Danes (95\%) say it has not been relevant to make a complaint while significantly fewer Swedes (91\%) think the same.

- Significantly more Swedes had complained during the last three years (3\% versus a Nordic average of $1 \%$ ).

- Looking at the individual countries we see that in Sweden and Norway significantly fewer 18-29 year olds say they have not made a complaint; however in Norway it is this group that are significantly more likely to say that have felt the need to complain but haven't done it.

- In Finland those between 30-39 years and those between 50-50 years are significantly more likely to answer that they have not made a complaint.

- While in Sweden widowers were significantly more likely to answer that they had not made a complaint the opposite is true for widowers in Finland. 



\section{Chapter 4 - Survey: Day care for children}

\subsection{Introduction}

This chapter will look at all survey findings within the area of day care for children. Findings on a Nordic level, a country level and a market level are summarised before the findings for each area of investigation are detailed.

\subsection{Usage of day care services}

\subsubsection{A summary of survey findings}

Across the Nordic countries the most common age of the eldest child in day care is 5 years (25\%).

Most children attend a public institution (66\%) and this tendency is particularly strong in Denmark where $78 \%$ attend public institutions.

Most children have been in day care for three years or less (70\%).

In Finland single parents are more likely to send their children to a public day care facility while in Norway, Denmark and Sweden households with 3 children are more likely to do the same than households with either fewer or more children.

\subsubsection{Survey findings}

Q45: How old is your eldest child in the pre-school age?

- Looking at all the Nordic countries together, we see that the majority of the children in day care (the eldest child) are 5 - 7 years old.

- A cross the Nordic countries the most common age of the eldest child in day care is 5 years (25\%). There are a significantly lower percentage of Danish children, and a significant higher percentage of Norwegian children (34\%) that are 5 years old compared to the Nordic average.

- A significantly higher percentage of Finnish children (30\%) are 6 years, and a significantly lower percentage (2\%) are one year old compared to the other Nordic countries.

- In Iceland there are no children over the age of 6 in day care and only $10 \%$ over the age of 5 . 
Figure 26: Type of day care attended

Q46: Which kind of day care facility does the child attend?

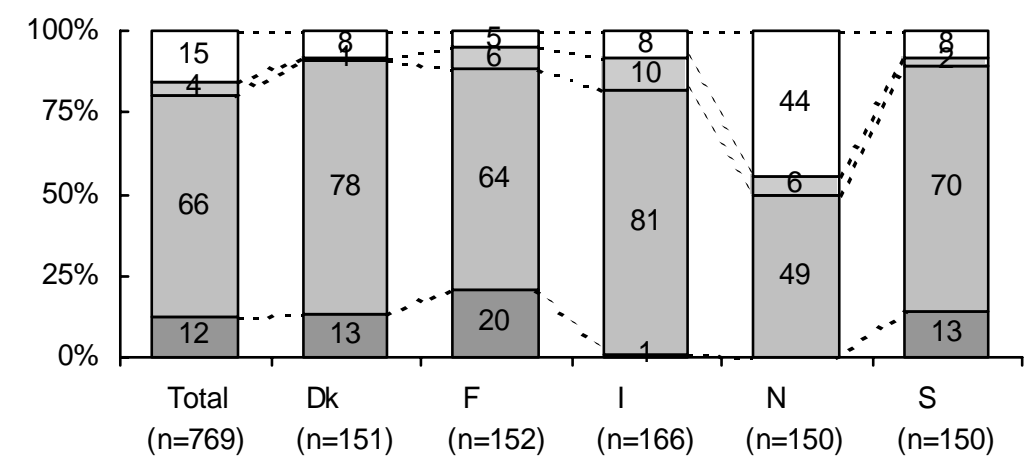

口 Private institution

Privately arranged day care with child-minder

$\checkmark$ Public institution

$\checkmark$ Publicly arranged day care with child-minder

- Looking at all the Nordic countries together the majority (66\%) of children attend a public institution.

- A significantly higher percentage of Danish children (78\%) attend a public institution, whereas a significantly lower percentage attend private institutions and privately arranged day dare with child minders compared to the other Nordic countries.

- In Sweden, a significantly lower percentage attends a private institution compared to the other Nordic countries.

- In Norway a significantly lower percentage attends a public institution, whereas a significantly higher percentage attends a private institution compared to the other Nordic countries.

- In Finland, a significantly higher percentage attends publicly arranged day care with a childminder, and a significantly lower percentage attends a private institution compared to the other Nordic countries.

- For Iceland it is worth noting that $81 \%$ of children attend a public institution, though this score is not significant in terms of the Nordic average.

- 40-49 year old in Sweden are significantly more likely than the other age groups to enrol their child in a private day care facility.

- Danes living in smaller towns are significantly less likely to send their children to private day care facilities.

- Finns living in metropolitan areas are significantly less likely to enrol their child in a publicly funded day care facility with childminder than those living in villages or in the countryside.

- In Finland, children of single parents are significantly more likely to attend a public day care facility.

- Norwegians that live in a metropolitan area or in larger provincial towns are significantly less likely to enrol their child in a public day care facility. 
- Households in Norway, Denmark and Sweden with 3 children are significantly more likely to enroll their child in a public day care facility.

Figure 27: Length of usage of current day care facility

Q47: How long has the child been using the current day facility?

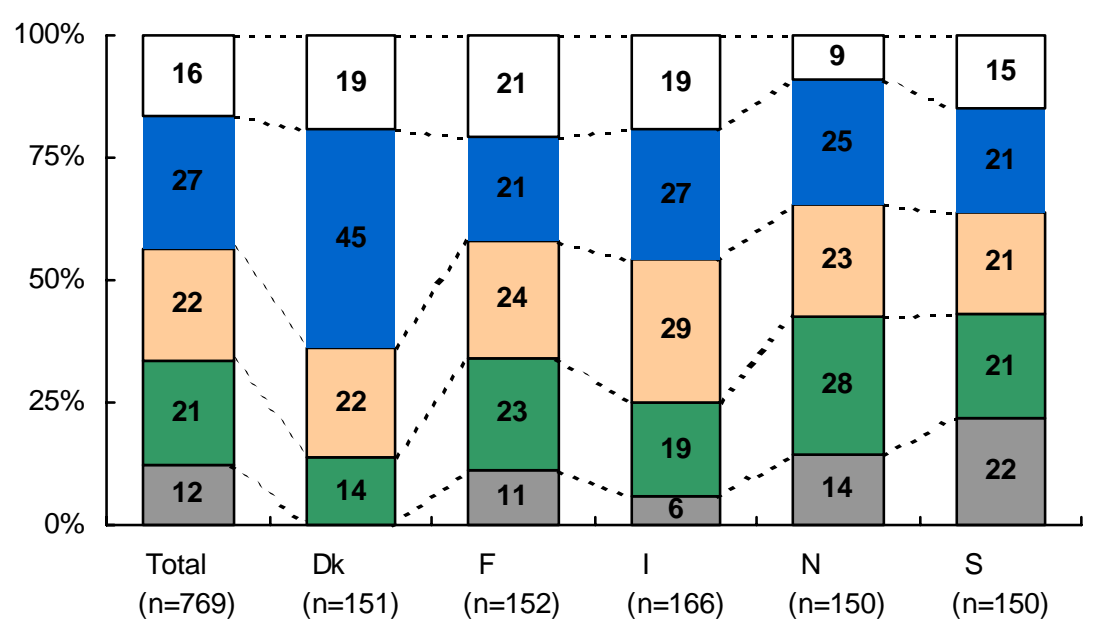

$$
\square 4 \text { yearst } \square 3 \text { years } \square 2 \text { years } \square 1 \text { year } \square 0 \text {-11 months }
$$

- Looking at all the Nordic countries, the majority of the children have been using the current day care facility for 3 years or less (70\%), and more have been using the current day care facility for 1 year (27\%), than 2 years (22\%) or 3 years (21\%).

- In Denmark, a significantly higher percentage of children have been using the current day care facility for 1 year, and a significantly lower percentage have been using it for 3 years than the other Nordic countries. The Danish system with strict age defined options may explain this finding.

- A significantly higher percentage of Swedish children have been using the current day care facility for 4 years, and a significantly lower percentage of Norwegian children have been using the current day care facility for less than 1 year.

- Although not significant in terms of the Nordic average, it is worth noting that in Iceland only $6 \%$ of children have been in day care for 4 years or more against a Nordic average of $12 \%$. This may be due to a need for stability as there is a very high proportion of double working parents in Iceland. 


\subsection{User motives and information gathering}

\subsubsection{A summary of survey findings}

Across the Nordic countries "location" is the most common reason for choosing the current day care facility. Other key reasons were, "Only day care facility with available places" which was particularly mentioned in Norway, "Safe setting" and "Recommended by friends", the latter being particularly mentioned by Danes.

$61 \%$ of people in the Nordic region collected information before their child first attended their current day care facility. Of these almost one half (48\%) spoke to family and friends, while just over one quarter contacted public authorities for information. Danes were the most likely to contact several day care facilities for information.

The most common reason for not gathering information prior to a child attending the day care facility was "other" reasons.

People living in metropolitan areas in Norway and Finland are more likely to mention "location" as a reason for choosing their current day care facility.

In Norway 18-29 year olds and those living in metropolitan areas are more likely to gather information on day care facilities.

In Sweden people between 40-49 years were significantly more likely to have contacted several day care facilities in order to gain information while in both Finland and Norway people between 40-49 years were significantly less likely to have contacted public authorities in order to gain information.

In Denmark those living in larger provincial towns and those living with 2 children in the household are more likely to have contacted public authorities.

If we compare motives for choice of provider and user information gathering patterns across the markets in the Nordic region we see that location and recommendations from either friends or from professionals was also an important reason for choice of provider for all three markets. However it should be noted that the most popular reason for choice of doctor (given by $17 \%$ of people) was "by chance".

Most people did not gather information about different doctors and dentists; however $61 \%$ did gather information about different day care facilities. For people who did gather information most cited friends and family as their main source of information in all three markets. Not surprisingly, the fact that they had a recommendation was the main reason cited for not gathering information about different doctors and dentists before choice. However when it came to day care provider "other" reasons were most cited when people were asked why they did not gather information. 


\subsubsection{Survey findings}

Table 27: Primary reasons for choosing current day care facility, $\%$ answering

Q48: What is the primary reason for choosing your current day care facility for your child?

\begin{tabular}{|c|c|c|c|c|c|c|}
\hline & $\begin{array}{r}\text { Total } \\
\mathrm{N}=769\end{array}$ & $\begin{array}{r}\text { Denmark } \\
\mathrm{N}=151\end{array}$ & $\begin{array}{l}\text { Finland } \\
\mathrm{N}=152\end{array}$ & $\begin{array}{l}\begin{array}{l}\text { Iceland } \\
\mathrm{N}=166\end{array}\end{array}$ & $\begin{array}{r}\text { Norway } \\
\mathrm{N}=150\end{array}$ & $\begin{array}{r}\text { Sweden } \\
\mathrm{N}=150\end{array}$ \\
\hline Location & 34 & 26 & 37 & 35 & 28 & 39 \\
\hline Only day care facility with available & & & & & & \\
\hline places for new children & 11 & 11 & 8 & 15 & 18 & 8 \\
\hline Safe settings/secure surroundings & 9 & 9 & 6 & 4 & 15 & 9 \\
\hline Recommended by friends & 8 & 14 & 8 & 9 & 4 & 9 \\
\hline $\begin{array}{l}\text { The facility has been used by the child's } \\
\text { siblings }\end{array}$ & 6 & 6 & 8 & 3 & 4 & 6 \\
\hline $\begin{array}{l}\text { Could not choose from different day care } \\
\text { facilities }\end{array}$ & 6 & 9 & 4 & 13 & 8 & 4 \\
\hline Knowledge/esperience & 5 & 4 & 9 & 1 & 4 & 3 \\
\hline Recommended by pedagogical experts & 4 & 2 & 4 & 1 & 7 & 3 \\
\hline By chance & 4 & 1 & 5 & 1 & 7 & 3 \\
\hline $\begin{array}{l}\text { The educationalist's personal data } \\
\text { (sex, age etc.) }\end{array}$ & 2 & 4 & 1 & 4 & 1 & 3 \\
\hline Suggested by the public authorities & 2 & 4 & 2 & 1 & 0 & 3 \\
\hline Attached to the school & 2 & 3 & 2 & 0 & 0 & 2 \\
\hline Good opening hours & 1 & 3 & 2 & 0 & 0 & 0 \\
\hline Size & 1 & 1 & 2 & 1 & 0 & 1 \\
\hline Price & 0 & 0 & 0 & 5 & 1 & 0 \\
\hline Other & 5 & 3 & 11 & 8 & 5 & 3 \\
\hline Don't know/don't remember & 0 & 0 & 0 & 0 & 1 & 0 \\
\hline
\end{tabular}

- Across the Nordic countries "Location" is the most common reason for choosing the current day care facility (34\%). Other reasons that are common are "Only day care facility with available places for new children” (11\%), "Safe settings/ secure surroundings” (9\%), and "Recommended by friends" (8\%).

- A significantly lower percentage of Danes (26\%) answer that the primary reason for choosing day care was "Location" compared with the other Nordic countries (34\%), whereas a significantly higher percentage (14\%) of Danes answered "Recommended by friends" compared to the other Nordic countries (8\%).

- In Norway, a significantly higher percentage (18\%) say that "Only day care facility with available places for new children" was the primary reason for choosing the current day care facility compared with the other Nordic countries (11\%). Limits in choice and long waiting lists in parts of Norway may explain this.

- It is also worth noting that a total of $26 \%$ in Norway said that they either could not choose from different day care facilities (8\%) or that their current day care was the only one with available places (18\%), although these scores are not significantly different in terms of the Nordic countries as a whole. 
- Looking at the individual countries it is significantly less likely that 40-49 year olds in Norway and Denmark base their choice of current day care facility on "safe settings".

- In Finland and Norway it is people living in metropolitan areas who are significantly more likely to have based their choice of current day care facility on "location".

- Swedes living in metropolitan areas are significantly less likely to consider "location" as the primary reason for their decision, but those that live in larger provincial towns are significantly more likely to consider "location" as the primary reason for their choice of day care facility.

Figure 28: \% gathering information prior to choosing the current day care facility Q49: Did you gather information on various day care facilities before your child attended the current day care facility?

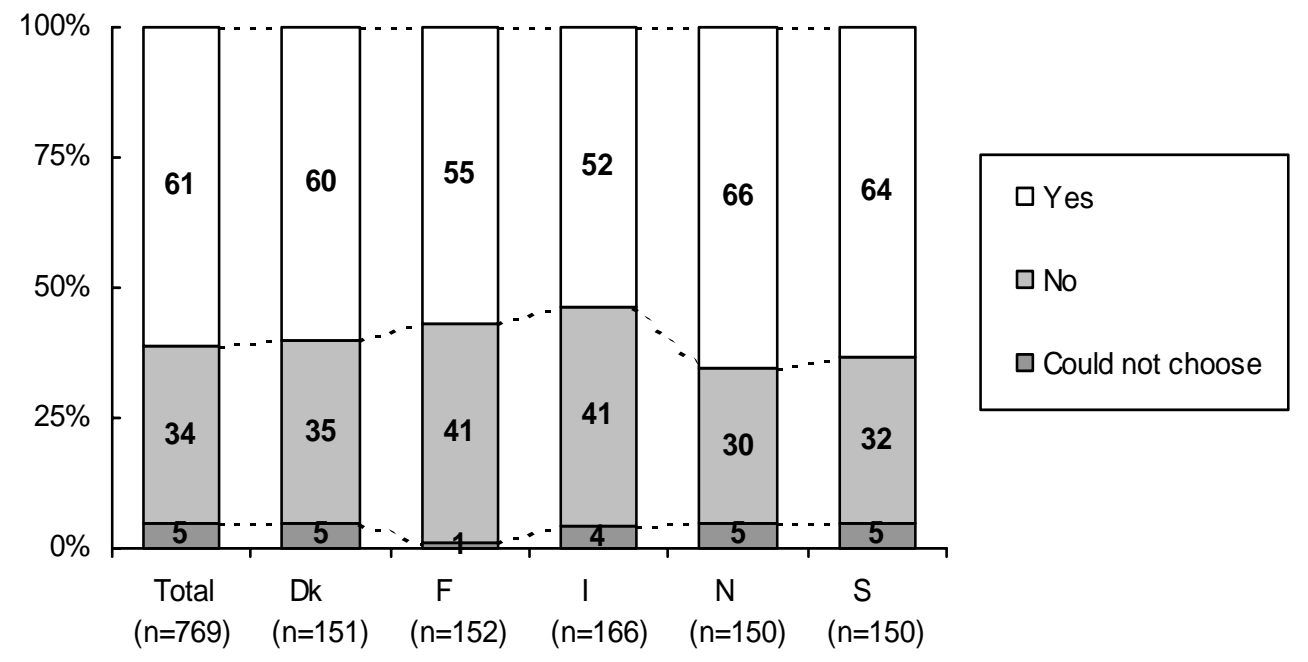

- A total of $61 \%$ gathered information on various day care facilities before the child attended the current day care facility across the Nordic countries.

- There are no significant differences between the countries included in the study, though we can see indications that there is more of a tendency to gather information in Norway and Sweden than in Finland and particularly than in Iceland.

- If we look at the individual countries, we see that in Norway people between 18-29 years are significantly more likely to have gathered information on various day care facilities.

- In Finland people that live in a household with a total income over $€ 65.000$ are significantly more likely to have gathered information; while in Norway it is significantly more likely that people with a household income of between €30.000-65.000 do not gather information. 
- In Norway people living in metropolitan areas are significantly more likely to have gathered information, whereas in Sweden those who live in middle sized provincial towns are significantly more likely to have gathered information beforehand.

Table 28: Sources of information about day care facilities, \% answering - more than one answer allowed

Q50: Which sources did you use to get information about the different day care facilities?

\begin{tabular}{|c|c|c|c|c|c|c|}
\hline & $\begin{array}{r}\text { Total } \\
\mathrm{N}=447\end{array}$ & $\begin{array}{r}\text { Denmark } \\
\mathrm{N}=87\end{array}$ & $\begin{array}{l}\text { Finland } \\
\qquad \mathrm{N}=84\end{array}$ & $\begin{array}{r}\begin{array}{r}\text { Iceland } \\
\mathrm{N}=85\end{array}\end{array}$ & $\begin{array}{r}\text { Norway } \\
\mathrm{N}=94\end{array}$ & $\begin{array}{r}\text { Sweden } \\
\mathrm{N}=97\end{array}$ \\
\hline Spoke to family/friends & 48 & 46 & 52 & 43 & 44 & 48 \\
\hline $\begin{array}{l}\text { Contacted public authorities and } \\
\text { gained information }\end{array}$ & 28 & 33 & 23 & 35 & 32 & 25 \\
\hline Surfed the internet & 22 & 27 & 18 & 19 & 27 & 19 \\
\hline $\begin{array}{l}\text { Contacted several day care facilities } \\
\text { for information }\end{array}$ & 18 & 26 & 16 & 17 & 13 & 17 \\
\hline $\begin{array}{l}\text { Contacted one day care facility for } \\
\text { information }\end{array}$ & 8 & 2 & 13 & 6 & 4 & 12 \\
\hline $\begin{array}{l}\text { Received information without asking } \\
\text { for it }\end{array}$ & 6 & 3 & 12 & 1 & 5 & 6 \\
\hline Read article in newspaper/magazine & 3 & 0 & 4 & 0 & 4 & 4 \\
\hline $\begin{array}{l}\text { Saw advertising in phone book/ } \\
\text { newspaper/magazine }\end{array}$ & 2 & 2 & 1 & 1 & 2 & 3 \\
\hline Other & 11 & 8 & 10 & 2 & 3 & 19 \\
\hline Don't know/don't remember & 2 & 4 & 1 & 3 & 3 & 1 \\
\hline
\end{tabular}

- Across the Nordic countries more people spoke to family and friends (48\%) to gain information about the different day care facilities than any other source.

- "Contacted public authorities and gained information" (28\%), "surfed the internet” (22\%), and "Contacted several day care facilities and gained information" (18\%) were also common answers.

- In Denmark, a significantly higher percentage (26\%) answered "Contacted several day care facilities and gained information" than the other Nordic countries as a whole (18\%).

- It is also worth noting that $35 \%$ of Icelanders said that they contacted public authorities for information, though this is not a significant percentage in terms of the Nordic average.

- In Finland people between 18-29 years were more likely to have surfed the internet in order to gain information.

- In Sweden people between 40-49 years were significantly more likely to have contacted several day care facilities in order to gain information while in both Finland and Norway people between 40-49 years were significantly less likely to have contacted public authorities in order to gain information.

- In Sweden people living in households that have an income over $€ 65,000$ and those living in larger provincial towns were significantly more likely to have contacted one day care facility in order to gain information. 
- In Denmark those who live in larger provincial towns are significantly more likely to have contacted public authorities in order to gain information.

- Danes living with 2 children in their household and Swedes living with 1 child are significantly more likely to have contacted public authorities.

Table 29: Reasons for not gathering prior information about day care facilities - more than answer allowed, \% answering

Q51: What is the reason for not gathering information on various day care facilities prior to choosing the day care facility your child is attending?

\begin{tabular}{|c|c|c|c|c|c|c|}
\hline & $\begin{array}{r}\text { Total } \\
\mathrm{N}=\mathbf{2 8 3}\end{array}$ & $\begin{array}{r}\text { Denmark } \\
N=58\end{array}$ & $\begin{array}{r}\text { Finland } \\
\qquad N=64\end{array}$ & $\begin{array}{r}\text { Iceland } \\
\mathrm{N}=67\end{array}$ & $\begin{array}{r}\text { Norway } \\
\mathrm{N}=47\end{array}$ & $\begin{array}{r}\text { Sweden } \\
\mathrm{N}=47\end{array}$ \\
\hline $\begin{array}{l}\text { I have good experiences with the day care } \\
\text { facility }\end{array}$ & 21 & 29 & 21 & 16 & 27 & 13 \\
\hline $\begin{array}{l}\text { Could not choose from different day care } \\
\text { facilities }\end{array}$ & 18 & 14 & 10 & 28 & 18 & 27 \\
\hline $\begin{array}{l}\text { The day care facility is the only one close } \\
\text { to my home/work }\end{array}$ & 14 & 10 & 17 & 27 & 16 & 12 \\
\hline $\begin{array}{l}\text { Did not want to spend time gathering the } \\
\text { information }\end{array}$ & 11 & 10 & 10 & 7 & 17 & 11 \\
\hline $\begin{array}{l}\text { Other friends/relatives had recommended } \\
\text { the day care facility }\end{array}$ & 9 & 8 & 18 & 12 & 8 & 2 \\
\hline $\begin{array}{l}\text { Recommendation from pedagogical } \\
\text { personnel }\end{array}$ & 4 & 3 & 0 & 0 & 13 & 1 \\
\hline Difficult to find information & 3 & 0 & 4 & 2 & 4 & 2 \\
\hline Other & 26 & 30 & 23 & 17 & 5 & 37 \\
\hline Don't know/don't remember & 1 & 0 & 0 & 7 & 0 & 0 \\
\hline
\end{tabular}

- Across the Nordic countries more people answered “Other” (26\%) than the other alternatives such as "I have good experience with the day care facility" (21\%), "Could not choose from different day care facilities" (18\%), or "Did not want to spend tine gathering the information” (11\%).

- In Norway, only 5\% answered "Other”, which is a significantly lower percentage than all the Nordic countries as a whole.

- In Finland, a significantly higher percentage (13\%) answered that "Pedagogical personnel had recommended the day care facility" compared to the Nordic countries as a whole (4\%).

- We can see that in Sweden and Iceland 27\% and 28\% respectively gave the fact that they had no choice of day care facility as a reason for not gathering information. Though interesting, these percentages are not significantly different in terms of the Nordic average.

- $27 \%$ of Icelanders also give the fact that the day care facility was the only one close to their home as a reason for not gathering information. Again this percentage is not significantly different in terms of the Nordic average.

- Looking at the individual countries both in Finland and Denmark people who live in smaller towns are significantly less likely to have had a good experience with the day care facility. 


\subsection{User satisfaction}

\subsubsection{A summary of survey findings}

People in the Nordic region are satisfied with the possibility for acquiring information about day care (mean score of 6.9) and very satisfied with the total offer provided by their child's day care facility (mean score of 8.29). Danes are the least satisfied with the total offer.

In Sweden 18-29 year olds and those with an income under $€ 30.000$ are more likely to be satisfied with the general offer.

Danish 18-29 year olds are less likely to be satisfied with the general offer.

If we compare satisfaction with the possibility for acquiring information about doctors, dentists and day care facility across the Nordic region we see that satisfaction is greatest with day care facilities with mean scores of over 7 in all countries except Sweden. Doctors scored over average while satisfaction with dentists was just a little better than average.

Satisfaction with total service scored high in all three markets.

\subsubsection{Survey findings}

Figure 29: Satisfaction with possibilities for acquiring general information ( 0 is 'not at all satisfied', 10 is 'very satisfied')

Q52: Based on all your experiences, how satisfied are you with the possibilities for acquiring general information about day care facilities for your child?

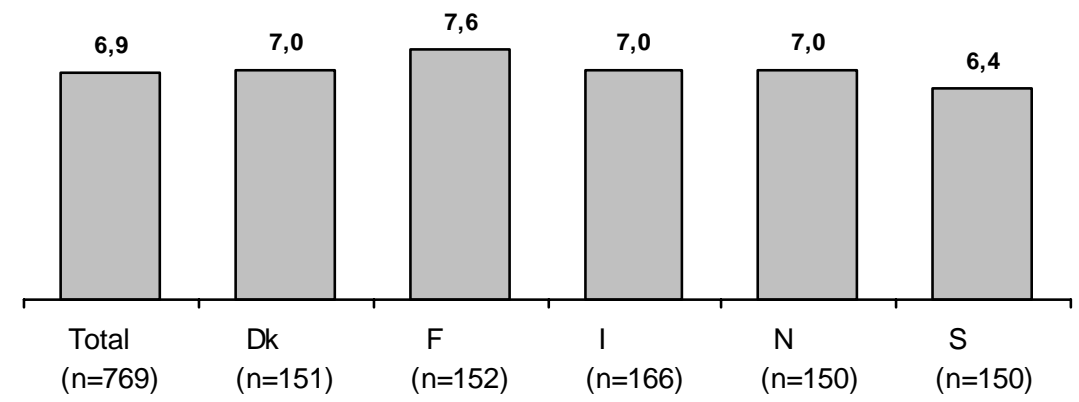

$\square$ Mean value

- Over all it seems that people in the Nordic Countries are more satisfied than dissatisfied with the possibilities for acquiring general information on day care facilities for their children with a mean Nordic score of 6.9.

- Finns were significantly more satisfied than their Nordic counterparts with a mean score of 7.6. 
- Swedes were significantly less satisfied than their Nordic counterparts with a mean score of 6.4 .

- When looking at the individual countries, Norwegian men are significantly less likely to be satisfied with the possibilities for acquiring general information on day care facilities than Norwegian women.

- In Finland, people between 50-59 years are significantly less likely to be satisfied, whereas in Norway people between 18-29 years and those over 60 are significantly more likely to be satisfied.

- In Finland, widowers were significantly more likely to be satisfied.

- Norwegians living in middle sized provincial towns and Swedes that live in larger provincial towns are significantly more likely to be satisfied.

Figure 30: Satisfaction in general with current day care facility ( 0 is 'not at all satisfied' and 10 is 'very satisfied')

Q53: On a scale from 0-10, where 0 is "not at all satisfied" and 10 is "very satisfied", how satisfied are/were you with your child's day care facility generally speaking?

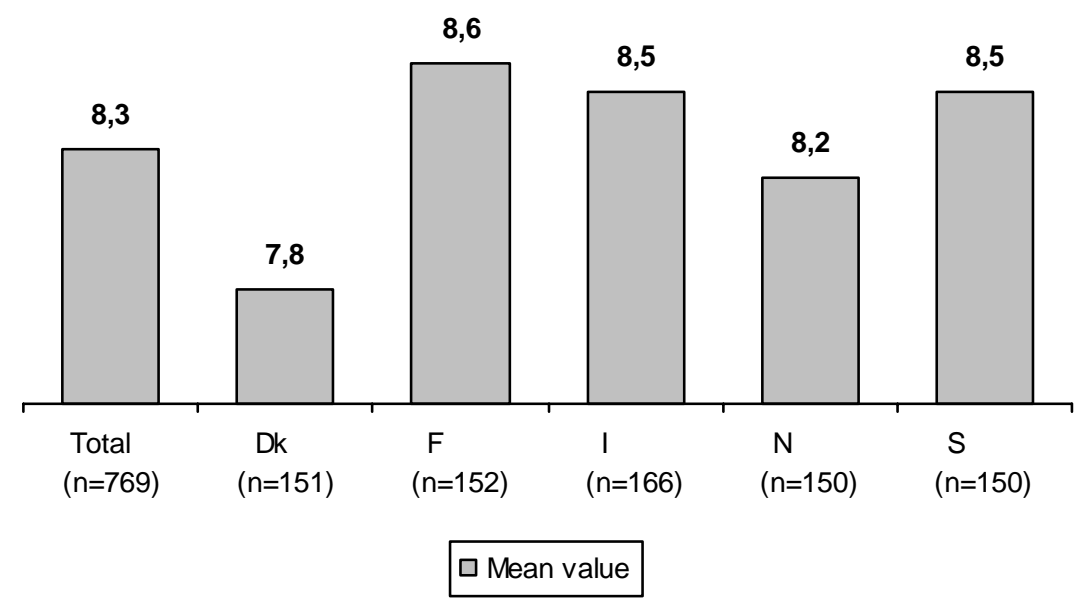

- Over all it seems that people in the Nordic Countries are mostly satisfied with their child's day care facility. The mean score for all countries was 8.3.

- Danes were significantly less satisfied than their Nordic counterparts, but were still pretty satisfied registering a mean score of 7.8. Finns were significantly more satisfied registering a mean score of 8.6.

- In Denmark significantly less people (18\%) were "very satisfied” than in the other Nordic countries (26\%).

- When looking at the individual countries, Danes between 18-29 years are significantly less likely to be satisfied, while in Sweden the same group are significantly more likely to be satisfied.

- In Sweden people with a total household income under $€ 30.000$ are significantly more likely to be satisfied. 
- In Norway, people who live in smaller towns are significantly more likely to be satisfied, whereas the same group in Sweden are significantly less likely to be satisfied. People living in larger provincial towns in Norway are significantly more likely to be satisfied.

\subsection{Change of day care services}

\subsubsection{A summary of survey findings}

$70 \%$ of people in the Nordic countries as a whole have not changed the day care facility of their eldest child. The Danes are the most likely to have either changed or considered changing their eldest child's day care facility.

The most mentioned reason across the Nordic countries for a change of day care facility was "wanting another location" though 3 out of 10 gave "other" reasons" for a change. 4 out of 10 Danes who had either changed or considered changing day care facility said it was because they "changed to a day care facility for older children".

Over one half (56\%) of those who had not considered changing said this was because they were satisfied with the current facility. Other important reasons for keeping their current day care facility were "safe setting”, "my child has many friends in day care" and "convenient location".

In Sweden it is those households with an income of under $€ 30.000$ and those living in households of 1 adult who are significantly less likely to have considered changing their day care facility.

18-29 year olds in Finland and 40-49 year olds in Sweden are more likely to cite satisfaction as a reason for keeping their child in the current day care facility.

Swedes between 30-39 years and single Danes are most likely to mention the need to have to build up a relationship with a new day care facility as a reason for keeping their child in the current day care facility.

If we compare how often people change their provider across the three markets in the Nordic region we see that $70 \%$ or more have neither considered changing or have changed provider in all three markets. More people have considered changing their child's day care facility than have considered changing either their doctor or dentist.

For those who have either changed or considered changing provider relocation was an important reason in all three markets, together with concerns about quality of (and dissatisfaction with) the service; satisfaction was the main reason for staying with their current provider in all three markets. 


\subsubsection{Survey findings}

Figure 31: \% who have changed or considered changing their child's day care

Q54: Have you changed or considered changing the day care facility of your eldest child within the past three years?

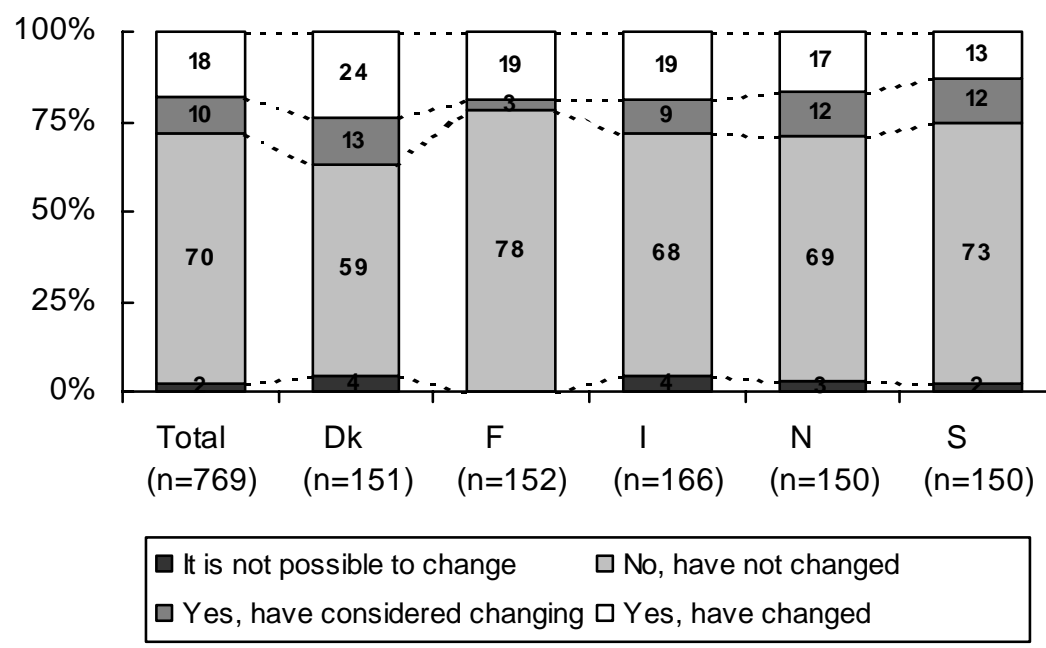

- $70 \%$ in total across the Nordic countries have not changed the day care facility of the eldest child within the past three years.

- In Denmark, a significantly lower percentage (59\%) has not changed, whereas in Finland a significantly higher percentage (78\%) has not changed compared to the average for the Nordic countries. The fragmented Danish market found in the desk research may explain this. This is backed up in the next question where we will see that significantly more Danes give the age of their child as a reason for a change of day care facility.

- In Finland, a significantly lower percentage (3\%) answered that they have considered changing compared to the average for the Nordic countries.

- In Sweden people living in households with an income of under $€ 30.000$ are significantly more likely to have not considered changing their child's day care facility.

- In Norway people living in smaller towns are significantly more likely to have not considered changing their child's day care facility.

- In Sweden households with one adult are significantly more likely to have not considered changing their child's day care facility. 
Table 30: The most important reasons for change or consideration of change, $\%$ answering - more than one answer allowed

Q55: What are the three most important reasons for your change or consideration of change of day care facility?

\begin{tabular}{|c|c|c|c|c|c|c|}
\hline & $\begin{array}{r}\text { Total } \\
\mathrm{N}=217\end{array}$ & $\begin{array}{r}\text { Denmark } \\
\mathrm{N}=56\end{array}$ & $\begin{array}{l}\text { Finland } \\
\qquad \mathrm{N}=33\end{array}$ & $\begin{array}{l}\text { Iceland } \\
\mathrm{N}=47\end{array}$ & $\begin{array}{r}\text { Norway } \\
\mathrm{N}=43\end{array}$ & $\begin{array}{r}\text { Sweden } \\
\mathrm{N}=\mathbf{3 8}\end{array}$ \\
\hline $\begin{array}{l}\text { Want different location (e.g. due to own } \\
\text { removal or new job) }\end{array}$ & 33 & 33 & 22 & 56 & 43 & 31 \\
\hline $\begin{array}{l}\text { My child was older and changed to a day } \\
\text { care facility for older children }\end{array}$ & 18 & 41 & 6 & 18 & 16 & 4 \\
\hline $\begin{array}{l}\text { Lack of trust in educational personnel in } \\
\text { former day care facility }\end{array}$ & 10 & 12 & 5 & 11 & 10 & 10 \\
\hline $\begin{array}{l}\text { Dissatisfied with information/service from } \\
\text { former day care facility }\end{array}$ & 7 & 7 & 7 & 8 & 4 & 8 \\
\hline $\begin{array}{l}\text { Former day care facility has changed } \\
\text { (moved/closed/new personnel) }\end{array}$ & 6 & 5 & 9 & 8 & 9 & 3 \\
\hline Unsafe settings/insecure surroundings & 5 & 4 & 5 & 2 & 4 & 7 \\
\hline $\begin{array}{l}\text { A wish for a facility applying a certain } \\
\text { pedagogy }\end{array}$ & 4 & 2 & 2 & 2 & 16 & 0 \\
\hline A wish for different opening hours & 4 & 0 & 2 & 2 & 17 & 0 \\
\hline My child was not comfortable & 4 & 11 & 2 & 6 & 0 & 2 \\
\hline Price & 2 & 0 & 5 & 2 & 3 & 2 \\
\hline $\begin{array}{l}\text { Too many children at the current day } \\
\text { care facility }\end{array}$ & 2 & 1 & 5 & 0 & 3 & 2 \\
\hline Recommendation from others & 1 & 0 & 7 & 0 & 0 & 0 \\
\hline $\begin{array}{l}\text { Too few children at the current day care } \\
\text { facility }\end{array}$ & 1 & 2 & 0 & 5 & 0 & 0 \\
\hline Other & 30 & 17 & 49 & 9 & & 53 \\
\hline Don't know/don't remember & 0 & 0 & 0 & 0 & 0 & 0 \\
\hline
\end{tabular}

- Across the five countries the most mentioned reasons for changing or considering changing a child's day care facility are: "We want different location" (33\%) or "Other" (30\%).

- A significantly higher percentage of Swedes (53\%) and Finns (49\%), and a significantly lower percentage of Danes (17\%) answered "Other" as one of the three most important reasons compared to the average of the Nordic countries.

- The third most common answer across the Nordic countries was "My child was older and changed to a day care facility for older children" (18\%).

- A significantly higher proportion of Danes (41\%), and a significantly lower proportion of Swedes (4\%) and Finns (6\%), gave "My child was older and changed to a day care facility for older children" as a reason for change than was average for the Nordic countries.

- Other differences between the countries worth noting are that significantly more Norwegians put "A wish for a day care facility applying a certain pedagogy" (16\% vs. the Nordic average of $4 \%$ ), and "A wish for different opening hours" ( $17 \%$ vs. a Nordic average of $4 \%$ ) as one of the three most important reasons for their change or consideration of change of day care facility.

- It is also worth noting that in Iceland 56\% said they had either considered changing or had changed their child's day care facility 
because of their own relocation. This percentage is not significantly different in terms of the Nordic countries as a whole.

Table 31: Three most important reasons for keeping child in current facility, $\%$ answering - more than one answer allowed

Q56: What are the three most important reasons for you keeping your child in the current day care facility?

\begin{tabular}{|c|c|c|c|c|c|c|}
\hline & $\begin{array}{r}\text { Total } \\
\mathrm{N}=605\end{array}$ & $\begin{array}{r}\text { Denmark } \\
\mathrm{N}=110\end{array}$ & $\begin{array}{r}\text { Finland } \\
\mathrm{N}=124\end{array}$ & $\begin{array}{r}\text { Iceland } \\
\mathrm{N}=127\end{array}$ & $\begin{array}{r}\text { Norway } \\
\mathrm{N}=118\end{array}$ & $\begin{array}{r}\text { Sweden } \\
\mathrm{N}=126\end{array}$ \\
\hline Satisfied with the current day care facility & 56 & 67 & 64 & 73 & 55 & 46 \\
\hline Safe settings/secure surroundings & 24 & 31 & 14 & 21 & 30 & 23 \\
\hline $\begin{array}{l}\text { My child has many friends in the current } \\
\text { day care facility }\end{array}$ & 23 & 27 & 23 & 22 & 23 & 22 \\
\hline $\begin{array}{l}\text { Have to built up personal relationship } \\
\text { between education personnel and child } \\
\text { again if change }\end{array}$ & 15 & 10 & 10 & 10 & 19 & 19 \\
\hline Other day care facilities are far away & 6 & 6 & 5 & 3 & 8 & $\theta$ \\
\hline It is not possible to change & 5 & 3 & 7 & 5 & 9 & 3 \\
\hline $\begin{array}{l}\text { The day care facility is the only one } \\
\text { nearby }\end{array}$ & 3 & 3 & 3 & 5 & 4 & 2 \\
\hline Difficult to find information on other day & 1 & 1 & 1 & 1 & 1 & 1 \\
\hline Difficult/bureaucratic to change & $\begin{array}{l}1 \\
1\end{array}$ & $\begin{array}{l}1 \\
2\end{array}$ & $\begin{array}{l}1 \\
1\end{array}$ & $\begin{array}{l}1 \\
1\end{array}$ & $\begin{array}{l}1 \\
1\end{array}$ & 1 \\
\hline Have not had the time & 1 & 1 & 3 & 0 & 0 & 0 \\
\hline Waiting time at the facility I want & 1 & 1 & 1 & 1 & 3 & 0 \\
\hline Afraid of child having difficulties adjusting & 1 & 1 & 2 & 1 & 1 & 1 \\
\hline Money - cannot afford to change & 1 & 0 & 2 & 2 & 3 & 0 \\
\hline Other & 18 & 15 & 18 & 11 & 4 & 28 \\
\hline Don't know/don't remember & 1 & 0 & 0 & 0 & 3 & 0 \\
\hline
\end{tabular}

- Across the Nordic countries the majority (56\%) gave "Satisfied with the current day care facility" as one of the three most important reasons for keeping their child in the current day care facility.

- A significantly higher percentage of Danes (67\%) and Finns (64\%) answered that they are satisfied with the current day care facility, whereas a significantly lower percentage of Swedes answered the same compared to their Nordic counterparts.

- It should be noted that $73 \%$ of Icelanders said one of the most important reasons for their child staying in their current day care facility was satisfaction with that facility. However this percentage is not significantly different in terms of the Nordic countries as a whole.

- Other common answers for keeping the child in the current day care facility across the Nordic countries are: "Safe settings/ secure surroundings" (24\%), "My child has many friends in the current day care facility" (23\%), and "The day care facility has the most convenient location” (20\%).

- A significantly higher percentage of Danes (31\%) answered "Safe settings/ secure surroundings" than the Nordic average (23\%), whereas a significantly lower percentage of Finns (14\%) answered the same. 
- In Denmark and Finland significantly fewer answered "The day care facility has the most convenient location" (12\% and 14\%), whereas significantly more (26\%) answered the same in Sweden.

- Looking at the individual countries people between 18-29 years in Finland are significantly more likely to keep their child in the current day care facility because they are satisfied.

- In Sweden people between 30-39 years are significantly less likely to cite satisfaction with the current day care facility as a reason for staying with the facility and significantly more likely to mention the fact that changing would entail having to build up a new relationship in a new day care facility and that their child has many friends in the current day care facility.

- Swedes between 40-49 years are significantly more likely to keep their child in the current day care facility because they are satisfied and significantly less likely to do so because of convenient location.

- Danes who live with a partner are significantly less likely to keep their child in the current day care facility because of "safe setting" or "convenient location".

- Single Danes are significantly more likely to keep their child in the current day care facility because a change would mean "building up a new relationship" and because of "convenient location".

- People who live in larger provincial towns in Denmark are significantly more likely to base their decision on "safe settings".

- Finns who live in metropolitan areas are significantly less likely to keep their child at the current facility because their child has many friends in the current day care facility, whereas in Sweden this applies for people who live in smaller towns.

- Swedish households with just one adult in the household are significantly more likely to base their decision on convenient location.

\subsection{Possibilities of comparison and information}

\subsubsection{A summary of survey findings}

Overall, people in the Nordic region rate the possibilities for comparison of day care service as quite good; mean Nordic scores for these questions were between 4.62 and 6.36. We see that overall the Danes rate the possibilities for comparison best.

Danes between 18-29, Norwegians living in households with an income between €30.000-65.000 and those living in metropolitan areas and Swedes living in villages are significantly more likely to rate the possibilities for comparing the quality of the day care facility lower.

Danish and Norwegian males are significantly more likely to rate the possibilities for comparing different day care facilities with respect to 
factual information lower while Danes and Norwegians living in middlesized provincial towns are significantly more likely to rate them higher.

If we compare the three markets with regard to ratings given to the possibilities for comparison of the service provided across the Nordic countries we see that there is a basic level of dissatisfaction when it comes to doctors and dentists and that people are more satisfied with the possibilities of comparison of day care facilities' total service (opening hours, number of children, number of employees). Finns are most satisfied as far as doctors and dentists are concerned and Danes are most satisfied as far as their child's day care facilities are concerned.

Furthermore we see that across all markets there is a sizeable minority that feels incapable of answering questions about the possibilities for comparison of these aspects of service. This is particularly true in Sweden.

\subsubsection{Survey findings}

Figure 32: Satisfaction with the possibility for comparing prices of day care ( 0 is 'very poor' and 10 is 'very good')

Q57: How would you assess the possibilities for comparing the price level of different day care facilities?

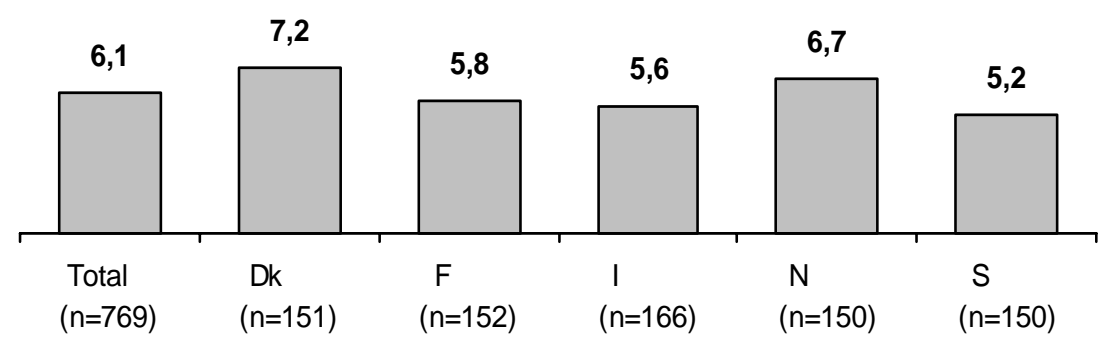

$\square$ Mean value

- Over all it seems that the people in the Nordic countries assess the possibilities for comparing the price level of different day care facilities as quite good (mean Nordic score of 6.1).

- The mean scores for Denmark (7.1) and Norway (6.7) are significantly higher than the mean for the Nordic countries as a whole, implying that they see the possibilities for comparing the price level of different day care facilities as better, whereas the Swedes assess the possibilities as slightly worse (5.2). This last finding is slightly paradoxical given the relatively open and clear pricing policies for day care facilities found in the Swedish desk research.

- Icelanders register a mean score of 5.6 when rating the possibilities for comparing the price level of different day care facilities. This score is not significantly different in terms of the Nordic countries as a whole. 
- Another interesting thing to note is that a significantly lower percentage of Finns assess the possibilities for comparing the price level as "very good" ( $2 \%$ vs. a Nordic average of $11 \%$ ).

- In Norway people over 60 years are significantly more likely to rate the possibilities for comparison of prices higher while in Sweden this applies to those between 40-49 years.

- Married Swedes, those living in a household with an income of over $€ 65.000$ and those living in households with 3 children are significantly more likely to rate the possibilities for comparison of prices higher.

- Swedes in smaller towns are significantly more likely to rate the possibilities for comparison lower.

Figure 33: Satisfaction with the possibilities for comparing quality of day care ( 0 is 'very poor and 10 is 'very good')

Q58: How would you assess the possibilities for comparing the quality of the day care facilities?

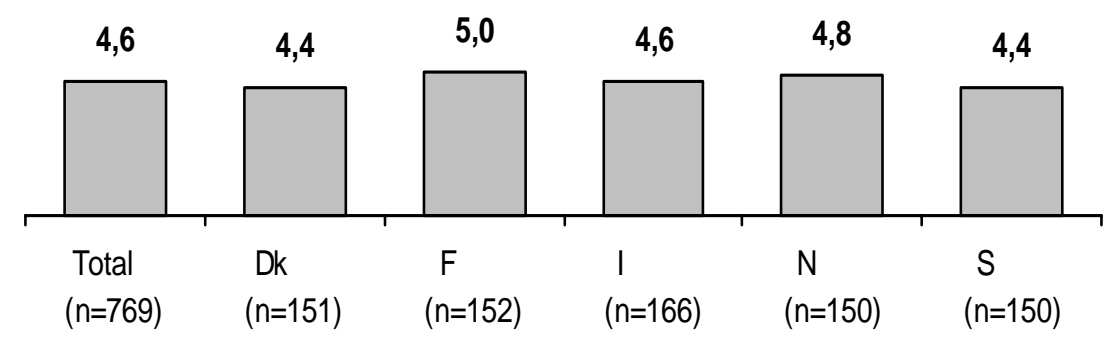

$\square$ Mean value

- Over all it seems that the people in the Nordic countries do not assess the possibilities for comparing the quality of the day care facilities very highly (mean score of 4.6).

- There are no significant differences between the Nordic countries related to this question, but a significantly lower percentage of Danes (3\%) chose to answer "very poor" than the Nordic average (7\%).

- Danes between 18-29 years are significantly more likely to rate the possibilities for comparing the quality of the day care facility lower.

- Norwegians living in households with an income between €30.00065.000 , and those living in metropolitan areas are significantly more likely to rate the possibilities for comparing the quality of the day care facility lower.

- Swedes living in villages are significantly more likely to rate the possibilities for comparing the quality of the day care facility lower.

- Finnish households with 4 children are significantly more likely to rate the possibilities for comparing the quality of the day care facility higher. 
Figure 34: Satisfaction with the possibilities for comparing factual information about day care ( 0 is 'very poor' and 10 is 'very good')

Q59: How would you assess the possibilities for comparing different day care facilities with respect to factual information such as opening hours, number of children and number of employed?

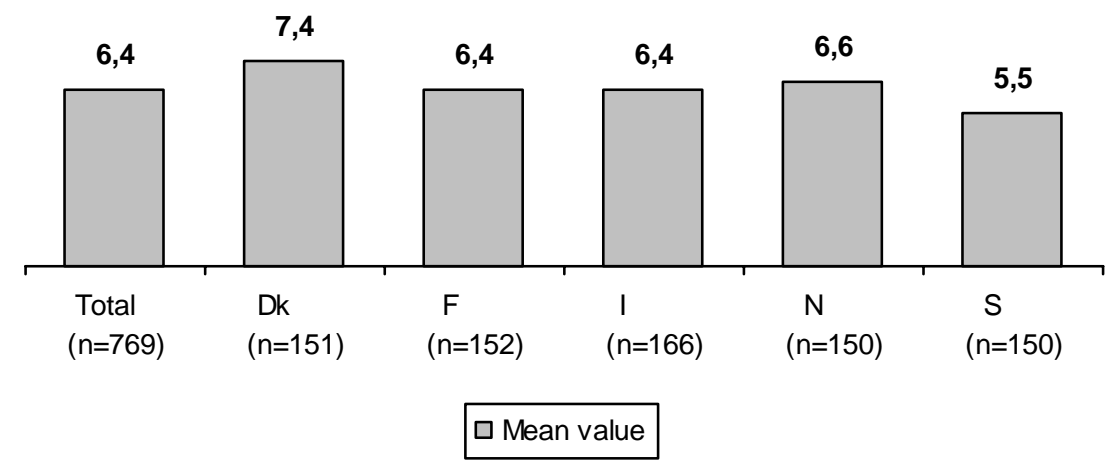

- Over all it seems that the people in the Nordic countries assess the possibilities for comparing different day care facilities with respect to factual information as quite good (6.4).

- Danes assess the possibilities highest registering a mean score of 7.4 compared to the Nordic mean of 6.4, whereas the Swedes assess the possibilities as worse with a mean score of 5.5

- Another interesting finding is that a significantly higher percentage of Danes (17\%) and Norwegians (16\%) chose to answer "very good" compared to the Nordic mean of 9\%. A significantly lower percentage of Finns (1\%) answer the same.

- Danish and Norwegian males are significantly more likely to rate the possibilities for comparing different day care facilities with respect to factual information lower while Danes and Norwegians living in middle-sized provincial towns are significantly more likely rate them higher.

\subsection{User rights and complaints}

\subsubsection{A summary of survey findings}

The majority of people (83\%) in the Nordic countries have not had the need to complain about their child's day care facility and with Nordic mean scores of over 6 when it comes to user rights and complaints it seems that people assess the possibilities for complaint as quite good. Finns rate the possibilities as slightly higher than other people in the Nordic region and are less likely to have complained.

Danes and Finns between 18-29 years are significantly more likely to rate the possibilities for complaint lower. 
Swedes living in households that have an income under $€ 30,000$, those who are single and those living in a household with 1 adult person are significantly more likely rate the possibilities for complaint higher.

If we compare perceptions about the possibilities for complaint across the three markets in the Nordic countries we see that satisfaction is average when it comes to doctors and dentists and a little better than average for day care facilities. Finns are the most satisfied with their possibilities for complaint in all three markets while Swedes are least satisfied as far as doctors are concerned and Icelanders (non significant) as far as dentists concerned. As far as day care facilities are concerned it is again the Swedes and Icelanders who are least satisfied with their opportunities for complaint.

Again we see sizeable minorities who feel incapable of answering questions about the possibilities they have for complaint across all three markets, though this is less the case for day care facilities than for the other two markets. It is the Swedes who are most likely to be unable to answer these questions when it comes to doctors and dentists.

A large majority in all three markets have not made a complaint about their doctors, dentists or child's day care facility.

\subsubsection{Survey findings}

Figure 35: Satisfaction with the possibilities for complaint about day care ( 0 is 'very poor' and 10 is 'very good')

Q60: How would you assess the possibility for complaining to a complaint board about your day care facility?

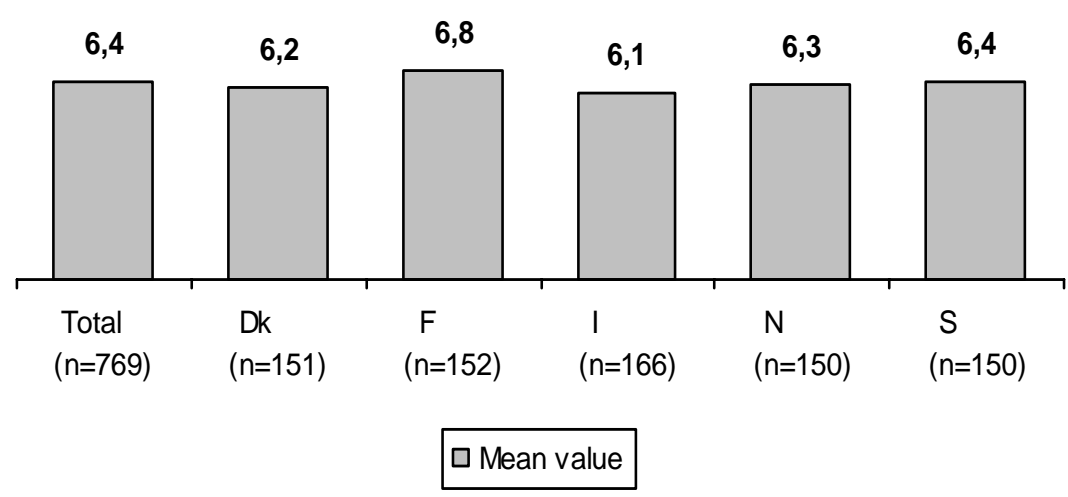

- Over all it seems that the people in the Nordic countries assess the possibilities for complaint about their day care facilities as quite good (6.4).

- There are no significant differences between the Nordic countries

- Danes and Finns under 30 are significantly more likely to rate the possibilities for complaint lower. 
- Swedes living in households that have an income under $€ 30,000$, those who are single and those living in a household with 1 adult person are significantly more likely rate the possibilities for complaint higher.

Figure 36: Satisfaction with the possibility for acquiring information about how to complain about day care ( 0 is 'very poor' and 10 is 'very good')

Q61: How would you asses the possibilities for acquiring information on how to complain?

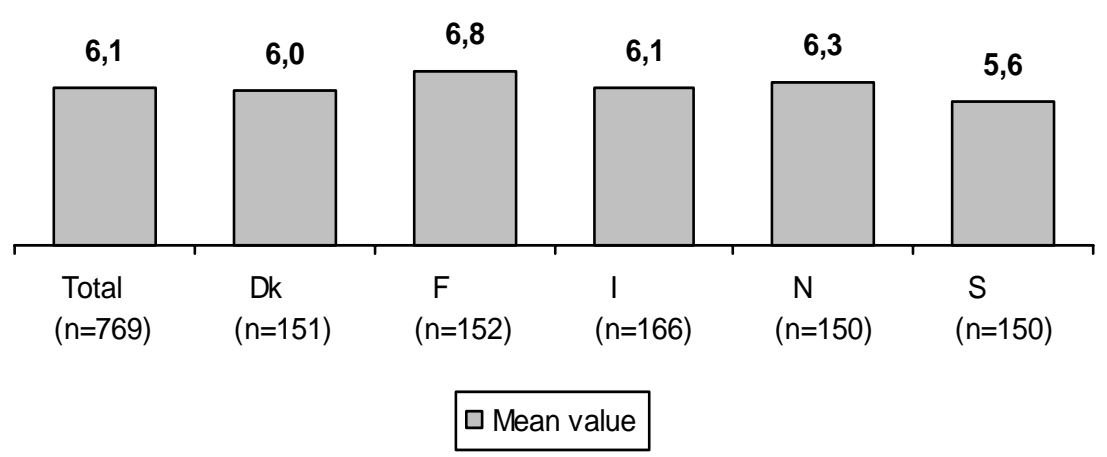

- Over all it seems that the people in the Nordic countries assess the possibilities for acquiring information on how to complain as quite good (6.1).

- The Finns assess the possibility for acquiring information on how to complain as slightly better (6.8), whereas the Swedes assess the possibilities for acquiring information as slightly poorer (5.6).

- Norwegian males are significantly more likely to rate the possibility for acquiring information about the complaints procedure lower than Norwegian women.

- Danes between 18-29 years are significantly more likely to rate the possibility for acquiring information about the complaints procedure lower, while the picture for 18-29 year olds in Norway is opposite.

- Danes who live with a partner are significantly more likely to rate the possibility for acquiring information about the complaints procedure lower while the picture for those living with a partner in Sweden is the opposite.

- Swedes living in villages are significantly more likely rate the possibilities for acquiring information about the complaints procedure higher. 
Figure 37: Need to complain about day care in the last $\mathbf{3}$ years

Q62: Have you, within the past 3 years, had the need to complain to a complaints board about a day care facility your child has attended?

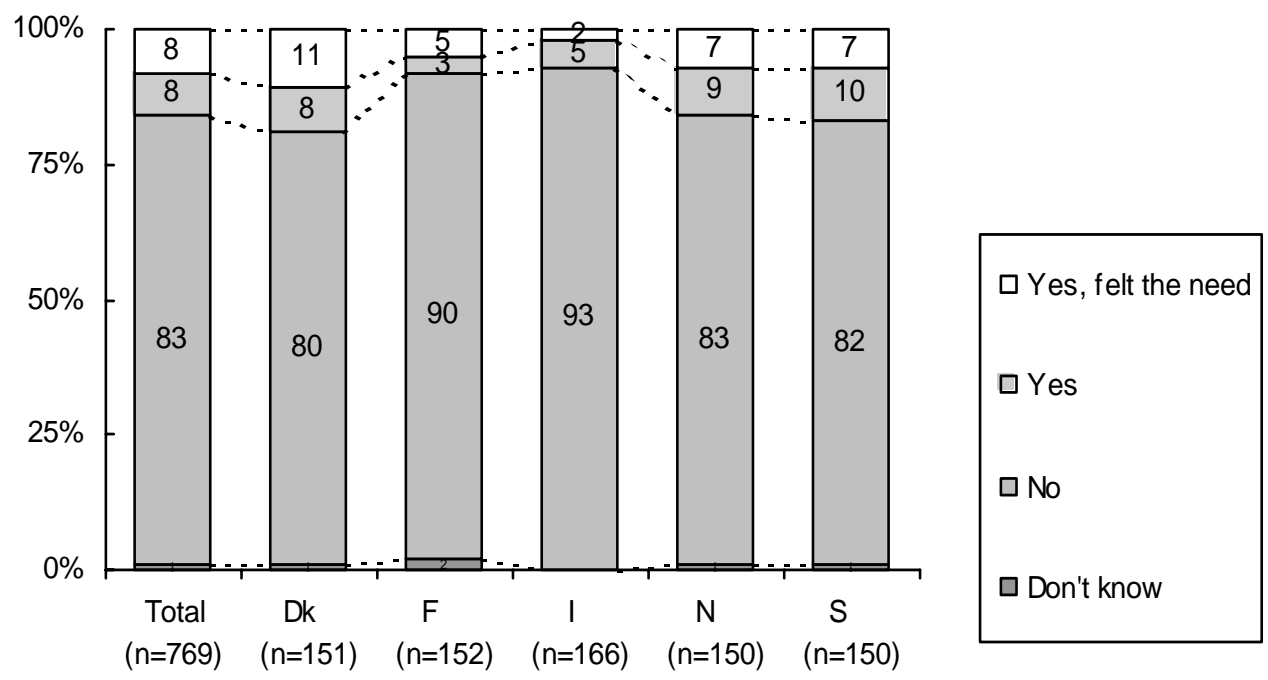

- Across the Nordic countries the majority (83\%) have not had the need to complain about a day care facility.

- A significantly higher percentage of Finns (90\%) have not complained compared to the Nordic average.

- It should be noted that $93 \%$ of Icelanders have not complained about their child's day care facility. However this percentage is not significant in terms of the Nordic countries as a whole.

- Finnish males are significantly more likely than Finnish women to say that making a complaint has not been relevant.

- Danish and Swedish singles are significantly more likely to say that making a complaint has not been relevant.

- Swedes living in households with an income under $€ 30,000$, those living in larger provincial towns and those living in households with 1 adult are significantly more likely to say that making a complaint has not been relevant.

- Norwegians living in households with 3 children are significantly more likely to say that making a complaint has not been relevant. 